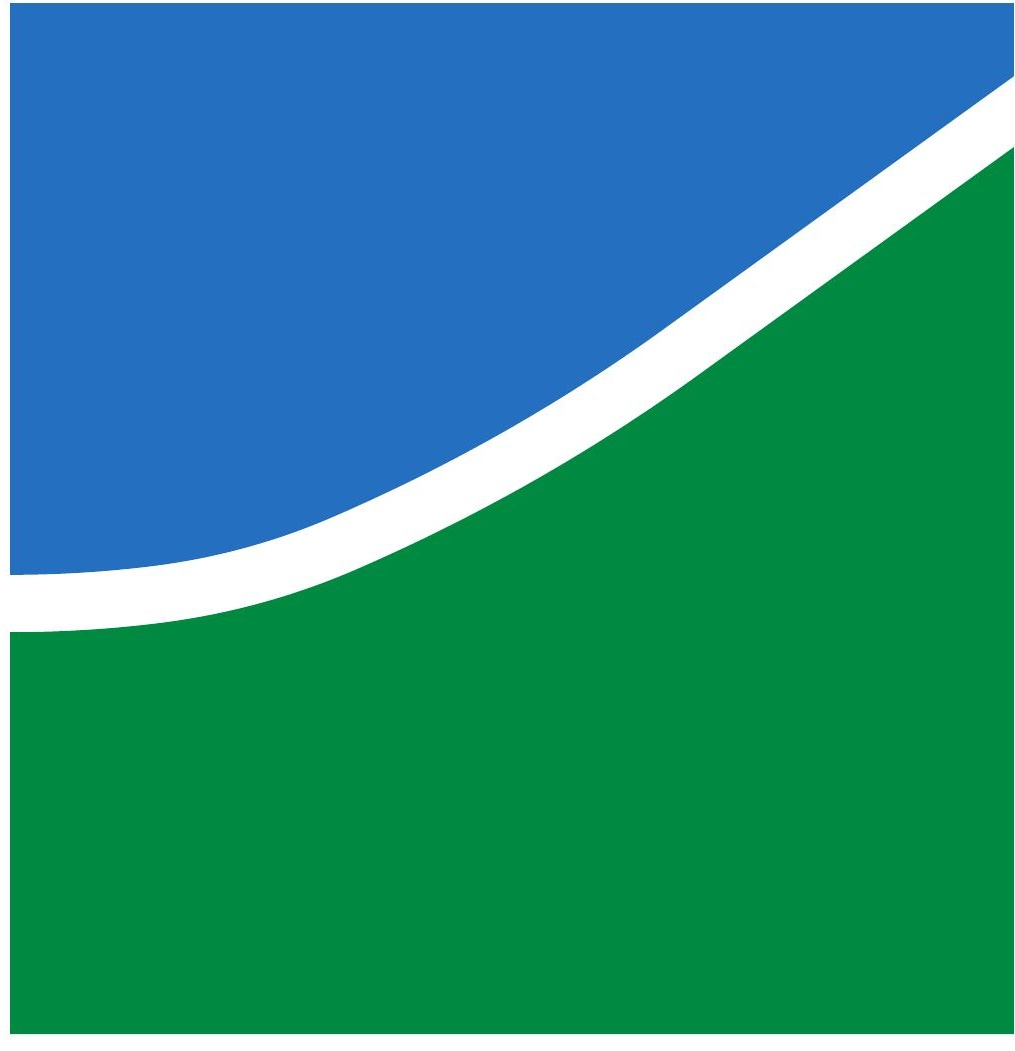

TESE DE DOUTORADO EM ENGENHARIA DE SISTEMAS ELETRÔNICOS E DE AUTOMAÇÃO

\title{
CHARACTERIZATION OF AMPUTEE GAIT USING A BIOMECHANICAL APPROACH
}

Claudia Patricia Ochoa Diaz

\section{UNIVERSIDADE DE BRASÍLIA}





\section{UNIVERSIDADE DE BRASÍLIA \\ FACULDADE DE TECNOLOGIA \\ DEPARTAMENTO DE ENGENHARIA ELÉTRICA}

\section{CHARACTERIZATION OF AMPUTEE GAIT USING A BIOMECHANICAL APPROACH}

\section{CLAUDIA PATRICIA OCHOA DIAZ}

TESE DE DOUTORADO SUBMETIDA AO DEPARTAMENTO DE ENGENHARIA ELÉTRICA DA FACULDADE DE TECNOLOGIA DA UNIVERSIDADE DE BRASÍLIA, COMO PARTE DOS REQUISITOS NECESSÁRIOS PARA A OBTENÇÃO DO GRAU DE DOUTOR.

APROVADA POR:

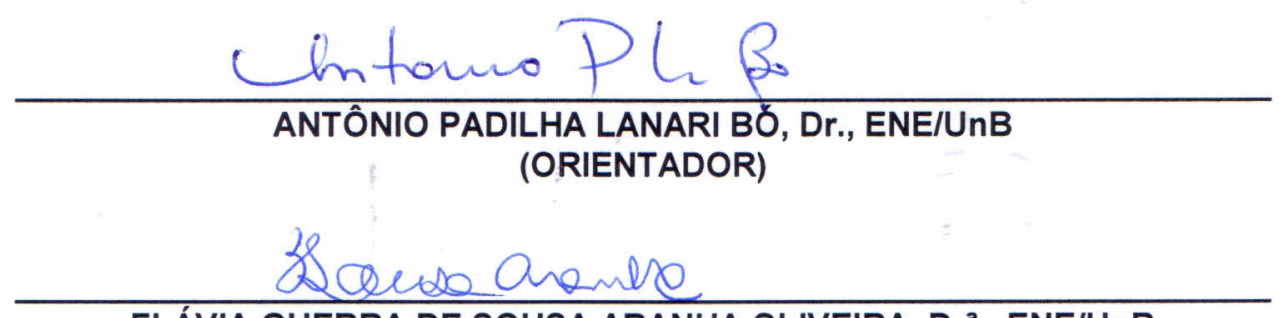

FLÁVIA GUERRA DE SOUSA ARANHA OLIVEIRA, Dra.,, ENE/UnB (EXAMINADORA INTERNA)

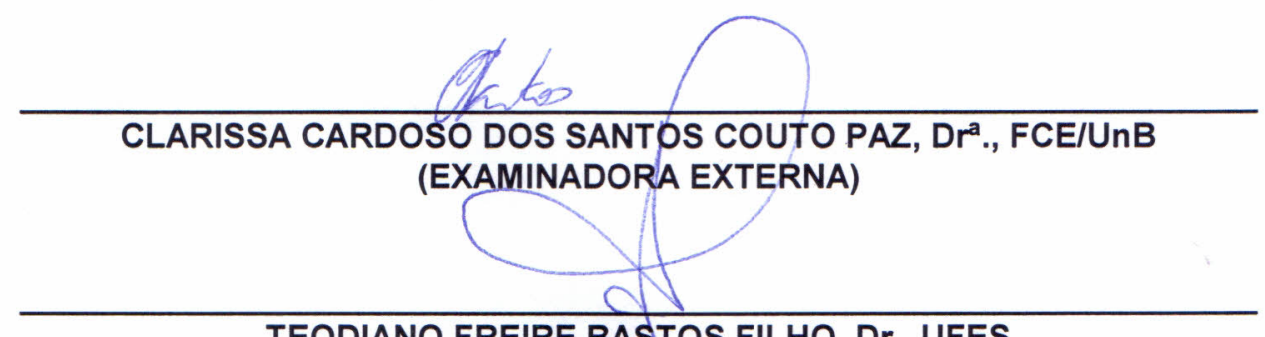

TEODIANO FREIRE BASTOS FILHO, Dr., UFES

(EXAMINADOR EXTERNO)

Suilia de S.Podnigues Lluny Dora

SUÉLIA DE SIQUEIRA RODRIGUES FLEURY ROSA, Dra., ENE/UnB

(EXAMINADORA EXTERNA) 



\section{FICHA CATALOGRÁFICA}

OCHOA DIAZ, CLAUDIA PATRICIA

Characterization of Amputee Gait using a Biomechanical Approach. [Distrito Federal] 2015.

xi, 105p., $210 \mathrm{~mm} \times 297 \mathrm{~mm}(\mathrm{ENE} / \mathrm{FT} / \mathrm{UnB}$, Doutor, Engenharia de Sistemas Eletrônicos e de Automação, 2015). Tese de Doutorado - Universidade de Brasília. Faculdade de Tecnologia.

1. Amputee gait 2. Biomechanics

3. Gait analysis 4. Symmetry analysis

5. Center of mass 5. Dynamic walking

I. $\mathrm{ENE} / \mathrm{FT} / \mathrm{UnB} \quad$ II. Título (Série)

\section{REFERÊNCIA BIBLIOGRĀFICA}

OCHOA-DIAZ, C. P., (2015). Characterization of Amputee Gait using a Biomechanical Approach. Tese de Doutorado em Engenharia de Sistemas Eletrônicos e de Automação, Publicação PGEA.TD096/2015, Departamento de Engenharia Elétrica, Universidade de Brasília, Brasília, DF, 105p.

\section{CESSÃO DE DIREITOS}

AUTOR: Claudia Patricia Ochoa Diaz

TÍTULO DA TESE DE DOUTORADO: Characterization of Amputee Gait using a Biomechanical Approach.

GRAU: Doutora

ANO: 2015

É concedida à Universidade de Brasília permissão para reproduzir cópias desta tese de doutorado e para emprestar ou vender tais cópias somente para propósitos acadêmicos e científicos. O autor reserva outros direitos de publicação e nenhuma parte desta tese de doutorado pode ser reproduzida sem autorização por escrito do autor.

Claudia Patricia Ochoa Diaz

SQN 209, Bloco C, Ap. 519 - Asa Norte.

70854-030 Brasília - DF - Brasil. 

To Jorge, Hernando, Isaura and Margarita. Love and family is all that I need.

Claudia Patricia Ochoa Diaz 



\section{Acknowledgements}

First, I want to thank my advisor, Prof. Antônio P. L. Bó, for giving me the opportunity to work with him during all these years and for offering the scientific support and the necessary tools I needed to fulfil this work.

An important part of this work would not be possible without the clinical support of Luciana Peixoto. Her significant collaboration in the gait experiments and their posterior analysis helped me to understand the biomechanical aspects of human gait.

I want to give special thanks to my colleagues and friends, David Fiorillo and Leonardo Broche, who helped me during the countless experiments I made. I also owe a big thanks to the rest of the colleagues of the LARA group: Mariana, Henrique, Roberto, Luis, Hugo, Marianne, Miguel, Thiago, André, Murilo, Lucas Fonseca and Lucas Levy. This thesis was an excellent excuse to meet such a smart and nice people.

For always be willing to help us during the RLEG project, I am deeply grateful to Jamerson Oliveira for accepting the challenge of walking using the RLEG prosthesis and also for being a part of my gait analysis experiments. He demonstrated that physical barriers do not stop us. In this same context, I want to thank all the undergraduate and graduate students who work with me, as well as the rest of the volunteers who participated in the gait analysis experiments.

During all this years in Brazil, I made a lot of friends who made me feel closer to home. Thanks to Juan Pablo, Edgar, Iván, Alejandra, Esteban, Catalina, Claudia, Jesús, Liliana, Enio and Jones.

Finally, I would like to express all my gratitude to my family who made this journey so much easier. I thank my parents, Hernando and Isaura, for inspiring me and for encouraging me to continue until the end. My only sister, Margarita, who has been my truly friend since forever. Lastly, all my love and thanks to Jorge. His unlimited patience and support, not only emotional but technical, were crucial along this process. It is so much easier when someone holds your hand. 



\begin{abstract}
This thesis proposes a biomechanical approach for the characterization of the lower limb amputee gait as a particular case of human gait. The study is divided in two parts. First, a complete gait analysis study is carried out by running some experiments in a non-amputee and an amputee group. Several kinematics and kinetics variables were measured and limb asymmetry in the amputee subjects was detected by visual inspection of the gait analysis results. A quantitative evaluation of limb symmetry was performed using techniques in the time and the frequency domain. The obtained results, in terms of indices values, confirm the observations from the experimental phase.

The second part is oriented to the analysis of human walking using the spring-loaded inverted pendulum (SLIP) model, which exploits the elastic behavior of legs to recreate the periodical motion of the body center of mass (CoM) during a gait cycle. Comparisons were made between the model output and the real data from the experiment results of both groups. The model was capable of representing both situations: high level of leg symmetry for a normal gait, and asymmetric legs for an amputee gait. Finally, a proposal for estimation of leg stiffness based on a extended Kalman filter (EKF) using the SLIP model is presented.
\end{abstract}

\title{
RESUMO
}

Esta tese propõe uma abordagem biomecânica para a caracterização da marcha de amputado de membro inferior, como um caso particular da marcha humana. O estudo foi dividido em duas partes. Na primeira parte, uma análise de marcha completa é executada a partir de experimentos realizados em sujeitos amputados e não amputados. Foram medidas diferentes variáveis cinemáticas e cinéticas, detectando assimetrias entre os membros amputados. Foi realizada uma avaliação quantitativa de simetria nos membros inferiores usando técnicas no domínio do tempo e da frequência. Os resultados obtidos, em termos de índices, confirmam as observações feitas na fase experimental.

A segunda parte está orientada à análise de marcha usando o modelo SLIP (do inglês springloaded inverted pendulum), o qual explora o comportamento elástico das pernas para recriar o movimento periódico do centro de massa corporal $(\mathrm{CoM})$ durante um ciclo de marcha. Foram realizadas comparações entre a saída do modelo e os dados reais dos resultados experimentais de ambos os grupos. O modelo foi capaz de representar ambas as situações: alto nível de simetria nas perna para uma marcha normal, e pernas assimétricas para uma marcha de amputado. Finalmente, é apresentada uma proposta para a estimação da rigidez da perna baseado em um filtro de Kalman estendido (EKF) utilizando o modelo SLIP. 



\section{CONTENTS}

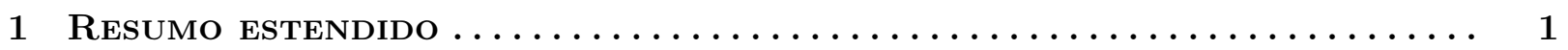

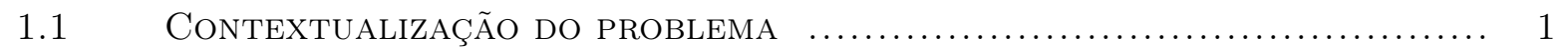

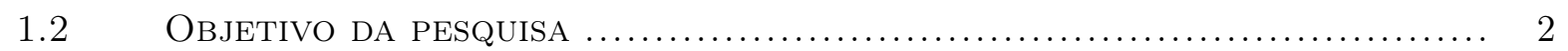

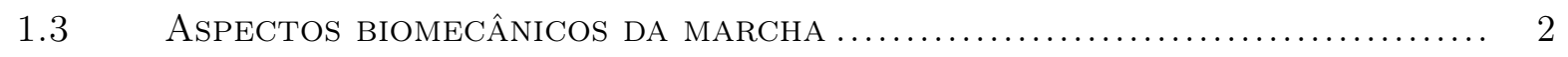

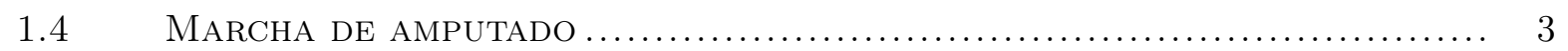

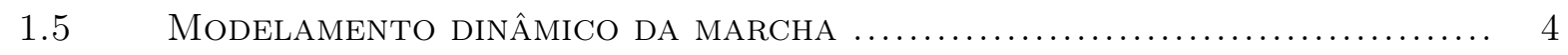

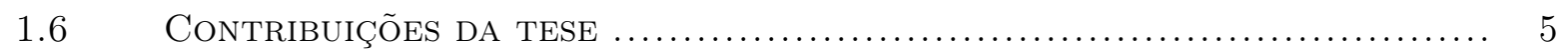

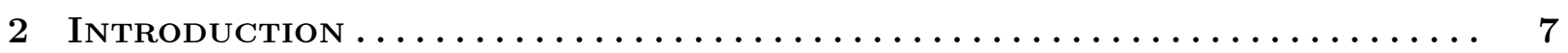

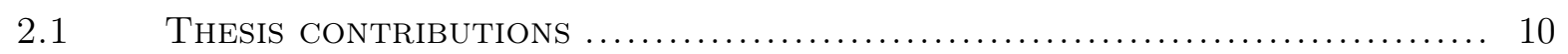

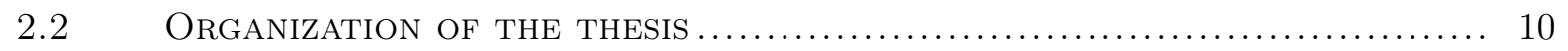

3 Biomechanical aspects of WALKing $\ldots \ldots \ldots \ldots \ldots \ldots \ldots \ldots \ldots \ldots$

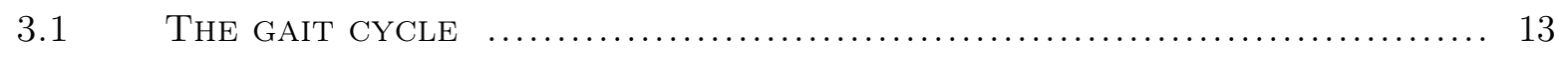

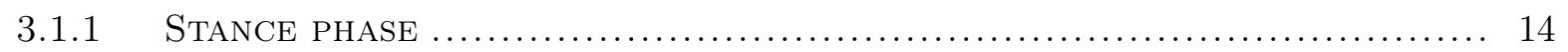

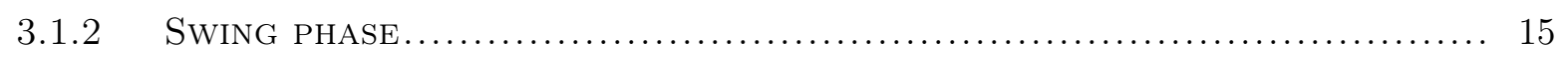

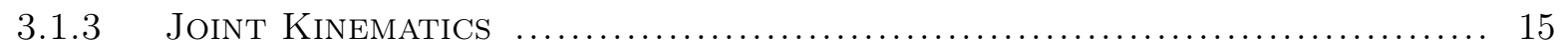

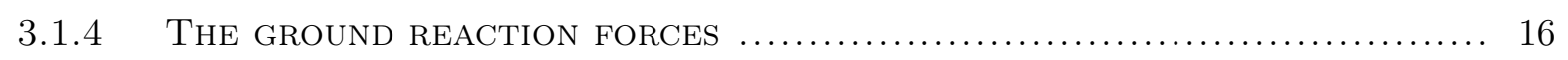

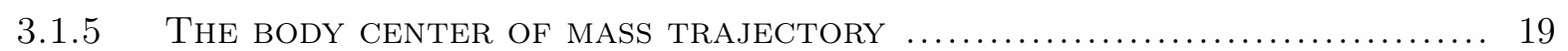

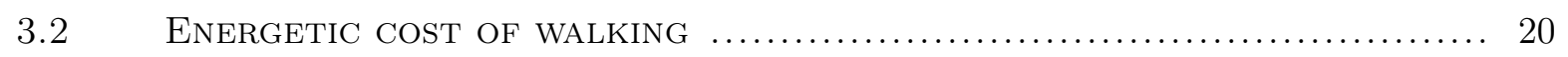

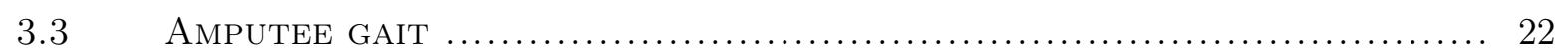

3.4 Transfemoral prostheses ........................................ 23

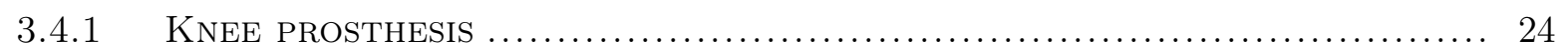

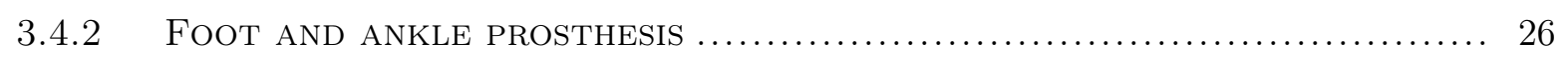

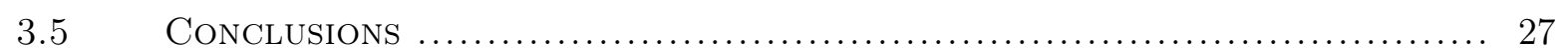

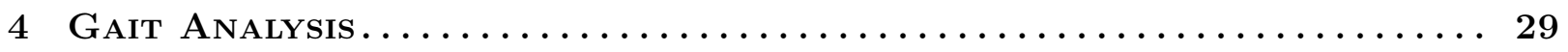

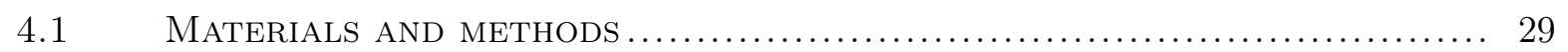

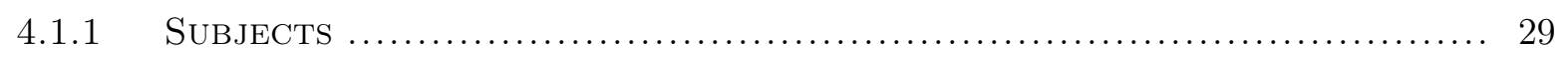

4.1.2 Characteristics of the LOWER Limb ProsthesES.......................... 30

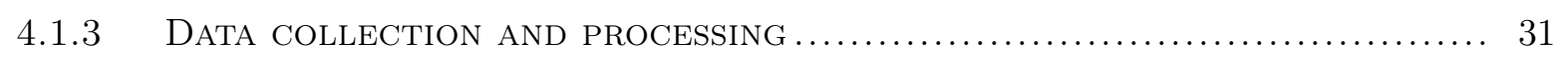

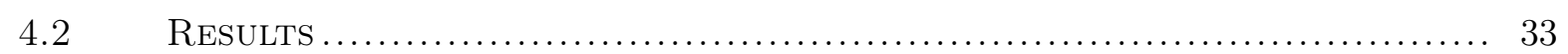

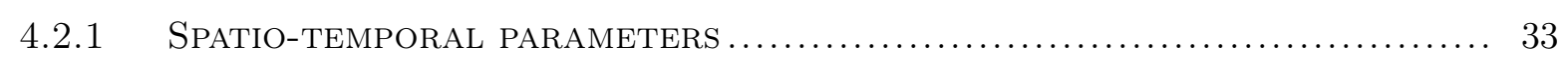

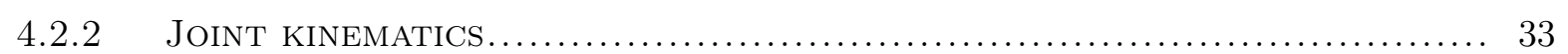




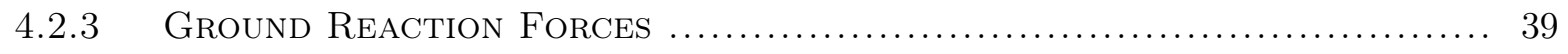

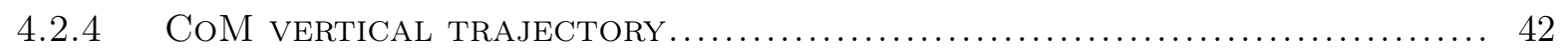

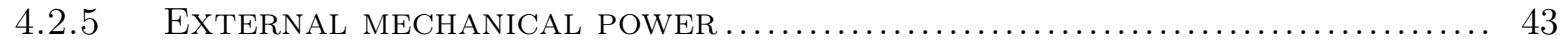

4.2.6 Mechanical Cost of Transport...................................... 45

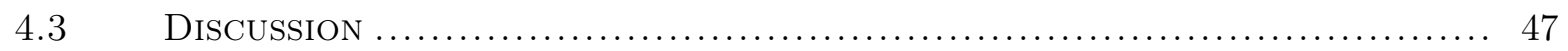

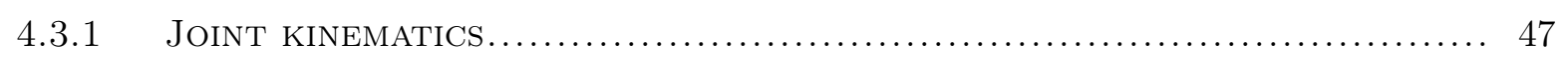

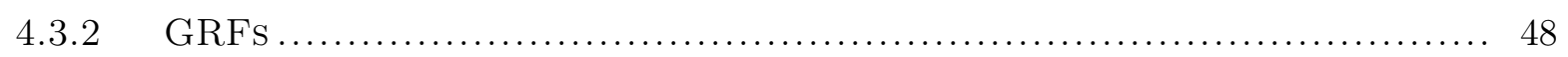

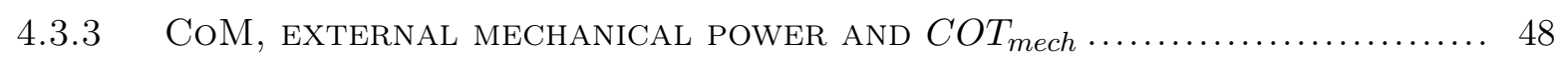

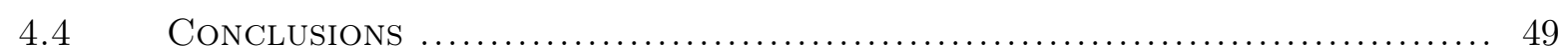

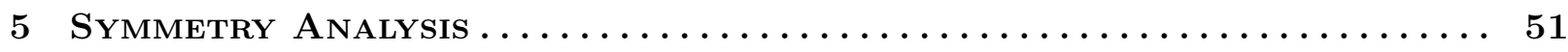

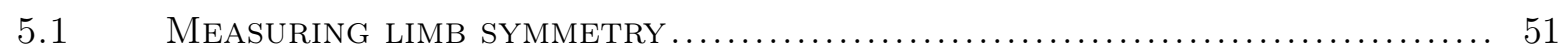

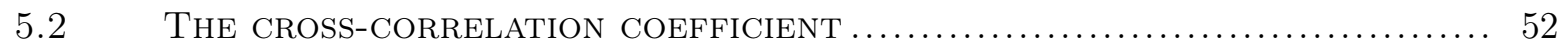

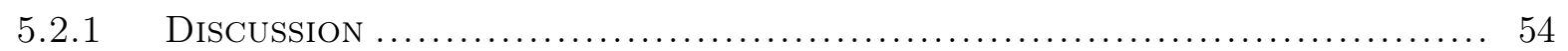

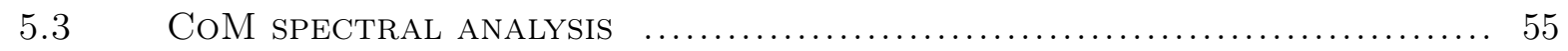

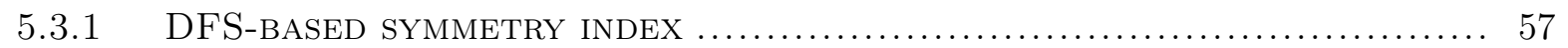

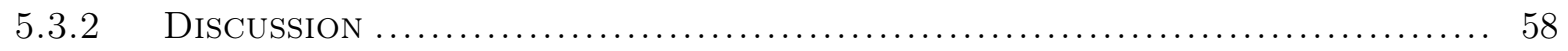

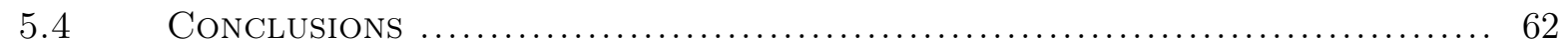

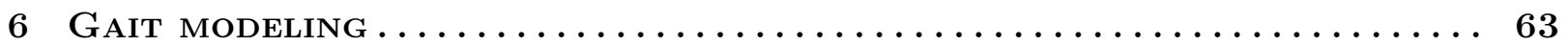

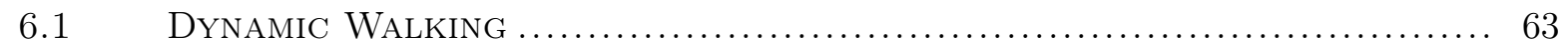

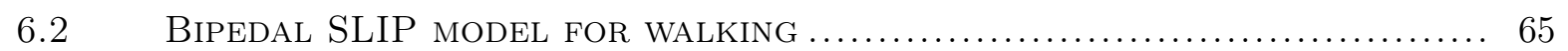

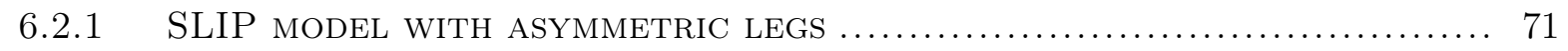

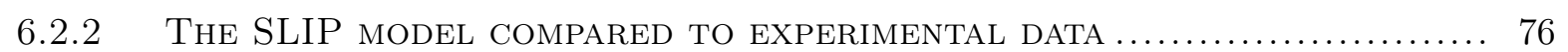

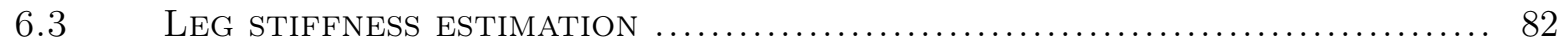

6.3.1 The EKF-BASEd APproAch to ESTIMATE LEG STIFFness .................. 82

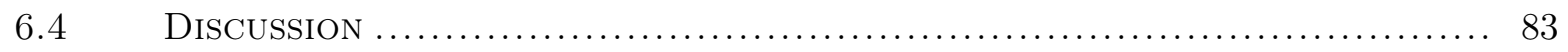

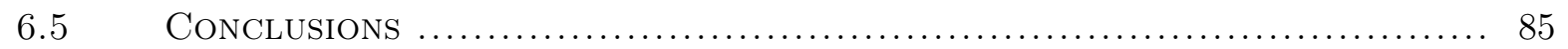

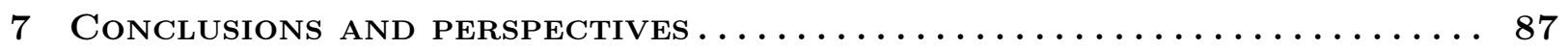

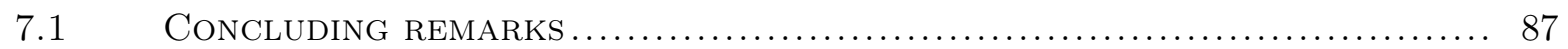

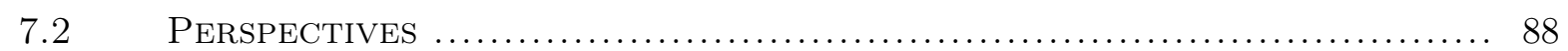

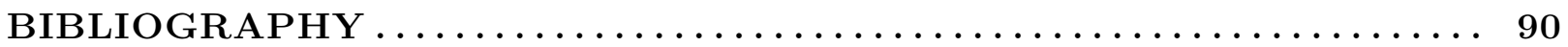

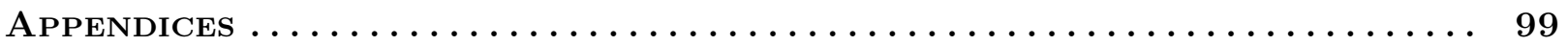

A MARKER PROTOCOL FOR the GAIT ANALYSIS EXPERIMENTS $\ldots \ldots \ldots \ldots \ldots 101$

B Approved consent by the ethics Committee $\ldots \ldots \ldots \ldots \ldots \ldots \ldots \ldots \ldots$

Publications....................................... 104 


\section{LIST OF FIGURES}

1.1 Fases e sub-fases de um ciclo de marcha (Adaptado de Neumann, 2002) .............. 2

1.2 Trajetória vertical do centro de massa corporal ao longo do ciclo de marcha. .......... 3

1.3 Modelo SLIP para marcha bípede. ......................................... 5

2.1 Prosthesis prototypes constructed at LARA. (a) 2005, (b) 2007, (c) 2008 and (d) 2010 versions.

2.2 RLEG. (a) The current prosthesis prototype. (b) The amputee volunteer wearing the protoype during the alignment test.

3.1 Gait cycle and its phases (adapted from Neumann 2002).

3.2 Planes of motion of the human body (courtesy of Wikimedia Commons). 16

3.3 Sagittal plane typical kinematics of the hip, the knee and the ankle joints (taken from Neumann, 2002). The zero position for the case of the hip and the knee joint is the one shown in the limb representation beside each graphic. The zero position of the ankle joint corresponds to that at initial contact.

3.4 The ground reaction forces. The vertical component for both feet are represented by the solid lines, while the anterior-posterior GRFs correspond to the dashed lines

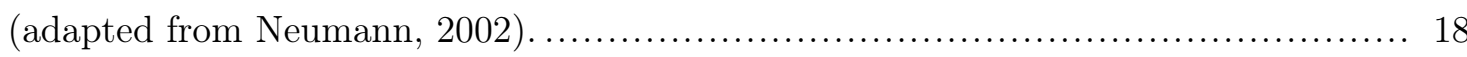

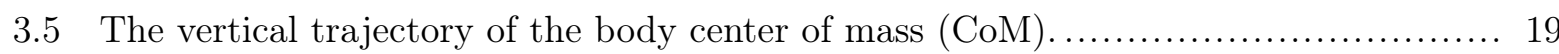

3.6 Some transfemoral prostheses commercially available: (a) Ottobock's C-Leg (courtesy of Ottobock); (b) The Rhe Knee (courtesy of Össur); (d) The Power Knee (courtesy from Össur).

3.7 Transfemoral prostheses in development: (a) the powered prosthesis with active knee and ankle joints developed at Vanderbilt University (Sup et al. 2009); (b) MIT's powered knee prosthesis with two series-elastic actuators (Martinez-Villalpando \& Herr 2009).

3.8 Ankle-foot prostheses: (a) Össur's Proprio Foot (courtesy of Össur); (b) The BioM T2 (courtesy of BiOM Personal Bionics).

4.1 The lower limb prosthesis used by the amputee group: (a) The 3R80 knee. (b) The 1C30 Trias foot (courtesy of Ottobock).

4.2 The experimental setup: (a) the walkway with three force platforms and eight cameras around it. The marker set used on the two groups: (b, e) frontal, (c, f) lateral, and $(\mathrm{d}, \mathrm{g})$ posterior view. 
4.3 Kinematics of the non-amputee subjects (mean $\pm 1 S D$ ). (a) Pelvis obliquity; (b) hip flexion-extension; (c) hip abduction-adduction; (d) knee flexion-extension and (e) ankle plantarflexion-dorsiflexion.

4.4 Pelvis and hip angles of the trailing leg (black line) against the leading leg (blue line). A: the reference subject; $\mathbf{B}, \mathbf{C}, \mathbf{D}$ : the amputee subjects. For the case of the amputee subjects the trailing leg corresponds the intact limb.

4.5 Knee and ankle angles of the trailing leg (black line) against the leading leg (blue line). A: the reference subject; $\mathbf{B}, \mathbf{C}, \mathbf{D}$ : the amputee subjects. For the case of the amputee subjects the trailing leg is the intact limb.

4.6 Ground Reaction Forces (mean $\pm 1 S D$ ) of all the non-amputee subjects. (a) The anterior-posterior and (b) the vertical components.

4.7 The anterior-posterior and the vertical GRF of the trailing leg (black line) against the leading leg (blue line). A: the reference subject. B, C, D: the amputee subjects. For the amputee subjects the trailing leg corresponds to the intact limb, while the prosthetic leg is the leading one.

4.8 The CoM vertical excursion (mean $\pm 1 S D)$ of the non-amputee group

4.9 Vertical displacement of the CoM. A: the reference subject, B, C, D: the amputee subjects. $H S_{1}$ and $H S_{2}$ correspond to the heel strike events of the trailing and the leading leg, respectively. The $T O_{1}$ and $T O_{2}$ are the toe-off events for the same legs. For the case of the amputee subjects, the trailing leg corresponds to the intact leg. .. 44

4.10 External mechanical power of the trailing leg (black line) and the leading leg (blue line) during a gait cycle. A: the reference subject; B, C, D: the amputee subjects. For the case of the amputee subjects, the trailing leg corresponds to the intact side. . 46

5.1 Magnitude spectrum (first column) and decomposition of the vertical CoM signal into its harmonics, the black curve is the original waveform

5.2 Left column: original signal (solid line) and its reconstruction (dashed line). Right Column: distortion in mm between the two signals.

6.1 McGeer's passive dynamic walker (adapted from McGeer, 1990). The parameter of this model are: the upper body mass $m_{h}$, concentrated at the hip joint, the leg masses, $m_{l 1}$ and $m_{l 2}$, the leg angles $\theta$ and $\alpha$, leg length $l$, the foot radius $r$ and the ramp slope $\phi$. Based on this model, Wisse et al. (2007) built Denise, a passive biped walker robot.

6.2 SLIP model for running and hoping (adapted from Blickhan, 1989). The point mass $m$ represented the whole body mass. The leg is a massless and linear spring, with rest length $L_{0}$ and stiffness $k_{0}$. At the aerial phase, the leg has an inclination with respect to the ground equals to $\alpha_{0}$. 
6.3 Bipedal SLIP model. A single step is defined by two single support phases and a double support phase. The transition between these phases are given by the touchdown (TD) and the lift-off (LO) events. The system parameters are the body mass $m$, the leg length $L_{0}$, the angle of attack $\alpha_{0}$, the leg stiffness $k_{0}$ and the system energy $E_{s}$. The beginning of a step happens when the stance leg is at the vertical leg orientation (VLO) event

6.4 SLIP solution for $m=80 \mathrm{~kg}, L_{0}=1 \mathrm{~m}, k_{0}=15696 \mathrm{~N} / \mathrm{m}, \alpha_{0}=75^{\circ}$ and $E_{s}=$ $812.27 \mathrm{~J}$. (a) The vertical trajectory of the CoM. (b) The anterior-posterior GRF and (c) the vertical GRF of both legs. (d) The mechanical power is calculated for one leg. A single step is defined between two consecutive VLO events. The double support takes place between the TD and the TO event, while the single support happens between the TO and the VLO event.

6.5 SLIP solution for $m=80 \mathrm{~kg}, L_{0}=1 \mathrm{~m}, k_{0}=15696 \mathrm{~N} / \mathrm{m}, \alpha_{0}=69^{\circ}$ and $E_{s}=$ 824.04 J. (a) The vertical trajectory of the CoM. (b) The anterior-posterior GRF and (c) the vertical GRF of both legs. (d) The mechanical power is calculated for one leg.

6.6 Two different solutions for the case of asymmetry in $\alpha_{0}$. The common parameters for each solution are $k_{0}=15696 \mathrm{~N} / \mathrm{m}, E_{s}=820 \mathrm{~J}, L_{0}=1 \mathrm{~m}$. In the first solution (row A) $\alpha_{0}=72^{\circ}$, while in the second (row B) $\alpha_{0}=73.5^{\circ}$. For both cases $\varepsilon_{\alpha}=2^{\circ}$. Leg 1 is the one which first touches the ground. The GRF components are presented for both legs (leg 1 in black, leg 2 in gray)...

6.7 Two different solutions for the case of asymmetry in $k_{0}$. The common parameters for each solution are $E_{s}=820 \mathrm{~J}$ and $L_{0}=1 \mathrm{~m}$. In the first solution (row A) $k_{0}=15696 \mathrm{~N} / \mathrm{m}, \alpha_{0}=70^{\circ}$, while in the second (row B) $k_{0}=15696 \mathrm{~N} / \mathrm{m}, \alpha_{0}=73^{\circ}$. For both cases $\varepsilon_{k}=2 k N / m$. Leg 1 is the one which first touches the ground. The GRF components are presented for both legs (leg 1 in black, leg 2 in gray).

6.8 Two different solutions for the case of asymmetry in $L_{0}$. The common parameters for each solution are $E_{s}=820 J$ and $k_{0}=15696 \mathrm{~N} / \mathrm{m}$. In the first solution (row A) $L_{0}=1 \mathrm{~m}, \alpha_{0}=71.6^{\circ}$, while in the second (row B) $L_{0}=1 \mathrm{~m}, \alpha_{0}=72.5^{\circ}$. For both cases $\varepsilon_{L}=7 \mathrm{~mm}$. Leg 1 is the one which first touches the ground. The GRF components are presented for both legs (leg 1 in black, leg 2 in gray)....

6.9 The SLIP solution (dotted lines) and the real data waveforms (solid lines) from the reference subject. (a) The vertical CoM. (b) The anterior-posterior GRF. (c) The vertical GRF and (d) the mechanical power. The cross-correlation coefficient for each pair of curves are (a) 0.943, (b) 0.960, (c) 0.901 and (d) 0.793.

6.10 Asymmetric solutions for the reference subject. (A) Solution with asymmetry in $\alpha_{0}$.

(B) Solution with asymmetry in $k_{0}$.

6.11 The SLIP solution (dotted lines) overlapped with the real data waveforms (solid lines) from subject B. (a) The vertical CoM. (b) The anterior-posterior GRF. (c) The vertical GRF and (d) the mechanical power. The cross-correlation coefficient for each pair of curves are (a) 0.814, (b) 0.976, (c) 0.889 and (d) 0.834. 
6.12 Leg stiffness estimation: (a) Vertical CoM for one of the SLIP solution used as measurements for the EKF filter. (b) A single step extracted for each solution. It can be observed the differences between vertical excursions of the CoM for the three values of $k_{0}$. (c) The $k_{0}$ (a.k.a. $k_{\text {leg }}$ ) estimation for the three walking solutions. (d) The corresponding estimation error. Black curve corresponds $k_{1}$, while the blue and the red ones belongs to $k_{2}$ and $k_{3}$, respectively.

A.1 The marker protocol for the kinematic capture : (a) frontal, (b) posterior and (c, d) lateral view. 


\section{LIST OF TABLES}

1.1 Principais restrições à marcha e os respectivos mecanismos de compensação encontrados na literatura.

3.1 The most common gait constraints and compensatory mechanisms found in the reviewed studies of transfemoral amputation.

4.1 Anthropometric data of all the subjects who participated in the study.

4.2 Mean values $( \pm S D)$ for the spatio-temporal parameters. A single gait cycle is defined as consecutive heel strike events of the same limb.

4.3 Main observations from the pelvis and the hip angles among the amputee subjects. The joint angles were compared against the non-amputee pattern. For each joint, the intact and the prosthetic side were analyzed during a gait cycle when each side began the stride (see figure 4.4 ). GC stands for gait cycle.

4.4 Main observations from the knee and ankle angles among the amputee subjects. The joint angles were compared against the non-amputee pattern. For each joint, the intact and the prosthetic side were analyzed during a gait cycle when each side

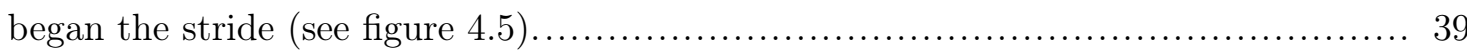

4.5 Power peak values at the step-to-step transition, extracted from Figure 4.10. ....... 45

$4.6 C O T_{\text {mech }}$ calculation based on the CoM power. ..................................... 45

5.1 Some discrete indices expressions used across the literature. $R$ and $L$ stands for the parameter value in the right and the left side, respectively.

5.2 $S_{M}$ index for the joint kinematics. The mean values were calculated from the am-

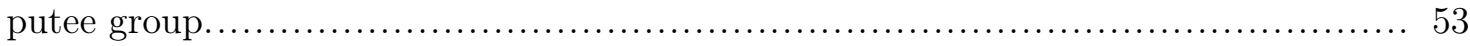

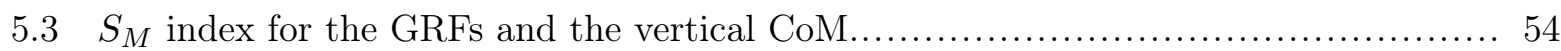

5.4 Inter-subject comparison of the joint kinematics, between the three amputee sub-

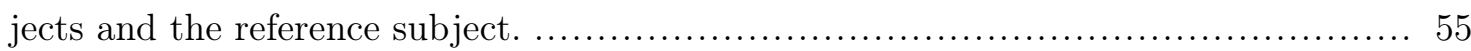

5.5 Inter-subject comparison of the GRF, the vertical $\mathrm{CoM}$ and the CoM power. ......... 55

5.6 Coefficient frequencies and its energy contribution to the DFS of the vertical CoM. . 58

5.7 Symmetry index based on the DFS of the vertical CoM.......................... 58

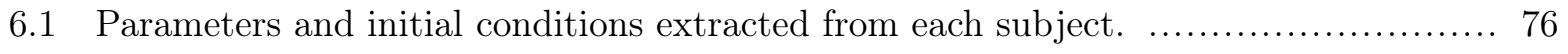

$6.2 S_{M}$ values for the different walking solutions for the reference subject case............ 78

A.1 Marker labels and their corresponding anatomical locations. 102 



\section{ACRONYMS}

$\begin{array}{cl}\text { LARA } & \text { Laboratório de Automação e Robótica } \\ \text { CoM } & \text { Center of Mass } \\ \text { SLIP } & \text { Spring Loaded Inverted Pendulum } \\ \text { EKF } & \text { Extended Kalman Filter } \\ \text { GC } & \text { Gait Cycle } \\ \text { GRF } & \text { Ground Reaction Force } \\ \text { SD } & \text { Standard Deviation } \\ \text { MOCAP } & \text { Motion Capture } \\ \text { BW } & \text { Body Weight } \\ \text { HS } & \text { Heel Strike } \\ \text { TO } & \text { Toe-off } \\ C O T_{m e c h} & \text { Mechanical Cost of Transport } \\ \text { DFS } & \text { Discrete Fourier Series } \\ \text { TD } & \text { Touch-Down } \\ \text { LO } & \text { Lift-Off } \\ \text { VLO } & \text { Vertical Leg Orientation } \\ \text { RMS } & \text { Root Mean Square }\end{array}$





\section{Resumo ESTENDIDO}

\subsection{ContextualizaÇÃo do PRoblema}

Amputação é definida como uma perda parcial o completa de algum membro do corpo (Perry, 1992). Esta condição traz um impacto severo na qualidade de vida das pessoas. Em alguns casos, a amputação pode representar a impossibilidade de estudar, trabalhar o de levar uma vida social normal. Uma prótese de membro inferior é um dispositivo que é projetado com o objetivo principal de substituir de alguma forma as funções perdidas decorrentes de uma amputação. A pesar que a maioria das próteses comerciais atingem tal objetivo, ainda existem limitações principalmente em termos de velocidade e de resposta positiva, isto é, um tipo de acionamento que auxilie ao usuário na hora de subir uma escada ou dar um pequeno pulo, por exemplo.

Alguns estudos clínicos apontam que as limitações funcionais da maioria de próteses comerciais de membro inferior podem ocasionar certas condições desfavoráveis nas articulações do membro não amputado, assim como nas articulações restantes do membro amputado (Norvell et al., 2005; Gailey et al., 2008; Morgenroth et al., 2014; Devan et al., 2014). A maioria destes achados estão baseados nas medições de variáveis cinemáticas e cinéticas obtidas a partir de experimentos de análise de marcha. A evolução destes estudos, desde um ponto de vista observacional a uma abordagem mais quantitativa, permite ter um conhecimento mais preciso em relação aos efeitos que uma prótese de membro inferior pode produzir no usuário.

Por outro lado, o uso recente de modelos dinâmicos de marcha, o quais nascem da robótica de sistemas movimentados com patas (do inglês legged robotics), tem-se convertido numa ferramenta útil que consegue explicar a dinâmica básica da marcha humana em certas condições. Alguns estudos, por exemplo, tem estabelecido a relação velocidade-comprimento do passo preferida pelos seres humanos (Kuo, 2001), assim como a relação entre o centro de pressão no pé e os movimentos oscilatórios do centro de massa corporal (Jung \& Park, 2014).

A motivação do estudo apresentado a seguir se enquadra dentro do contexto do projeto RLEG, concebido no Laboratório de Automação e Robótica (LARA). O principal objetivo do projeto é construir prótese ativas de membro inferior para amputados transfemurais e transtibiais. O diferencial destas próteses, além de um projeto mecânico que deve cumprir com certos requisitos de custo e de peso, estará no controle do dispositivo, o qual estará inspirado no comportamento complacente dos membros humanos. Neste contexto do projeto RLEG, esta tese de doutorado nasce da necessidade de entender a marcha de amputado como um caso particular da marcha humana, e a partir da caracterização deste problema, chegar numa estratégia de controle mais 


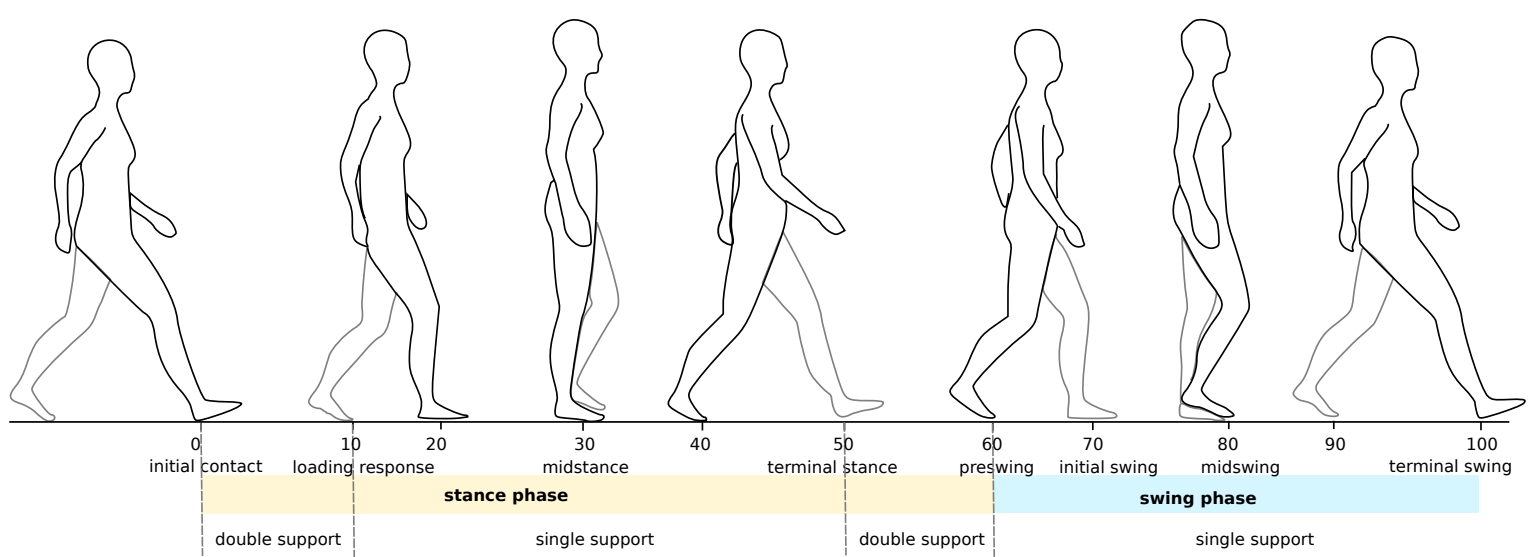

Figura 1.1: Fases e sub-fases de um ciclo de marcha (Adaptado de Neumann, 2002)

adequada à realidade do fenômeno.

\subsection{OBJetivo DA PESQUisa}

O Objetivo principal deste trabalho é caracterizar a marcha de amputado desde duas perspectivas: análise de marcha baseado em experimentos com um grupo de indivíduos amputados; e modelamento dinâmico da marcha utilizando um modelo biomecânico simples. O uso destas duas propostas em conjunto resultará em uma representação mais completa da marcha de amputado, o que significará melhoras nos tratamentos de reabilitação para indivíduos nesta condição, assim como novos projetos de próteses de membro inferior baseadas nesta abordagem.

\subsection{Aspectos BIOMECÂNICOS DA MARCHA}

O ciclo de marcha é uma sequência de movimentos repetitivos dos membros superiores e inferiores com o objetivo de promover o avanço do corpo ao mesmo tempo que o equilíbrio do mesmo é mantido (Perry, 1992). O ciclo de marcha é basicamente dividido em duas fases, a fase de apoio, quando o membro que está sendo o de referência está em contato com o solo; e a fase de balanço, quando o mesmo membro está no ar se balançando até o próximo contato inicial. As duas fases geralmente são divididas em sub-fases, as quais representam características especificas de cada uma das articulações do membro inferior que participam na marcha (ver Figura 1.1).

Os movimentos das articulações ao longo do ciclo de marcha é estudado para identificar características particulares da marcha desde o ponto de vista cinemático. Estas variáveis cinemáticas correspondem aos ângulos das articulações do quadril, do joelho e do tornozelo nos três planos de referência: frontal, sagital e transverso. Os maiores deslocamentos angulares acontecem no plano sagital. Desde o ponto de vista cinético, as forças de reação do solo definem a interação entre o pé e a superfície enquanto a pessoa caminha. Os padrões de cada uma de suas componentes são iguais para cada pé no caso de uma marcha normal.

Outra variável importante na hora de analisar a marcha humana corresponde à trajetória da 


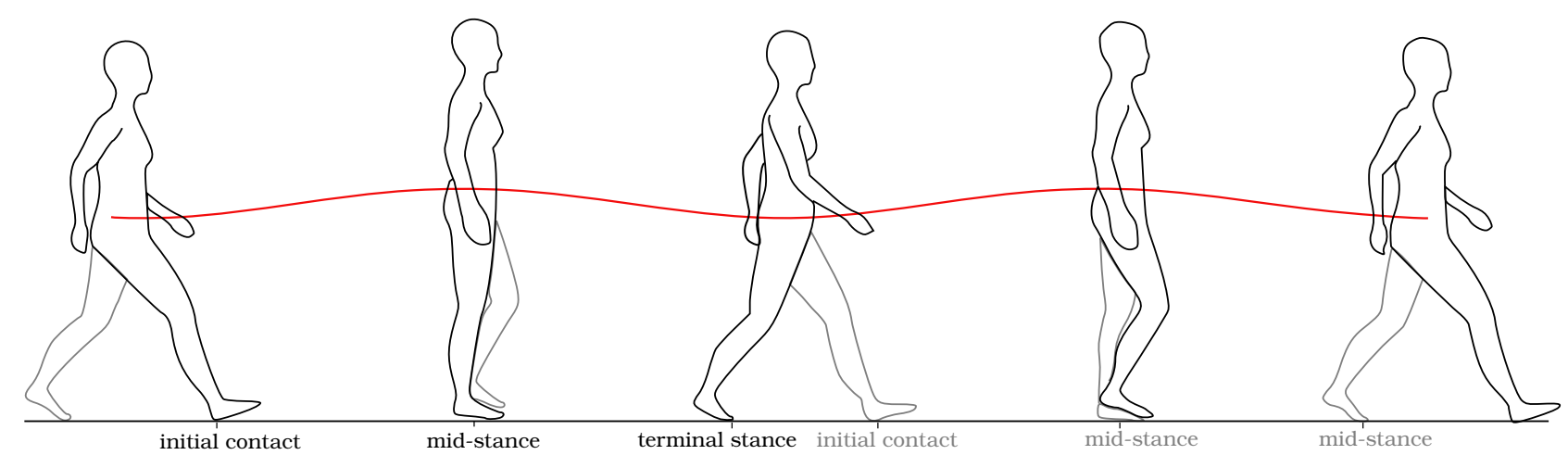

Figura 1.2: Trajetória vertical do centro de massa corporal ao longo do ciclo de marcha.

centro de massa corporal, definido como o local anatômico onde toda a massa de nosso corpo se concentra. Tipicamente, a trajetória do centro de massa no plano sagital possui um padrão sinusoidal, como o representado na Figura 1.2. Se o andar de uma pessoa se vê afetado por algum tipo de condição motora, este padrão passará a ter outras características.

A ultima variável analisada neste estudo corresponde ao custo em termos de energia da marcha. Especificamente, a energia mecânica armazenada nos nossos músculos e que posteriormente se transformará em movimento dos nossos segmentos tem sido associada com o trabalho mecânico aplicado no centro de massa. Cavagna et al. (1977) comprovaram que as oscilações da energia cinética e potencial do centro de massa se assemelhavam ao comportamento de um pêndulo invertido. Assim, uma forma de aproximar o custo da marcha em termos de energia mecânica é através do cálculo do trabalho necessário para movimentar o centro de massa.

Neste trabalho todas as variáveis apresentadas anteriormente foram medidas em dois grupos formados por voluntários amputados e não amputados. O objetivo destes experimentos de análise de marcha é extrair os padrões típicos de uma marcha normal e compará-los com os obtidos no grupo de indivíduos amputados.

\subsection{MARCha DE AMPUtAdo}

Como já foi mencionado anteriormente, a amputação representa uma perda de funções importantes desde o ponto de vista anatômico é fisiológico. A pessoa amputada deve-se adaptar ao mecanismo que substituirá a parte do membro ausente. As limitações funcionais das próteses de membro inferior impõem restrições à marcha que geram estratégias ou mecanismos de compensação para tentar superar estas limitações. Os mecanismos de compensação por sua vez se refletem em comportamentos assimétricos das variáveis cinemáticas e cinéticas medidas. A Tabela 1.1 resume as principais restrições à marcha e os principais mecanismos de compensação identificados na literatura revisada. 
Tabela 1.1: Principais restrições à marcha e os respectivos mecanismos de compensação encontrados na literatura.

\begin{tabular}{|c|c|}
\hline Restrição à marcha & Mecanismo de compensação \\
\hline $\begin{array}{l}\text { Flexão involuntária do joelho da prótese } \\
\text { Descarga inadequada de peso }\end{array}$ & $\begin{array}{l}\text { Joelho completamente estendido no lado da prótese } \\
\text { Flexão anterior do tronco } \\
\text { Forças verticais de reação do solo com maior amplitude } \\
\text { Fase de apoio mais prolongada no lado não amputado }\end{array}$ \\
\hline $\begin{array}{l}\text { Ausência de estabilidade } \\
\text { Base para andar reducida }\end{array}$ & Movimento lateral do tronco \\
\hline Encurtamento inadequado da prótese no balanço & Inclinação para o lado não amputado \\
\hline Interface entre o coto e o soquete inapropriada & $\begin{array}{l}\text { Aumento da inclinação da pelve } \\
\text { Aumento da flexão/extensão do quadril no lado não amputado } \\
\text { Diminuição da flexão/extensão do quadril no lado da prótese }\end{array}$ \\
\hline Ausência de dorsiflexão no pé da prótese & Elevação do quadril \\
\hline Empurre reduzido no lado da prótese & $\begin{array}{l}\text { Momentos maiores no quadril no lado não amputado } \\
\text { Velocidade menor do centro de massa }\end{array}$ \\
\hline
\end{tabular}

\subsection{Modelamento DiNÂMICO DA MARCHA}

O andar dinâmico, ou dynamic walking em inglês, é um conjunto de conceitos que aproveitam a dinâmica natural das pernas para propor modelos que consigam reproduzir a marcha (Remy, 2011). Diferente de propostas que dependem em grande em parte da inclusão de atuadores para promover o movimento, o sistemas baseados em dynamic walking são capazes de produzir marcha com uma mínima intervenção de atuadores. As estratégias de controle estão orientadas a produzir um movimento cíclico que garanta a estabilidade do sistema ao longo da marcha.

As diferentes propostas de modelos que utilizam esta abordagem podem ser divididas em dois tipos, aquelas baseadas em pernas rígidas, como o modelo proposto por McGeer (1990), e aquelas baseadas em pernas elásticas ou complacentes, como o modelo proposto pelo Blickhan (1989). Este último modelo consiste em um sistema elástico composto por uma mola linear, que representa a perna, junto com uma massa no extremo da mola, que representa a massa corporal. A saída do modelo corresponde à trajetória vertical do centro de massa. O modelo de Blickhan (1989) foi chamado de spring-loaded inverted pendulum, abreviado como SLIP, e representa o salto humano por meio da repetição sequencial de fases áreas e de contato. Cada fase é definida pela equação de movimento correspondente.

Geyer et al. (2006), baseado no trabalho inicial do Blickhan, demonstrou que também era possível utilizar pernas complacentes para representar o andar bípede. Ele propõe então a versão bípede do modelo SLIP. A Figura1.3 representa o modelo SLIP para o andar bípede. O modelo SLIP representa a duas pernas como sendo duas molas lineares. A massa do corpo está representada por meio de uma massa pontual cuja posição corresponde ao centro de massa. Um passo é definido como uma sequência de suporte simples, seguido de um suporte duplo e um suporte simples final. As fases de suporte simples e suporte duplo estão limitadas pelos eventos de touch-down, que é equivalente ao contato inicial, e lift-off ou instante de desprendimento dos dedos. 


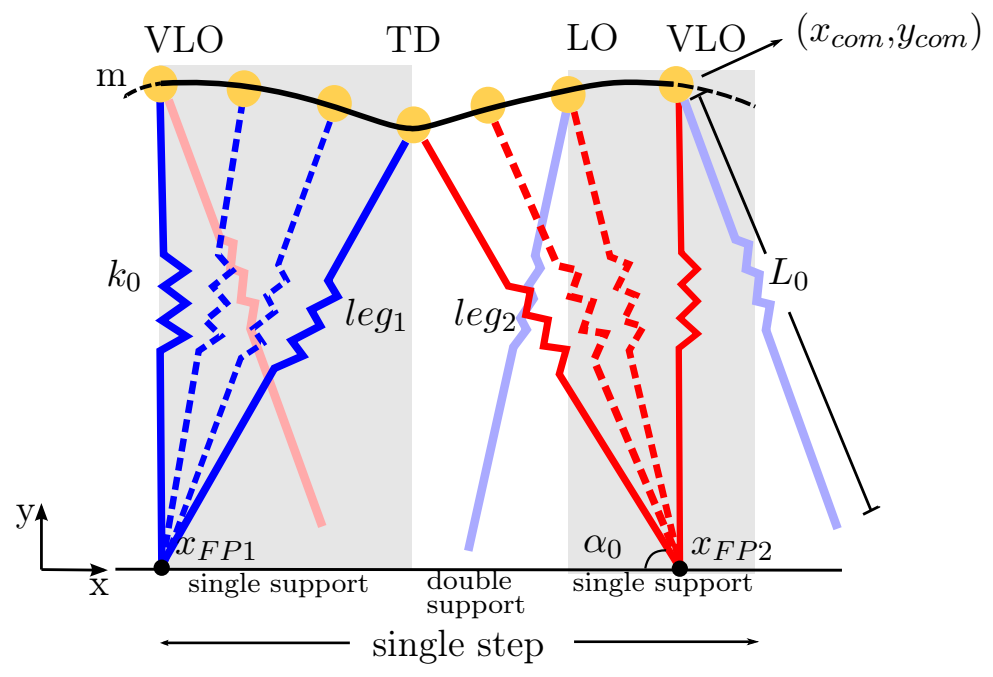

Figura 1.3: Modelo SLIP para marcha bípede.

Os parâmetros do modelo SLIP são a massa corporal $m$, o comprimento da perna $L_{0}$, o ângulo de ataque $\alpha_{0}$ definido entre a perna de contato e a superfície, o coeficiente de rigidez da perna $k_{0}$ e a energia total do sistema $E_{s}$. Diferentes combinações de parâmetros e de condições inicias podem gerar diferentes tipos de trajetórias de centro de massa. Esta formulação inicial do SLIP gera solução simétricas, quer dizer, as trajetórias do centro de massa são iguais para cada perna, o que pode ser pensado como uma marcha normal. Para extrair soluções assimétricas deve-se ter pernas com características diferentes. Um proposta assimétrica do SLIP é desenvolvida emMerker et al. (2011), onde as diferenças entre as pernas são introduzidas como perturbações que afetam os valores de controle de cada um dos parâmetros.

Neste trabalho é implementada a formulação inicial do modelo SLIP proposta por Geyer et al. (2006) para gerar trajetórias do centro de massa corporal semelhantes ao caso não amputado. Para tentar representar os padrões observados nos indivíduos amputados, foi implementado o SLIP asimmétrico proposto pelo Merker et al. (2011).

\subsection{CONTRIBUiÇÕes DA TESE}

As contribuições derivadas desta tese podem ser divididas em três partes:

- Análise de simetria dos membros inferiores utilizando técnicas matemáticas no dominio do tempo e no dominio da frequência. Considerando as variáveis cinemáticas e cinéticas da marcha como sendo séries temporais ao longo de um ciclo de marcha, a primeira técnica estudada neste trabalho tem como objetivo detectar semelhanças entre os sinais comparados em termos da magnitude do sinal e o deslocamento temporal entre eles. A segunda técnica estuda a simetria da trajetória do centro de massa para um ciclo de marcha. Este sinal é definido por meio de seus componentes espectrais. Níveis de assimetria são associados com componentes ímpares no espectro. Como resultado desta análise, dois índices são propostos para analisar quantitativamente a simetria das variáveis medidas nos experimentos de marcha. 
- Representação da marcha de amputado usando um modelo dinâmico de marcha. A implementação do modelo SLIP para gerar soluções simétricas a assimétricas baseadas nas características dos sujeitos estudados, deu como resultados padrões da trajetória do centro de massa próximos aos obtidos experimentalmente.

- Abordagem baseada no filtro de kalman estendido para estimar a rigidez da perna. O método proposto utiliza um filtro de Kalman estendido baseado nas equações do modelo SLIP para estimar a rigidez da perna $k_{0}$. Ao invés de utilizar informações de forca como na maioria dos métodos propostos na literatura, a proposta desenvolvida neste trabalho utiliza informações de posição e velocidade do centro de massa. Resultados de simulação demonstraram a potencialidade do método desenvolvido. 


\section{INTRODUCTION}

Amputation is defined as a partial or a complete loss of a limb (Perry, 1992). This condition severely impacts the quality of life of a person. In some cases, it could represent the impossibility of working, studying or having a normal social life. Today, the major cause of amputation worldwide is diabetes, while in a smaller proportion, cancer, deformities or severe injuries also lead to a limb loss (Ephraim et al., 2003; Gailey et al., 2008). According to Ziegler-Graham et al. (2008), an estimate of 185, 000 persons suffer from any type of amputation each year in the United States. The study also projected that the amputee population in the U.S. will be approximately 3.6 million by the year 2050. For the case of Brazil, Spichler et al. (2004) presented the incidence of peripheral arterial diseases and diabetes mellitus on 4,818 major lower extremity amputations reported from the year 1990 to 2000 in the city of Rio de Janeiro. From these amputations, $71.8 \%$ corresponded to an above-knee level.

The main goal of a lower limb prosthesis is to guarantee stability and security during ambulation in a comfortable way. Even though most commercial prostheses meet these requirements, the limitations in terms of speed and active response still prevail among them. Previous studies have reported that limitations in the functional characteristics of the prosthetic limbs can lead to serious physical conditions on the remaining joints of the lower body of the amputee subject ${ }^{1}$ (Norvell et al., 2005; Gailey et al., 2008; Morgenroth et al., 2014; Devan et al., 2014). Most of these findings are based on measurements of cinematic and kinetic variables obtained from gait analysis experiments. The evolution of the gait analysis, from an observational approach to a quantitative assessment, provides a more precise knowledge about the different effects that a prosthetic limb may produce on the user body.

On the other hand, the use of dynamic walking models, which emerged from the field of legged robotics, have become an useful tool to explain the dynamics of human walking on different conditions. The representation of human legs by simple mechanisms have demonstrated to successfully emulate the basics characteristics of biped locomotion, i.e., simplicity, self-stability and energy efficiency. Using dynamic walking models, some studies have already came into important insights about human walking, from the preferred speed-step length adopted by humans (Kuo, 2001) to the relationship between the center of pressure position along the foot and the oscillatory motion of the body center of mass (Jung \& Park, 2014). For the case of the amputee gait, a few studies have used gait modeling to represent special characteristics of this type of gait. In Morgenroth et al.

\footnotetext{
${ }^{1}$ For simplification purposes, when not explicit, the term amputation will refer exclusively to lower limb amputation in this document.
} 


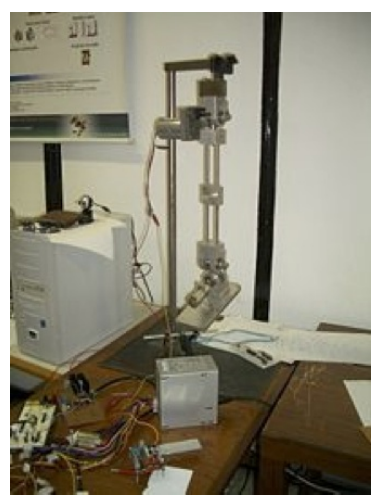

(a)

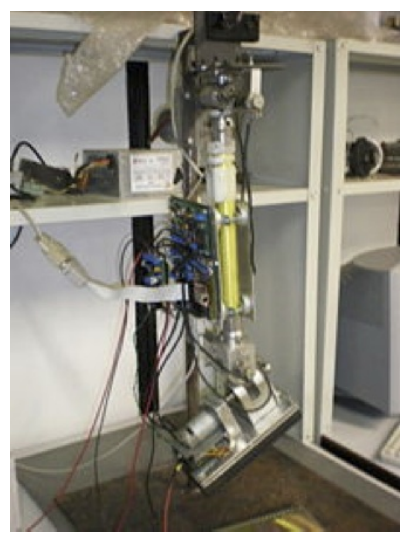

(c)

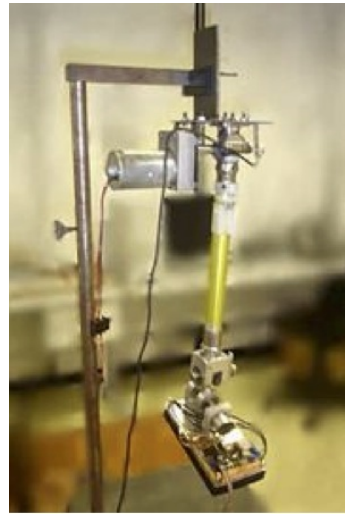

(b)

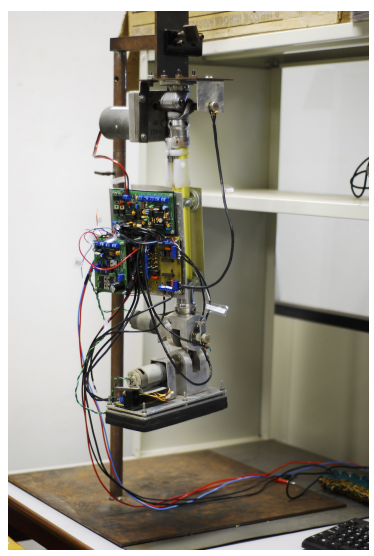

(d)

Figure 2.1: Prosthesis prototypes constructed at LARA. (a) 2005, (b) 2007, (c) 2008 and (d) 2010 versions.

(2011), the effect of the prosthetic foot push-off was associated to the increase of the knee external abduction moment in the transtibial amputee population. Other work focused on transtibial amputees is presented in Adamczyk \& Kuo (2014). A model that predicts asymmetries in the foot mechanical work is used to explore its consequences on the rest of the body. In this sense, the model-based study of human walking, in conjunction with the clinical evidence provided by gait analysis, seems to be the key for improving the design and the control of lower limb prosthesis.

This thesis was conceived within the RLEG project, whose main objective is the construction of an active lower limb prosthesis for above-knee amputees. The Laboratório de Automação e Robótica (LARA) began with the idea of constructing rehabilitation devices in 2005. Several prototypes of the prosthetic leg were constructed from 2005 to 2010 (see Figure 2.1), improving the mechanical (Júnior, 2005), electronic (Alves, 2007) and control (Scandaroli, 2007, Scandaroli, 2009, Scandaroli et al., 2009, Delis-López, 2010) design from one model to another. Although important advances were obtained from these works, the prosthesis prototypes were never tested on humans. A new version of the initial project began in 2011, with the financial support of the Financiadora de Estudos e Projetos (FINEP). The approved project contemplates the conception of an active above-knee prosthesis that would be tested on amputee patients. The system will 


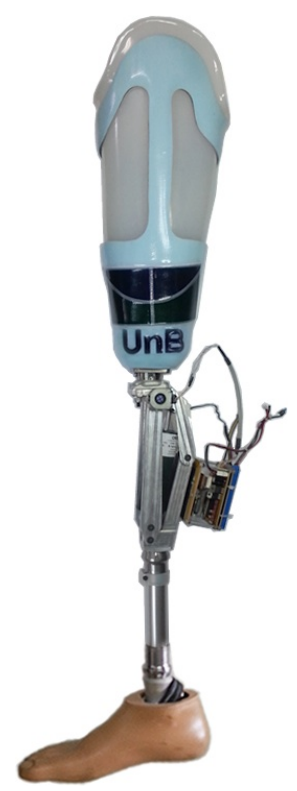

(a)

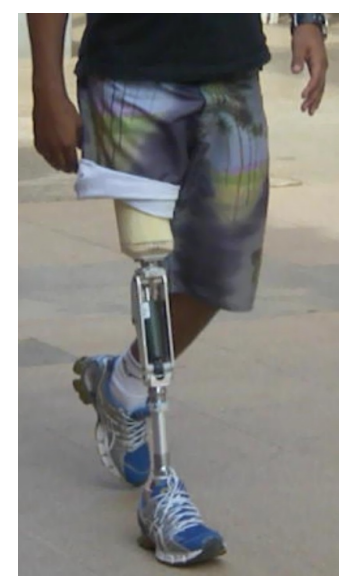

(b)

Figure 2.2: RLEG. (a) The current prosthesis prototype. (b) The amputee volunteer wearing the protoype during the alignment test.

collect information using on-board sensors in order to identify the mode of locomotion desired by the user. Then, a control strategy will modulate the actuator impedance to produce an adequate operation of the prosthesis along walking. The first prototype was finished in the 2013 (see Figure $2.2)$.

In this context, this thesis is mainly focused on the problem of understanding the prosthetic walking from the point of view of gait analysis and dynamic walking modeling. As stated before, we believe that unification of concepts between these two areas will provide important guidelines for therapists to better conduct rehabilitation programs based on the findings from the gait models, and also to prostheses designers to improve the functional characteristics of the prosthetic devices.

To accomplish this main task, the biomechanical principles of human walking were examined. The particular case of amputee gait was studied as the difference between the typical pattern of the studied gait variables in normal conditions and their corresponding values for the case of the amputee population. Based on this knowledge, gait experiments were carried out on able-bodied and amputee subjects to identify the main differences between the two groups. From a symmetry analysis, which compare the variable values on each limb, the gait variables that best reflected such differences were identified. The trajectory of the center of mass $(\mathrm{CoM})$ was one of them. Particularly, this variable reflects the interaction between the different body segments in order to execute motion. From a modeling perspective, its periodical motion is appealing in terms of representation, since it reflects the energy exchanges occurred during walking. The spring-loaded inverted pendulum (SLIP) is a dynamic gait model that exploits the elastic behavior of legs to recreate the periodical motion of the CoM during a gait cycle (Rummel et al., 2010). In this work the SLIP model was initially used to represent the basic characteristics of human walking. An extension of the SLIP model is considered to represent the case of the amputee gait. 


\subsection{Thesis CONTRIBUTIONS}

The thesis contributions can be divided in three parts:

1. An analysis of limb symmetry using mathematical tools in the time and in the frequency domain. Considering the gait variables as time sequences during a gait cycle, the first studied technique looks for similarities between the compared signals in terms of magnitude and time shift. The second technique examines the symmetry of vertical CoM between consecutive steps. The vertical CoM trajectory is defined in terms of its spectral components. Since the vertical CoM in a normal gait exhibits even symmetry, the presence of odd components in its magnitude spectrum can be associated to asymmetric behaviors; therefore the energy contribution of these components to the total energy signal is proportional to the level of asymmetry of the signal. As a result, two symmetry indices, based on the aforementioned techniques, were used to evaluate symmetry in all the gait variables measured during the experiments.

2. Representation of the amputee gait using a dynamic walking model. The implementation of the SLIP model for simulating the vertical CoM, in situations of symmetric and asymmetric legs, generated walking patterns close to normal and amputee gaits. From this, the SLIP model was adapted for the real characteristics of a non-amputee and an amputee subject from our experiments. As a result, a model template for the analysis of human walking was implemented. This model can be adapted to meet the specific characteristics of the subjects to be studied.

3. An EKF-approach for estimating leg stiffness. The proposed method uses the extended Kalman filter (EKF) to estimate the value of leg stiffness based on the equations of motion of the SLIP model. It uses information of the CoM position and its velocities and no force measurements are needed. Preliminary results based on simulations showed the potential of this method for stiffness estimation.

\subsection{ORganization OF THE THESIS}

The rest of the thesis is organized as follows:

- Chapter 2 introduces the basic concepts around gait analysis from a biomechanical perspective. Kinematic and kinetics variables are defined and their patterns from normal walking are exhibited. Amputee gait is examined from the perspective of the gait constraints found in the amputee population and the corresponding compensatory mechanisms developed by the subjects.

- Chapter 3 presents the results from the experiments carried out in non-amputee and amputee subjects. Different kinematics and kinetics variables were measured and their outcomes from both groups were analyzed. A detailed discussion of these results highlights the compensatory mechanisms identified in the amputee subjects. 
- Chapter 4 is devoted to the limb symmetry analysis. Two indices for measuring limb symmetry based on the cross-correlation coefficient and the discrete Fourier series (DFS) are employed. The results from both techniques confirm the presence of asymmetries in most of the measured gait variables.

- Chapter 5 describes the SLIP model used for representing the human walking by means of the vertical trajectory of the CoM. Different solutions from its basic formulation are generated. Limb asymmetry is also represented by this model by modifying the systems parameters. This extension of the SLIP model is used to compare the experimental trajectory of the CoM and the model output based on the characteristics of a reference non-amputee subject and an amputee subject.

- Chapter 6 presents the concluding remarks and the discussion of the future perspectives related to the study of amputee gait. 



\section{BIOMECHANICAL ASPECTS OF WALKING}

To initiate the study of the amputee walking, first it is necessary to understand how humans walk on normal conditions. As locomotion is a process which mainly involves the interaction of the sensory-motor and the musculoskeletal system, the approaches to understand locomotion depend on which of these systems have been selected as the matter of study. Biomechanics, in a broader sense, is the discipline that studies the biological systems using the laws of mechanics (Whittle, 2007). It studies the lowest level of locomotion generation, i.e., the muscles and the joint torques generation that promote the motion of the rigid segments of the body limbs, which in turn exert forces on the environment that surround them.

This chapter is devoted to present the basic concepts around gait analysis from a biomechanical perspective. This knowledge is extremely important for the subsequent analysis and modeling presented in the following chapters. First, the definition of gait cycle is provided. From this definition, several kinematic and kinetics variables will be defined and their patterns from normal walking will be exhibited. Secondly, elaborated calculations derived from the gait variables will also be presented, stressing their importance for further analysis of the gait experiments conducted in this work. The third part of this chapter is oriented to explain the main characteristics of the amputee gait, based on the differences between the gait variables measured on this condition and the references values from a normal gait. Those differences will lead us to the concept of gait symmetry, and it will be shown how this definition is important to characterize the amputee gait.

\subsection{THE GAIT CYCLE}

The word gait refers to the repetitive sequence of limb motions which move a body forward while simultaneously maintaining its stability (Perry, 1992). This sequence involves a series of interactions between two multi-segmented legs and the total body mass. Due to the periodic nature of the gait, this can be analyzed separating a single period or cycle.

The gait cycle (shown in Figure 3.1) begins when the observed foot touches the ground and ends when the same foot meets the ground again. In this way, a complete gait cycle, also known as a stride, is composed by two subsequent steps. The cycle is divided mainly in two phases: the stance phase is the period of time when the reference leg is in contact with the ground, while the swing phase is when the same leg is waving on the air until the next contact. To facilitate the gait assessment, the legs receive special names according to whether they are in the stance or in the swing phase. From now on, the leg that initiates the stride will be identified as the trailing leg, 


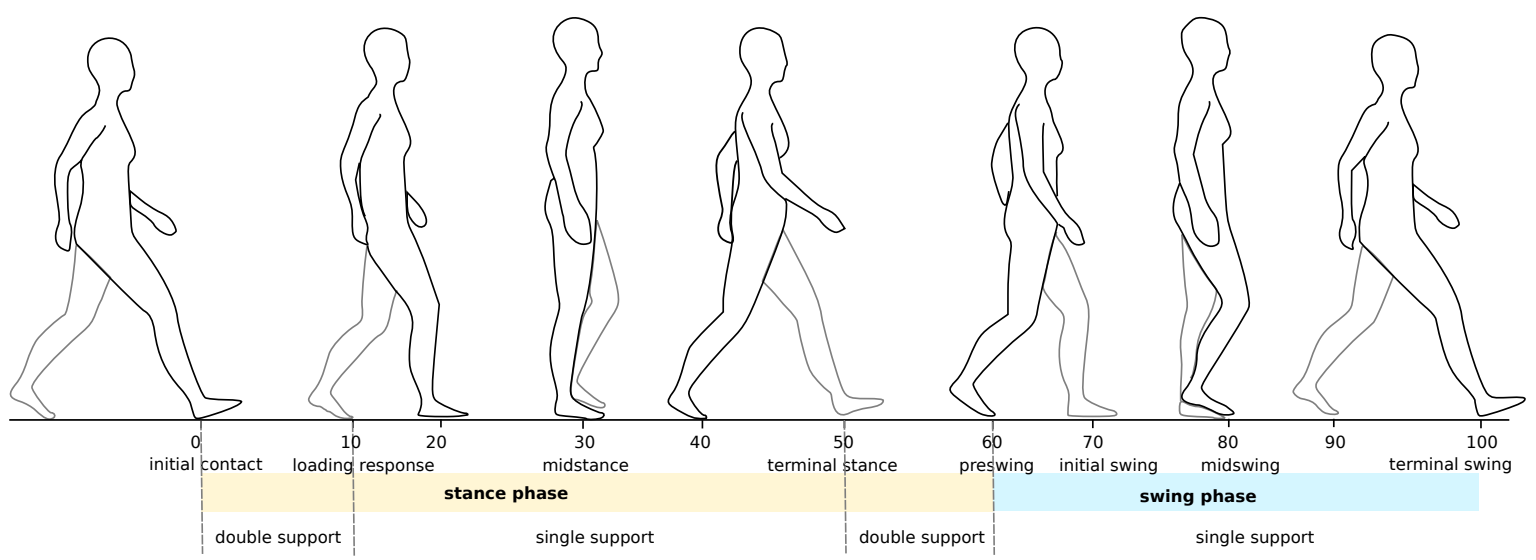

Figure 3.1: Gait cycle and its phases (adapted from Neumann 2002).

while the other leg will be the leading leg.

At normal walking, the stance phase lasts $60 \%$ of the whole gait cycle, while the swing phase happens during the remaining $40 \%$. Each phase is divided by functional subphases, indicating the specific moment when each of the involved joints (hip, knee and ankle) have a specific behavior. This division facilitates the walking assessment by the clinicians, allowing to identify specific pathologies. Since the most relevant profiles of the leg's joints take place in the sagittal plane, the functional sub-phases presented below are explained according to the behavior of the joints in this plane. This division is based on the work of Perry (1992).

\subsubsection{Stance phase}

During the stance phase the body weight is transferred between the limbs. This requires great stability from the trailing leg in order to preserve the body progression during this transfer. The body weight loading takes place twice during this phase: at the beginning of the gait cycle, when the leading transfers the body weight onto the trailing leg; and between the $50 \%$ and $60 \%$ of the gait cycle, when the legs changes functions. The two moments of body weight loading requires a double support from the two limbs, i.e., the two legs are in contact with the ground. The sub-phases involved in stance are described below.

1. Initial contact. This is the moment when the foot of the trailing leg touches the ground. The hip is flexed, while the knee joint is extended. The ankle dorsiflexes to a neutral position. This sub-phase is also called heel strike, referring to the event when the posterior part of the foot makes contact with the floor.

2. Loading response. Here, the body weight is passed from the leading to the trailing leg. The hip continues flexing, while the knee begins to flex and the ankle moves to plantarflexion, in order to produce the limb progression.

3. Midstance. This sub-phase happens at $10 \%$ of the gait cycle and finishes at approximately $30 \%$ of the stride. During midstance the single support period takes place. The hip and the 
knee are extended. The ankle joint dorsiflexes because of the flat position of the trailing foot. This ankle motion is also known as the ankle rocker.

4. Late stance. Continuing in single support, the heel of the trailing foot lifts from the surface as the contralateral limb is preparing to contact the ground. The ankle continues in dorsiflexion, while the knee and the hip increase their extension angle.

5. Pre-swing. This is the last sub-phase of the stance period. Here, the second double support occurs as the leading leg begins the stance phase. The ankle presents its maximum plantarflexion, while the knee has a great flexion angle. The hip extension starts to decrease.

\subsubsection{Swing phase}

This phase mostly describes the swaying behavior of the trailing leg while it meets the surface again in the next step. The leg presents three postures which originates the three sub-phases.

1. Initial swing. The trailing leg starts to moves forward by hip flexion. The knee is increasing its flexion and the ankle presents a moderate dorsiflexion. Another usual name to this subphase is toe-off.

2. Midswing. At this moment the trailing leg passes the leading leg, which is in stance. The hip increases its hip flexion, while the knee starts to extend. The ankle joint continues in dorsiflexion.

3. Late swing. This is the final moment of the gait cycle. The hip keeps flexed and the knee is completely extended. The ankle meets again its neutral position.

\subsubsection{Joint Kinematics}

As a person walks, the interaction of all the involved segments describe movements in the three plane of motions: the sagittal, the frontal and the transverse plane (see figure 3.2). Even though the hip, the knee and the ankle joints perform movements in all these planes, it is at the sagittal plane where the angular motion of the three joints presents its larger value. Figure 3.3 presents the typical joint kinematics in the sagittal plane for all the involved joints during a single gait cycle.

Beginning with the hip joint, its angular motion in the sagittal plane begins with approximately $30^{\circ}$ of flexion at the initial contact. Then, as the body moves forward, the hip extends up to $10^{\circ}$ before the beginning of the swing phase. During pre-swing, hip flexion reaches a zero position at toe-off. After that, the hip starts to flex again up to approximately $30^{\circ}$ prior to heel strike.

The motion of the knee joint in the sagittal plane is characterized by two moments of flexionextension along the stride. At initial contact, the knee flexes around $5^{\circ}$ and continues to flex until approximately $20^{\circ}$, during loading response. The rate of flexion at this time is about $300^{\circ} / \mathrm{s}$. From this point, the knee begins to extend up to $3^{\circ}$, at a slower rate compared to the initial flexion velocity. At terminal stance the second knee flexion occurs; by the time pre-swing (or heel-off) 


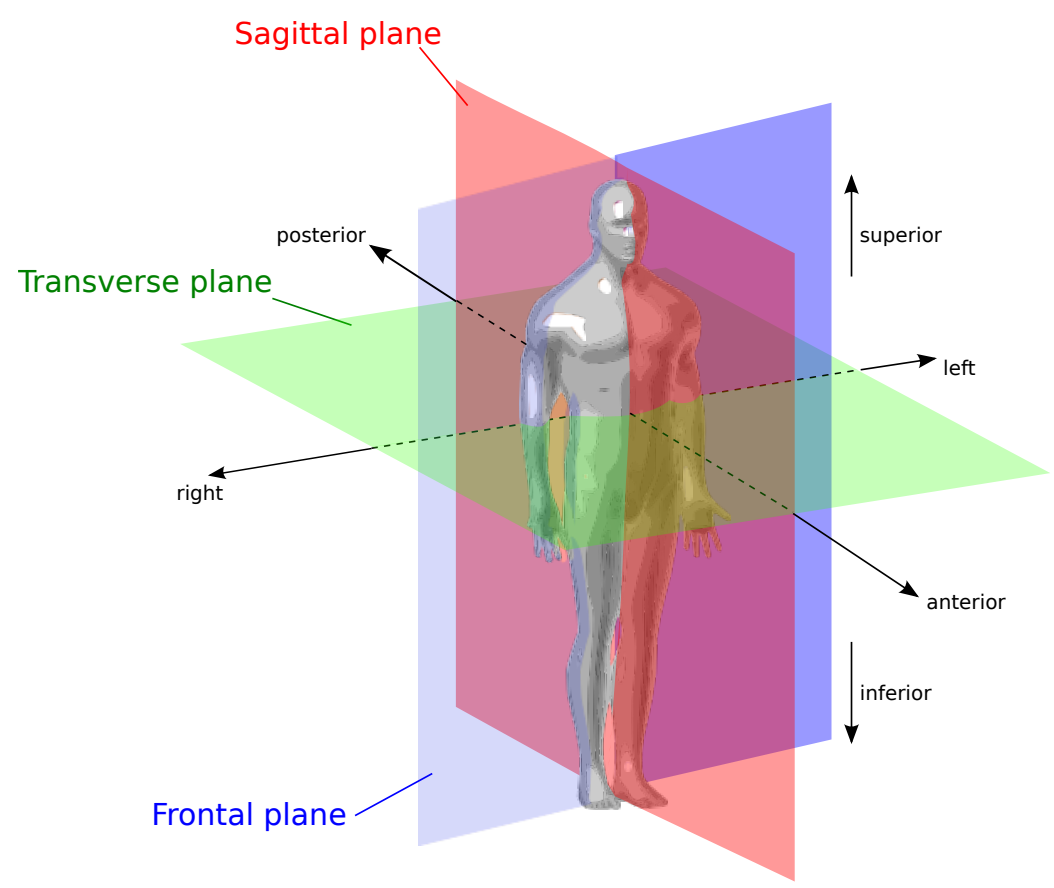

Figure 3.2: Planes of motion of the human body (courtesy of Wikimedia Commons).

happens, the knee has already flexed $40^{\circ}$, reaching the highest value at midswing, when the flexion angle can be $60^{\circ}$. This second moment of flexion has an angular velocity of approximately $350^{\circ} / \mathrm{s}$ (Perry 1992). Finally, the knee extends again as fast as it flexes during the first half of the swing phase, until it gets full extension at terminal swing. Before the gait cycle ends, the knee has a slightly flexed posture of around $5^{\circ}$.

The last joint to be considered is the ankle. At the beginning of the gait cycle, its position is considered neutral, slightly plantarflexed at $3^{\circ}$. Then, the ankle continues in plantarflexion until it reaches approximately $10^{\circ}$ at the loading response. From this point, the joint begins to dorsiflex until it reaches half of the gait cycle, with an angle value close to $10^{\circ}$. From the $50 \%$ to the $60 \%$ of the gait cycle, the ankle rapidly plantarflexes reaching its highest value, between $15^{\circ}$ to $20^{\circ}$. At the swing phase, the joint dorsiflexes to the zero position. At the end of the gait cycle the ankle often plantarflexes $3^{\circ}$ to $5^{\circ}$.

\subsubsection{The ground reaction forces}

The interaction between the foot and the surface while a person walks originates a series of forces on the vertical, the anterior-posterior and the medial-lateral direction. The forces exerted by the ground to the foot are known as the ground reaction forces (GRFs). These forces are equal in magnitude but opposite in direction from the ones applied by the foot on the contact surface, according to the Newton's third law of motion. The GRFs change in magnitude, direction and point of application on the foot along the step (Neumann, 2002). The knowledge of these forces is useful for the calculation of the reaction moments of each joint during gait, and the appropriate muscle moments that must be generated in order to counteract the interaction moments. 

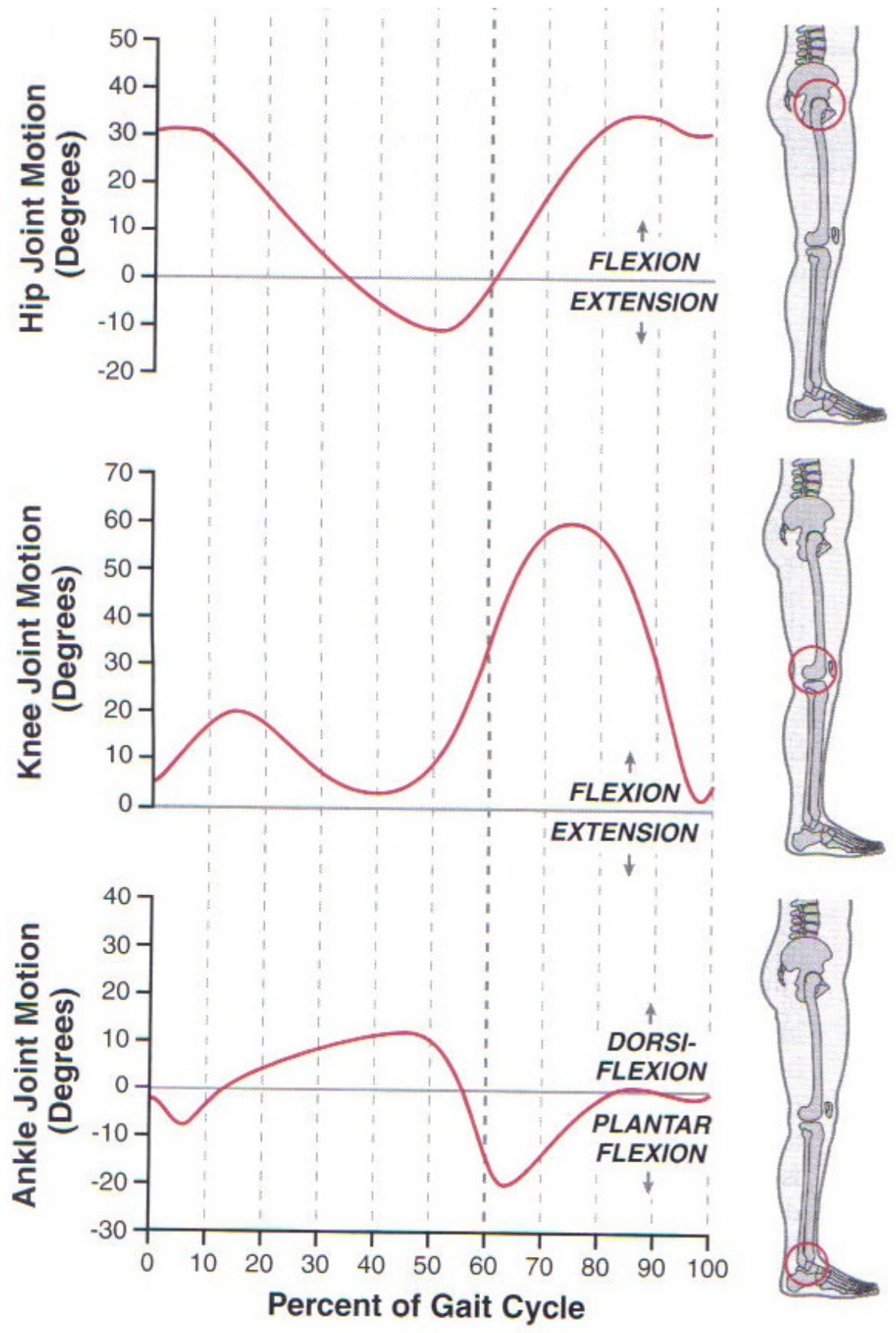

Figure 3.3: Sagittal plane typical kinematics of the hip, the knee and the ankle joints (taken from Neumann, 2002). The zero position for the case of the hip and the knee joint is the one shown in the limb representation beside each graphic. The zero position of the ankle joint corresponds to that at initial contact. 


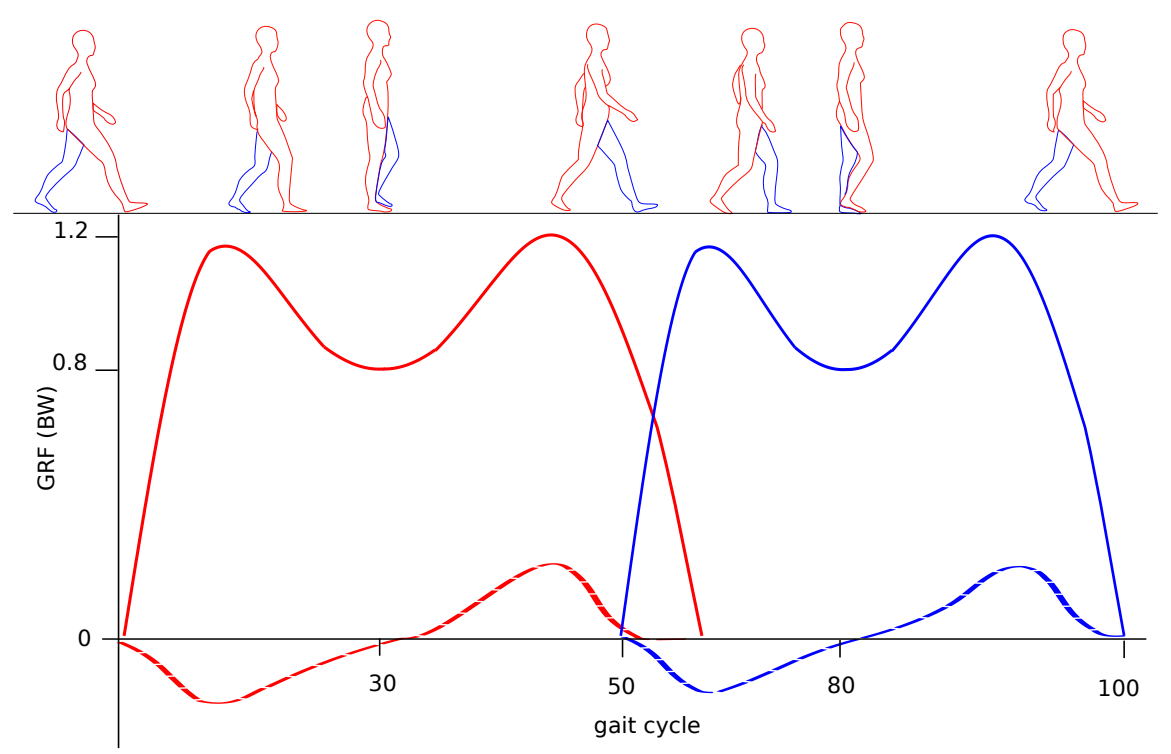

Figure 3.4: The ground reaction forces. The vertical component for both feet are represented by the solid lines, while the anterior-posterior GRFs correspond to the dashed lines (adapted from Neumann, 2002).

The GRFs are directly measured using a force platform. It consists of strain gauge or piezoelectric transducers located along the platform. The most recent devices can measure the three components of the resulting force applied on the plate, as well as the resultant moments according to the local coordinate system; and from these two quantities the location of the force application can be calculated. In figure 3.4, the GRF patterns for the vertical and the anterior-posterior component are shown. The magnitude of the medial-lateral component is almost negligible, so it is not considered here.

The vertical component of GRFs presents two peaks along the gait cycle, at loading response and terminal stance. These values usually are greater than the body weight, exceeding in approximately $10 \%$ its value. Between these two peaks, there is a valley that corresponds to the lowest value of the vertical force, approximately $80 \%$ of the body weight, taking place at midstance. The first maximum value of the vertical GRF occurs due to the effect of the downward movement of the center of mass, as the body weight is loaded onto any of the two legs. Then, as the center of mass is lifted at midstance, the GRF decreases in value, reaching its lowest point. The second peak at terminal stance is caused again to counteract the downward of the center of mass, as the body weight falls over the forefoot, at the moment of the double support.

The anterior-posterior GRF has the pattern shown in figure 3.4. At the beginning of the gait cycle, the foot exerts an anterior force to the ground, so the GRF component presents a force in the posterior direction, the higher the value the higher the friction that is generated. At midstance, this force goes to zero and changes its direction due to the posterior force that the foot applies in order to impulse the body forward. The anterior-posterior GRFs are small in magnitude, between $10 \%$ to $20 \%$ of the total body weight. 


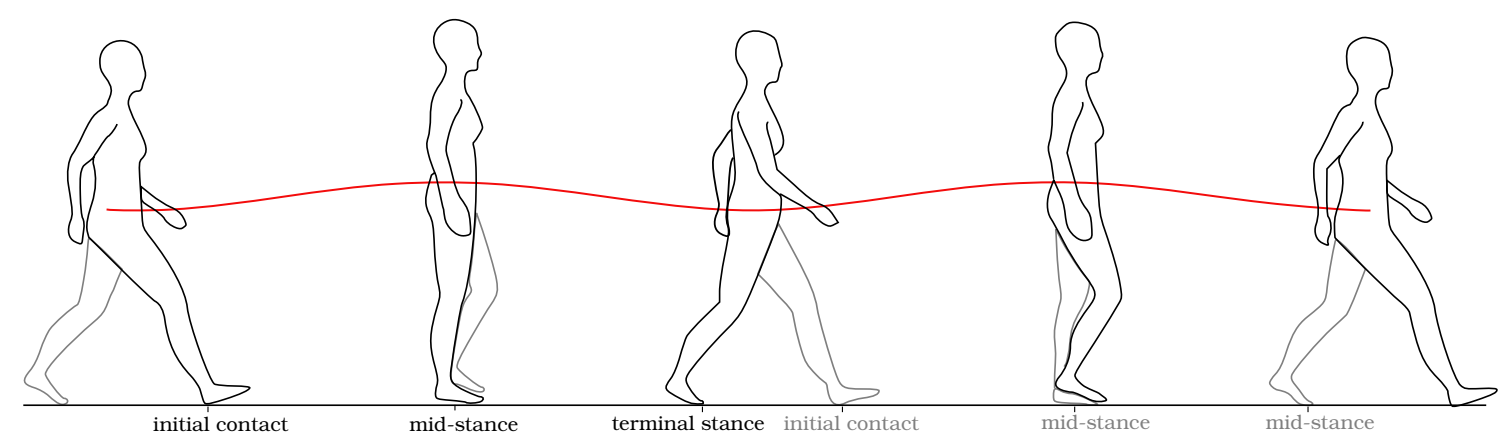

Figure 3.5: The vertical trajectory of the body center of mass (CoM).

\subsubsection{The body center of mass trajectory}

The body center of mass (CoM) has an important role in the study of the human motion. It has mainly been used as an estimator of the human balance and posture. In a more dynamic scenario, the trajectory of the CoM can also be used to describe the human gait. For instance, walking can be defined as a series of up-down and medio-lateral motions of the CoM in the forward direction. Additionally, as the CoM represents the total body weight location, it is also useful for studying the overall energy expenditure during different types of locomotion.

The CoM trajectory describes a clear sinusoidal pattern in the vertical and the medio-lateral direction. Figure 3.5 presents the vertical excursion of the CoM during a gait cycle. The initial contact is taken as the reference point. From here, the vertical excursion of the CoM increases as the body weight is loaded onto the trailing leg, reaching its highest value at midstance. After that, this value decreases until the leading leg meets the stance phase, i.e., a new step has begun. Next, the sequence is repeated, the body weight is now loaded onto the leading leg. As it can be observed from Figure 3.5, during a single gait cycle the CoM vertical position has two minimal and maximal points, that correspond to the instants of initial contact and midstance of each leg.

To estimate the CoM location while the body is on motion, some methods have been proposed. The segmental method uses classical anthropometric tables that give the position of the center of mass of the body segments and their weights as a percentage of the whole body. From these data, the entire body CoM can be calculated as (Winter, 2009)

$$
C o M=\frac{1}{M} \sum_{i=1}^{n} m_{i} \operatorname{CoM}_{i}
$$

where $M$ represents the whole body mass, $C o M_{i}$ corresponds to the CoM locations of each body segment and $m_{i}$ are its masses. This method is somehow limited, because most of the anthropometric tables are calculated based on specific population characteristics (average height, weight and mass distribution), restricting their use only to subjects who meet those specifications.

Another method uses the approximated anatomical location of the body CoM, known as the sacral marker method. In this method a marker is placed on the second sacral vertebra (Neumann 2002, Smith et al. 1996), which is the anatomical location closest to the true position of the body CoM. Its main advantage is that it provides a direct calculation, although its value can be 
influenced by the erroneous marker placement, errors from the measurement system and the effect of wobbling masses movement on the measurement region.

Finally, kinetic information can also be used to the estimate CoM. Using the GRF measurements provided by force platforms, the CoM value may be obtained by double integrating these information and dividing this result by the subject mass (Cavagna, 1975). The accuracy of the kinetic method relies on the force measurements and the integration constants.

These three methods are widely used in the literature (Lee \& Farley, 1998; Gard et al., 2004), although new proposals have been developed recently. For instance, Cotton et al. (2009) presented a technique for CoM estimation initially used in humanoids robots and extended it to human beings. The technique represents the whole body as a single serial chain whose end-effector corresponds to the body center of mass. Another approach is developed by Maus et al. (2011), where the CoM estimation is carried out as a combination of force and kinematic information, using a frequencydomain analysis.

\subsection{ENERGETIC COST OF WALKING}

Up to this point the human gait has been explained in terms of the joint angular motions, the interaction forces between the body and the ground, and the motion of the body center of mass during walking. In classic mechanics, motion can also be explained from another approach: the perspective of work and energy. First, a few related concepts will be presented before addressing the problem of human walking.

If a force is applied to a certain object causing its displacement along the direction of the force, then it can be said that the force is performing a positive work on the object. Conversely, when the direction of the applied force and the direction of the displacement of the object are opposite, it is said that the force is performing a negative work on the object, as it is slowing down. Furthermore, the capacity of doing work is defined as energy. For the case of the applied force doing positive work, the object has gained energy in the process, as it has changed its velocity. Finally, power is the rate of doing work or expending energy.

Regarding the human body, different situations can produce work upon the body, and the body itself can also perform work on a external load. The mechanical work is the one generated by the muscles; they are also the major location of energy absorption. Positive mechanical work is done during concentric contraction of the muscles, when the muscle moment acts in the same direction as the angular velocity of the joint. The negative mechanical work takes place during an eccentric contraction, when the muscle moment acts in the opposite direction as the angular velocity of the joint. This usually happens when an external force acts on the segment and is such that it creates a joint moment greater than the muscle moment. The external force could include the gravitational force or the GRFs (Winter, 2009).

The mechanical work to promote gait has been associated to the work performed on the CoM. Based on experimental evidence, Cavagna et al. (1977) explained the mechanisms of locomotion in terms of energy exchange, using the analogy of the inverted pendulum. Specifically, they stated 
that during locomotion on a average speed, there are oscillations of both potential and kinetic energy of the CoM as it rises and falls, accelerates and decelerates, like in a inverted pendulum. This phenomenon occurs only if external forces are applied from the ground to the body. This was called the external work of locomotion, while the internal work was defined as the one done by the muscles to change the kinetic energy of the limbs relative to the center of mass. They also stated that this mechanism of continuous energy exchange minimizes the work done by the muscles to transfer energy in order to maintain motion.

The approach of Cavagna et al. (1977) does not explain the fact that during walking there is energy dissipation (negative work) in every initial contact, leading to the idea that muscles probably may exert some work in order to sustain gait. According to Donelan et al. (2002a), during a transition to a new step both limbs simultaneously performed external mechanical work on the CoM. Specifically, the leading leg performs a negative work at moment of the heel strike (collision work) to redirect the CoM velocity vector from a forward and downward direction to a forward a upward direction, while the trailing leg performs a positive work at final stance (push-off work) to compensate the energy lost at the contralateral limb. This period is also known as the step-to-step transition and it has been claimed as a significant factor of the metabolic energy cost of walking (Donelan et al., 2001, 2002b; Neptune et al., 2004). To estimate the external mechanical work performed during gait, the calculation of the external mechanical power generated on the CoM by each limb has been used. It corresponds to the work rate performed from both limbs to the center of mass and can be calculated from the GRF and the CoM velocities of the trailing and the leading leg

$$
\begin{gathered}
P_{\text {trail }}=\mathbf{F}_{\text {trail }} \cdot \mathbf{v}_{\mathbf{c o m}}=F_{z, \text { trail }} v_{z, \text { trail }}+F_{y, \text { trail }} v_{y, \text { trail }}+F_{x, \text { trail }} v_{x, \text { trail }} \\
P_{\text {lead }}=\mathbf{F}_{\text {lead }} \cdot \mathbf{v}_{\mathbf{c o m}}=F_{z, \text { lead }} v_{z, \text { lead }}+F_{y, \text { lead }} v_{y, \text { lead }}+F_{x, \text { trail }} v_{x, \text { lead }}
\end{gathered}
$$

where the vectors $\mathbf{F}_{\text {trail,lead }}$ correspond to the GRF of each leg, while $\mathbf{v}_{\mathbf{c o m}}$ is the velocity of the center of mass. The subscripts $x, y$ and $z$ refer to the medio-lateral, the anterior-posterior and the vertical components of the force, respectively. From the knowledge of the CoM external mechanical power, a measure of the energy efficiency during gait can be extracted. Specifically, the mechanical cost of transport, $C O T_{\text {mech }}$, is a measure of the energy efficiency in walking systems and is defined as the energy consumed to move a unit weight a unit distance (Kuo, 2007). This measurement is used to compare different kind of walking systems in a objective manner, so as different types of locomotion. Since the energy transfer during a period of time corresponds to work, the calculation of $C O T_{m e c h}$ can be performed from the work values, which corresponds to the integral of the power during a gait cycle (Rummel et al., 2010; Srinivasan \& Ruina, 2006; Alexander, 1992)

$$
C O T_{\text {mech }}=\frac{1}{m g d}\left(\int_{0}^{T}\left[P_{\text {trail }}\right]^{+}+\int_{0}^{T}\left[P_{\text {lead }}\right]^{+}-\int_{0}^{T}\left[P_{\text {trail }}\right]^{-}-\int_{0}^{T}\left[P_{\text {lead }}\right]^{-}\right)
$$

where $\left[P_{\text {trail lead }}\right]^{+}$and $\left[P_{\text {trail,lead }}\right]^{-}$are the positive and negative mechanical power of each leg calculated using the expression in (3.2). The rest of the parameters are the body mass $m$, the gravitational acceleration $g$ and the length of a single stride $d$. The $C O T_{\text {mech }}$ calculated in (3.3) is dimensionless. Other definitions of $C O T_{\text {mech }}$ can be found in the literature, relating this parameter 
to different gait characteristics, such as step length (Donelan et al., 2002b), step width (Donelan et al., 2001), or walking velocity; and also joint properties like stiffness (Zelik et al., 2014).

\subsection{Amputee gait}

Lower limb amputation, specially at the above-knee level, implies the loss of important anatomical and physiological functions. People who have suffered from amputation and become users of lower limb prostheses must learn to deal with this new situation. Most of them tend to maximize the capacities of the contralateral limb to counteract the limitations of the prosthetic device. These actions may result on serious physical consequences that could yield new physical impairments, like osteoarthritis on the joints of the intact limb (Norvell et al. 2005, Morgenroth et al. 2014), osteopenia and osteoporosis of the amputee limb (Gailey et al., 2008), as well as low back pain (Devan et al., 2014).

The measurement of kinematic and kinetic variables on the amputee population have identified common compensatory strategies developed by the users of lower limb prostheses. Regarding the spatio-temporal variables, relevant differences are found on the stance and the swing time: the former tends to be shorter on the amputee side, while the latter is longer on this same side. The main reason for this temporal asymmetry relies on the lack of confidence that the user has on the prosthesis, choosing to stay more time on the intact leg. Schaarschmidt et al. (2012) also found that this contact time asymmetry remains almost constant when increasing the walking speed. Conversely, Nolan et al. (2003) reported that with increasing walking speed temporal gait variables reduce in duration, particularly on the prosthetic side, thus temporal asymmetry is also reduced.

Gait constraints are also evident on the joints motion. The asymmetric weight loading at the stance phase is reflected in a fully extended prosthetic knee. Users sometimes perform an anterior trunk bending to keep the knee in complete extension (Whittle, 2007). Asymmetry on the range of motion of the hip joint is also seen in above-knee amputees. Rabuffetti et al. (2005) showed that the hip is less flexed and less extended at the prosthetic side and the pelvis is significantly more anterior tilted when the prosthetic leg is the trailing leg, i.e., the leg at initial contact. On the other side, the hip on the intact limb increases its flexion as a compensatory mechanism. The authors related these strategies with constraints imposed by the interface between the residual limb and the anterior part of the prosthesis, better known as the stump-socket interface. The absence of dorsiflexion on the prosthetic side causes a compensatory mechanism known as hip hiking, which is a great pelvic motion on the frontal plane to counteract the inability of the prosthetic ankle to guarantee foot clearance at the swing phase (Michaud et al., 2000; Sagawa et al., 2011).

Differences in joint moments is another factor of gait asymmetry and the tendency is the same as that of kinematics variables. The lower-limb amputee subject compensates the functional loss on the missing joints increasing the net joint moments on the intact limb (Nolan \& Lees 2000). For the case of the hip joint, the increment of the joint moments are explained for two reasons (Seroussi et al. 1996): in early stance the hip extensor moment on the intact leg counteracts the 
lack of ankle push-off on the prosthetic side at late stance. At the same time, the increase of the hip flexor moment on the amputee side ensures foot clearance at the subsequent swing phase. For the case of the ankle joint, according to the same authors, the ankle of the intact side generates approximately one third more work than the same joint of a non-amputee subject during push-off.

The alterations on weight loading are also visualized on the vertical GRFs. Higher values on this component on the intact limb has been reported in Nolan et al. (2003) and Schaarschmidt et al. (2012), while the anterior-posterior component is usually smaller in magnitude on the prosthetic side, decreasing at higher speeds. The GRF impulses (time integral of the GRF) were calculated in Castro et al. (2014) in order to measure the breaking and propulsion profile of both limbs. The authors found higher propulsive impulses from the vertical component at initial stance of the intact leg, meaning that the weight transfer from the prosthetic to the intact leg takes more time on this side. Furthermore, the mechanism of hip hiking is evidenced in a small negative peak of the anterior-posterior GRF and, consequently, in a small breaking impulse, both on the prosthetic side.

Finally, Detrembleur et al. (2005) studied the relationship between the external mechanical cost, the vertical excursion of the CoM and the knee angle in the sagittal plane. According to their results, the vertical CoM showed an amplitude four times greater than normal values from able-bodied subjects, besides different shape from the sine-wave shape. The authors explained the increase of the CoM magnitude by the absence of a proper knee flexion at the stance phase on the prosthetic side. This CoM behavior apparently did not affect the energy expenditure on walking. In this same line, Adamczyk \& Kuo (2014) used a dynamic walking model to predict how weak push-off work could affect the CoM mechanics in unilateral amputee subjects. They found that this mechanical constraint could produce another asymmetric behaviors like slower midstance speed, greater stance duration and slower CoM velocity, all on the intact side.

To summarize all the gait constraints and the associated compensatory mechanisms found in the amputee gait of unilateral transfemoral amputees, Table 3.1 presents the most common results found along the review of all the studies discussed above.

\subsection{Transfemoral PRostheses}

Basically, the purpose of a transfemoral prosthesis is to substitute the functions of the missing joints: the knee and the ankle-foot complex. Any lower-limb prosthesis is composed by a socket, which is the interface between the residual limb (also called stump) and the functional parts of the prosthesis.

These technologies have evolved quite a lot in the past few years. Today, there is a variety of commercially available transfemoral prostheses, with different mechanical designs and additional components, which enable the users to choose a device that better fulfill their demands of locomotion. Along this section, different transfemoral prostheses will be presented. The selected designs have been chosen to illustrate the major developments in recent years. Moreover, evaluation studies of some of them will be pointed, in order to highlight their functional advantages. 
Table 3.1: The most common gait constraints and compensatory mechanisms found in the reviewed studies of transfemoral amputation.

\begin{tabular}{l|l}
\hline \multicolumn{1}{c|}{ Gait Constraint } & \multicolumn{1}{c}{ Compensatory Mechanism } \\
\hline $\begin{array}{l}\text { Knee buckling } \\
\text { Unequal weight loading }\end{array}$ & $\begin{array}{l}\text { Full extended knee on the prosthetic side } \\
\text { Anterior trunk bending } \\
\text { Greater vertical GRF } \\
\text { Longer stance time on the intac side }\end{array}$ \\
\hline $\begin{array}{l}\text { Lack of stability } \\
\text { Reduced walking base }\end{array}$ & Lateral trunk motion \\
\hline Improper leg shortening at swing & Vaulting on the intact side \\
\hline Improper stump-socket interface & $\begin{array}{l}\text { Increased pelvic tilt } \\
\text { Increased hip flexion/extension on the intact side } \\
\text { Reduced hip flexion/extension on the prosthetic side }\end{array}$ \\
\hline Absence of dorsiflexion on the prosthetic foot & Hip hiking \\
\hline Small push-off on the prosthetic side & $\begin{array}{l}\text { Greater hip joint moments } \\
\text { Smaller CoM velocities }\end{array}$ \\
\hline
\end{tabular}

\subsubsection{Knee prosthesis}

The Ottobock's C-Leg (Figure 3.6a) was first introduced in 1997, and according to the manufacturer, it was the first micro-controlled prosthesis commercially available. It measures the knee position, the ankle torque and moment to detect the initial contact and the toe-off events. The C-leg controls the flexion and the extension of the knee during the swing phase, by modulating the damping levels of its hydraulic actuator. Additionally, it has a stance control mode which sets a default resistance level. Since its first release, this prosthesis has been part of multiple clinical studies, in which it has been compared to other knee prosthesis, with or without damping-level control. Schmalz et al. (2002) measured the energy consumption of 12 transfemoral amputee volunteers wearing a non-controllable knee prosthesis and the C-Leg when walking on a treadmill, along with other biomechanical parameters in level-ground walking. They noticed that the net oxygen consumption values when using the C-Leg clearly reduced at low speeds. On the other hand, no significant reduction was found at high speeds using either the C-Leg or the totally mechanical prosthesis. In another study, Kahle et al. (2008) compared the performance of 19 transfemoral amputees with a conventional prosthesis and the C-Leg. They evaluated the incidence of falls and stumbles, stair descent performance and walking speed in different terrains. According to their results, the volunteers showed a improved performance using the C-Leg: a reduced risk of stumble or fall, a better stair descent motion and faster walking speeds in level-ground and uneven terrains. Regarding joint kinematics, Segal et al. (2006) found no difference between the performance of the C-Leg and a non-controllable passive prosthesis during the stance phase; the absence of stance knee flexion occurred using both prosthesis. The same study found an increase in the knee moment of the prosthetic side, which suggests a potential stance knee flexion using the C-leg.

Another variable-damping commercial prosthesis is the Rheo Knee (Össur), shown in Figure 3.6b. It is a magnetorheological (MR) brake, that uses this fluid to produce the proper damping levels along the gait. The prosthesis controls the damping level by changing the magnetic field 


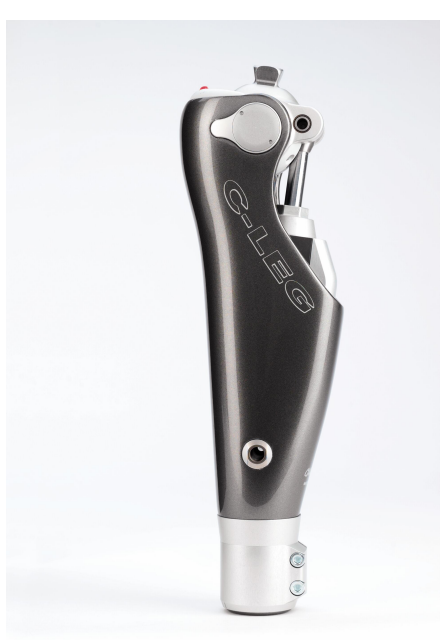

(a)

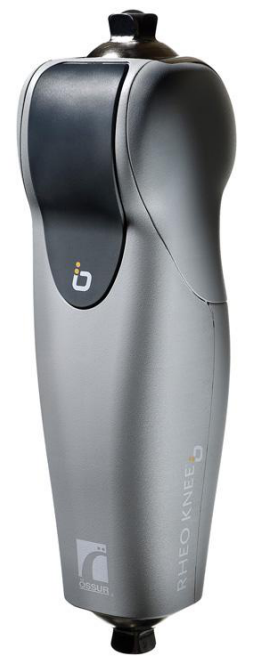

(b)

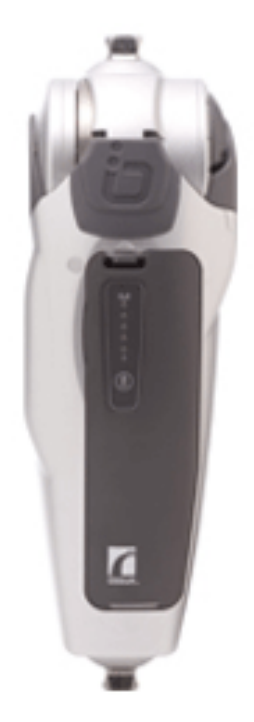

(c)

Figure 3.6: Some transfemoral prostheses commercially available: (a) Ottobock's C-Leg (courtesy of Ottobock); (b) The Rhe Knee (courtesy of Össur); (d) The Power Knee (courtesy from Össur).

inside the brake, which in turn changes the MR fluid's viscosity. The Rheo Knee contains strain gauge sensors, along with angular position sensors, to detect the gait phases or the load changes. It also has a constant damping level by default in case of non-expected situations. There are also investigations that have evaluated the Rheo Knee performance among others transfemoral prostheses. Johansson et al. (2005) collected kinematic, kinetic and electromyographic (EMG) data from eight unilateral amputees walking at self-selected speeds. The volunteers used the Rheo Knee, the C-Leg and another mechanically passive prosthesis. They noticed that both variabledamping controlled knees have advantages over the totally mechanical prosthesis, in terms of lower metabolic rates, decrease in the hip work at the amputee side, lower hip moments and reduced peak hip power values. According to the authors, their results still suggest that the MR knee has advantages over the hydraulic-based designs, because of the difference of the hip behavior in the swing phase and the prosthetic foot-ground interaction at early stance. However, there is not a clear explanation for such a statement.

Even though the aforementioned designs bring numerous advantages to the users in level-ground walking, they are still incapable of producing the positive mechanical power necessary to perform other activities like sit-to-stand from a chair and stair/slope climbing. The Össur's Power Knee (see Figure 3.6c) is the first active knee prosthesis commercially available. It comprises gyroscopes, accelerometers, force and pressures sensors to deliver information about the angular position and velocity of the knee joint, as well as the forces and loads applied to the prosthesis at any time. Regarding clinical evaluations, a single study was found comparing the Rheo Knee, the C-Leg and a purely mechanic knee, while the subjects were executing sit-to-stand and stand-to-sit movements (Highsmith et al. 2011). According to the study, the Rheo Knee did not assist the users to stand up, while it seems to enhance symmetry in sitting down. 


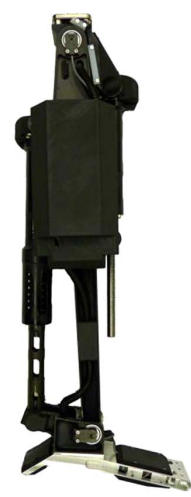

(a)

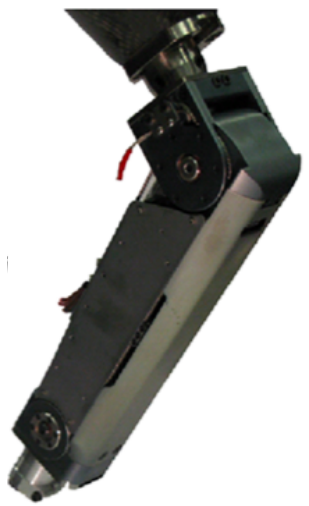

(b)

Figure 3.7: Transfemoral prostheses in development: (a) the powered prosthesis with active knee and ankle joints developed at Vanderbilt University (Sup et al. 2009); (b) MIT's powered knee prosthesis with two series-elastic actuators (Martinez-Villalpando \& Herr 2009).

In addition to the commercial prostheses, academic research groups also have came out with new transfemoral prostheses designs. Some works have focused on the development of powered (or active) devices. Sup et al. (2009) present a complete transfemoral prosthesis with powered knee and ankle joints, illustrated in figure 3.7a. The electrical actuators that drive the system are controlled for walking and standing using an impedance-based strategy. Figure 3.7b shows the complete prosthetic system. Martinez-Villalpando \& Herr (2009) proposed a powered knee prosthesis with an agonist-antagonist configuration. The control strategy is based on a variableimpedance behavior for improving gait behavior during stance and swing phases in level-ground walking. To our knowledge, there are not published clinical evaluations of these two prototypes up to date.

\subsubsection{Foot and ankle prosthesis}

The Proprio Foot (Össur) was the first commercial micro-controlled feet introduced on the market in 2006 (Figure 3.8a). It uses accelerometers to identify gait events, such as heel-strike and toe-off. This prosthetic foot also has a controllable damping mechanism to modulate the damping levels according to the gait events. According to the manufacturer's claim, the Proprio Foot is capable of identifying slopes or stairs after a few steps, which allows active plantarflexion and dorsiflexion (Laferrier \& Gailey 2010). In Fradet et al. (2010), they concluded that the Proprio Foot enabled the transtibial amputees to walk in a more physiologic manner due to the increased of dorsiflexion during ramp ascent, which positively affects the knee joint kinematics. Conversely, the authors found an increased plantarflexion during the ramp descent, which is a less physiologic behavior.

Another ankle-foot prosthesis now commercially available is the one developed by Hugh Herr and his colleagues at the MIT Media Lab (Au et al., 2008). The BiOM T2, in Figure 3.8b, is an 


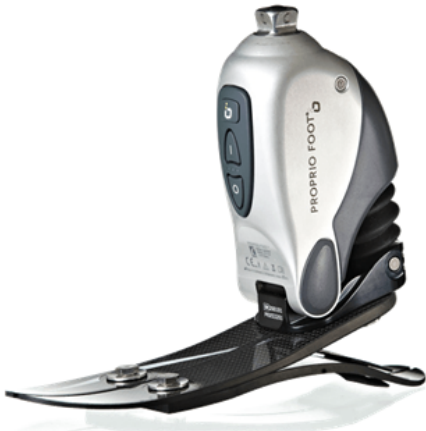

(a)

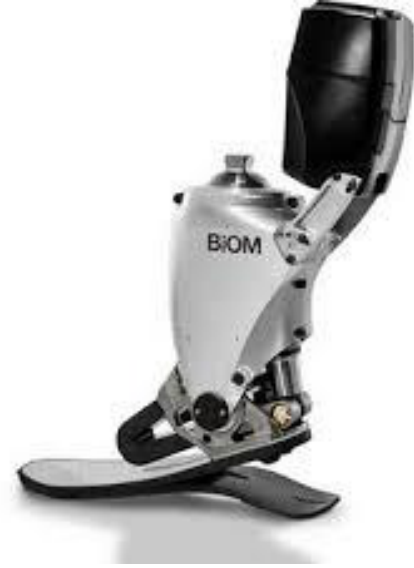

(b)

Figure 3.8: Ankle-foot prostheses: (a) Össur's Proprio Foot (courtesy of Össur); (b) The BioM T2 (courtesy of BiOM Personal Bionics).

active device that can perform on different locomotion modes, like walking at different terrains and velocities, as well as stair and slope climbing. According to the inventors, the BiOM restores normal ankle stiffness and power during stance phase of walking, by means of an unidirectional spring, configured in parallel to a high-power, force-controllable actuator with series elasticity. Regarding to clinical studies evaluating the use of the BiOM T2, Grabowski \& Susan D'Andrea (2013) analyzed the kinematics and kinetics of seven transtibial patients wearing a passive prosthesis and the BiOM T2. They found a decrease on the GRF on the intact limb at slow and moderate walking speeds when using the active ankle-foot prosthesis. Meanwhile, Aldridge et al. (2012) observed the effects of the ankle power provided by the BiOM $\mathrm{T} 2$ on the kinematic and kinetic data during a stair ascending exercise. Their results showed an increase of the peak ankle plantarflexion on the prosthetic limb using the $\mathrm{BiOM}$, if compared it to a passive ankle-foot prosthesis. However, the ankle angle is still lower than the normal values. Furthermore, the study pointed that even though the active prosthesis normalize some biomechanical parameters during this locomotion task, there is still evidence of hip strategies adopted by the amputees while ascending stair, which lead to gait asymmetries.

\subsection{CONCLUSIONS}

This chapter presented a general overview of the main concepts related to the biomechanics of normal and amputee gait. First, the gait cycle, as the fundamental period of legged locomotion, was explained, as well as its phases and subphases. In the sequence, the kinematic and the kinetic parameters used in the gait analysis were introduced. The special case of amputee gait was reviewed in the next part of this chapter. This type of gait is characterized by an overall asymmetric behavior of its parameters, caused by compensatory mechanisms developed by the amputees as an intent to achieve a more functional gait. From the review of several clinical studies, some common gait constraints and the related compensation mechanisms were found. The study of the 
gait variables will be useful for the gait analysis presented in the next chapter. The notion of the compensatory mechanisms in terms of these variables asymmetries will help us to characterize the amputee subjects who participated in the study.

Finally, a review of the most developed lower limb prostheses is presented, highlighting their benefits and drawbacks according with clinical studies. The common outcome between these studies is the improvement of certain gait variables when using an actuated prosthesis if compared to the most used regular passive mechanisms. 


\section{Gait Analysis}

The previous chapter presented the concepts related to the biomechanic study of the human gait. The typical patterns from the kinematic and kinetic variables were presented. These references curves are useful in order to evaluate the results from population in a special condition of mobility, like the case of people with lower-limb amputation.

The main objective of the gait analysis experiments carried out in this work is to identify which compensatory mechanisms are presented in the studied subjects and how much these mechanisms can deviate the developed walking from a normal pattern. In the following sections the results from the gait experiments conducted in two different groups are presented. First, the resultant curves from the non-amputee and the amputee group are exhibited. The main observations are described for each group, and the differences between a reference non-amputee subject and each amputee subject are established. Since the vertical trajectory of the CoM is one of the main variables for this work, some other calculations were performed to quantitatively measure the energetic differences between the non-amputee and the amputee gait by looking at this parameter. Finally, the last section of this chapter is a detailed discussion of the results from the gait experiments, oriented to characterize the amputee subjects in terms of the compensatory mechanisms presented in the previous chapter.

\subsection{MATERIAls AND METHODS}

The experiments presented here were conducted in the motion analysis laboratory of the Ceilândia Faculty (FCE-UnB). The experiments were previously approved by the ethics committee of the Faculty of Health Science with a protocol number CEP 119/11 (see appendix B). The characteristics of the subjects who participated in this study, as well as the description of the experiments, will be presented below.

\subsubsection{Subjects}

The participants of this study were all volunteers. The control group is constituted by five male subjects with a good health condition and no previous or current joint pain or injury. The inclusion criteria for the amputee group was unilateral transfemoral amputation caused by trauma or malignancy. The amputee group also uses the same knee prosthesis model (3R80, Otto Bock) for at least five years. These amputee subjects have a moderate to high mobility level and they 
Table 4.1: Anthropometric data of all the subjects who participated in the study.

\begin{tabular}{|c|c|c|c|c|c|c|}
\hline Subject & Age (yrs) & Height (m) & Weight (kg) & $\begin{array}{c}\text { Amputation } \\
\text { Side }\end{array}$ & $\begin{array}{c}\text { Time of } \\
\text { amputation } \\
(\mathrm{yrs})\end{array}$ & $\begin{array}{c}\text { Time with } \\
\text { the current } \\
\text { prosthesis } \\
\text { (yrs) }\end{array}$ \\
\hline 1 & 32 & 1.76 & 80 & - & - & - \\
\hline 2 & 31 & 1.79 & 65 & - & - & - \\
\hline 3 & 26 & 1.73 & 70 & - & - & - \\
\hline 4 & 27 & 1.75 & 73 & - & - & - \\
\hline 5 & 29 & 1.73 & 86 & - & - & - \\
\hline 6 & 28 & 1.72 & 80 & left & 8 & 6 \\
\hline 7 & 30 & 1.83 & 72 & right & 14 & 7 \\
\hline 8 & 32 & 1.79 & 82.5 & left & 14 & 5 \\
\hline
\end{tabular}

practice physical activities regularly.

Table 4.1 presents the anthropometric data of all the volunteers of this study. The mean height $( \pm S D)$ for the two groups is $1.75( \pm 0.02 \mathrm{~m})$ and $1.78( \pm 0.06 \mathrm{~m})$ for the non-amputee and the amputee subjects, respectively. The mean body mass is $74.8( \pm 8.3 \mathrm{~kg})$ for the non-amputee subjects and $78.17( \pm 5.48 \mathrm{~kg})$ for the amputee group. The experimental procedures were explained to the participants and signed consent terms were obtained before the beginning of the tests.

\subsubsection{Characteristics of the lower limb prostheses}

As it was mentioned before, the three amputee volunteers use the same knee prosthesis. The 3R80 from Ottobock is a rotary hydraulic joint (see figure 4.1a), which uses a weight-loading mechanism to switch between the standing and the walking behavior (Tang et al., 2008). At the stance phase, the knee engages with a small weight bearing and automatically disengages as the leg starts to swing. The knee damping is previously adjusted according to the subject requirements. Due to the fact that the joint impedance is not dynamically adapted, the $3 \mathrm{R} 80$ is limited to perform at a small range of velocities, as well as at even terrains where the conditions of knee impedance are almost constant. Conversely, the main advantage of this knee prosthesis lies in its stability, which represents a secure gait to the user, besides its moderate cost if compared to other technologies.

The additional part of the lower limb prosthesis is the foot. In this case all the amputee subjects also use the same reference of prosthetic foot: the 1C30 Trias foot, from Ottobock. This device (see figure $4.1 \mathrm{~b}$ ) is formed by three carbon leaf-spring elements that, according to the manufacturer, are capable of storing energy at heel strike and returning it at midstance (Ottobock, 2015), which results in a smoother and a more continuous rollover. 


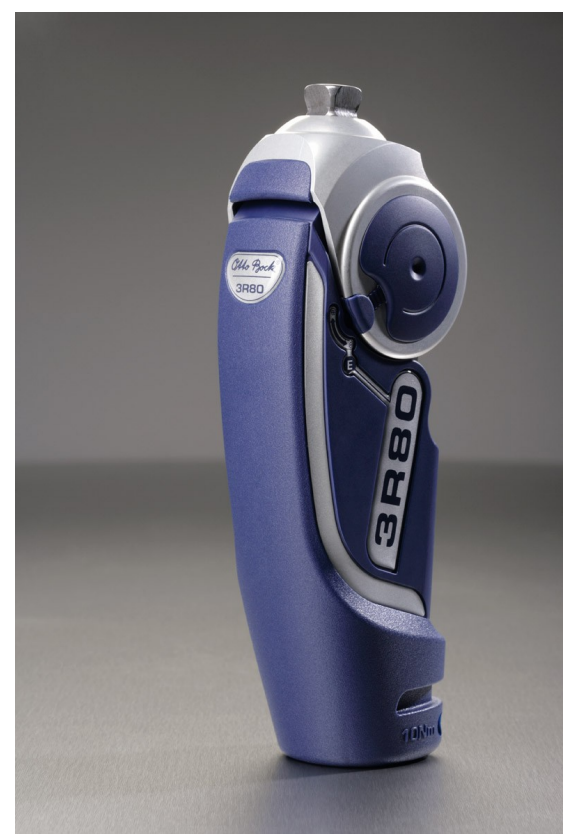

(a)

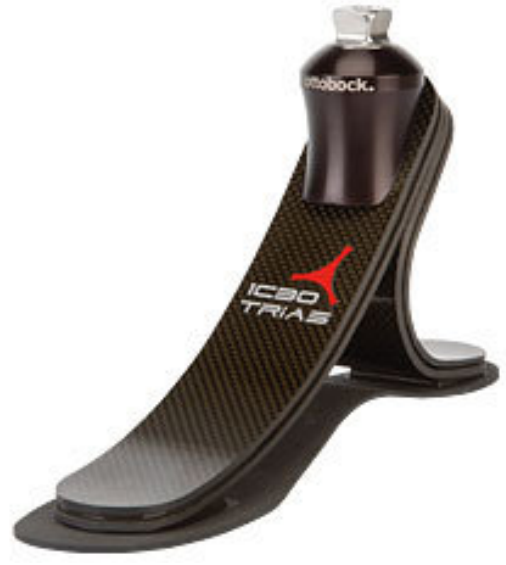

(b)

Figure 4.1: The lower limb prosthesis used by the amputee group: (a) The 3R 80 knee. (b) The 1C30 Trias foot (courtesy of Ottobock).

\subsubsection{Data collection and processing}

The participants of this study were asked to walk at their normal walking speed over a walkway with a length of $3 \mathrm{~m}$, where three instrumented force platforms (Bertec, Columbus, USA) were embedded along the path to collect the GRF information of each step (see Figure 4.2a). At the same time, a motion capture (MOCAP) system (Qualisys, Inc., Gothenberg, Sweden) was used for recording the trajectory of 31 passive markers placed across the lower limbs and the pelvis of the subjects. The frequency rate of the MOCAP system and the force platforms were both set to $250 \mathrm{~Hz}$. The marker placement is based on the Helen Hayes protocol (Kadaba et al., 1990) and mostly consists on locating the markers at the bony prominences of the lower limb to define the segments, as well as at other anatomical locations for motion tracking purposes. Figures $4.2 \mathrm{~b}$ to $4.2 \mathrm{~g}$ shows the marker set . For more details about the marker protocol, please refer to Appendix A.

During the experiments, the non-amputee subjects walked on barefoot, while the amputee participants used their usual sport footwear. Due to space limitations, only one complete gait cycle could be recorded per trial. In order to capture entire gait cycles initiated with both limbs, experiments were conducted in two directions, so characteristics from both sides could be evaluated. For the case of the amputee subjects this is critical because of the differences between the limbs during the gait. A total of ten trials (five for each direction) per subject was recorded and the datasets were analyzed using MATLAB (The Mathworks, Inc., Natick, USA) and the Visual 3D software (C-Motion, Inc., Rockville, USA) for calculating the joint kinematics and kinetics. 


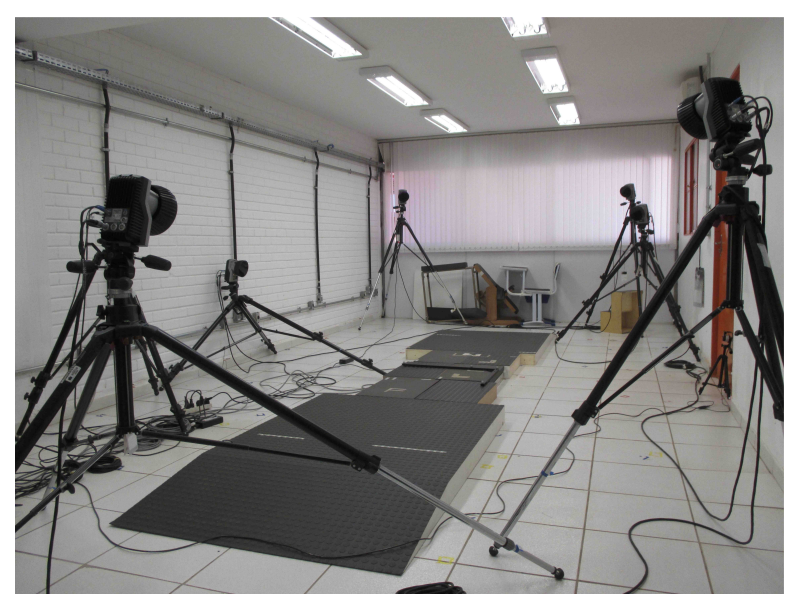

(a)

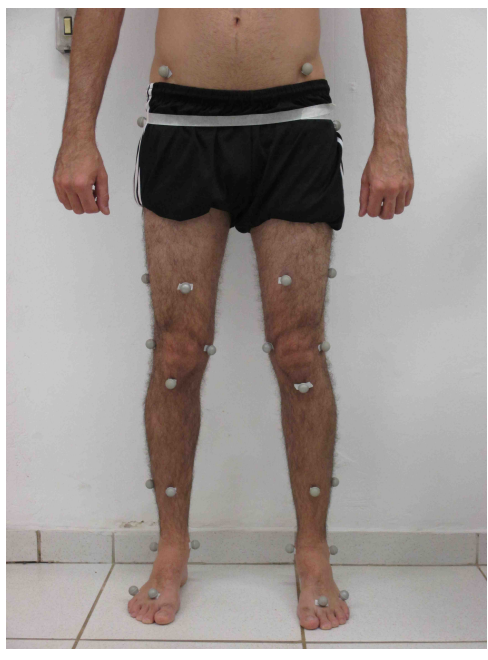

(b)

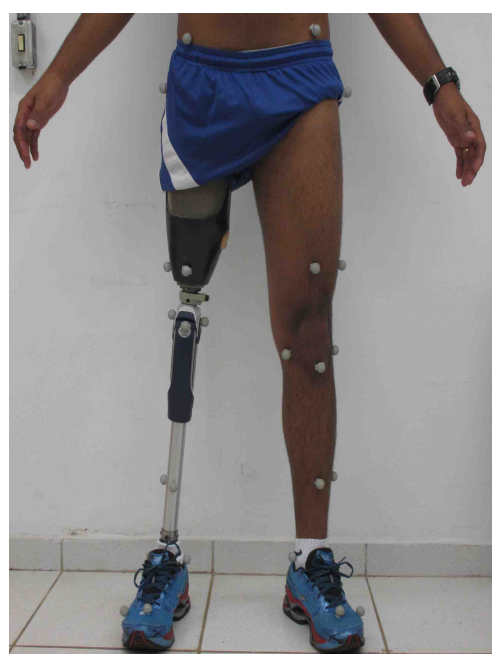

(e)

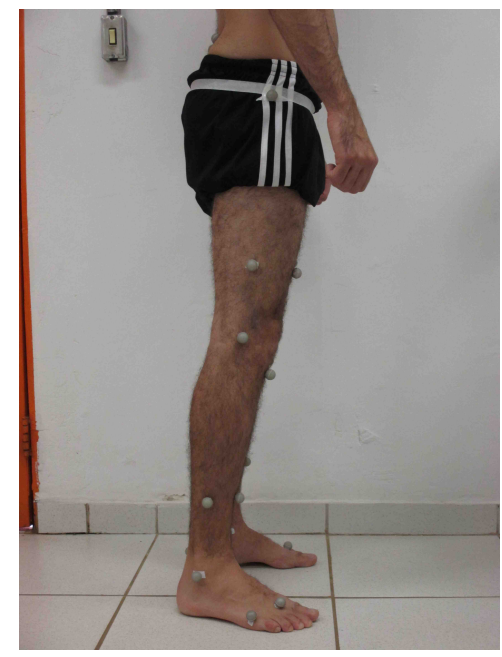

(c)

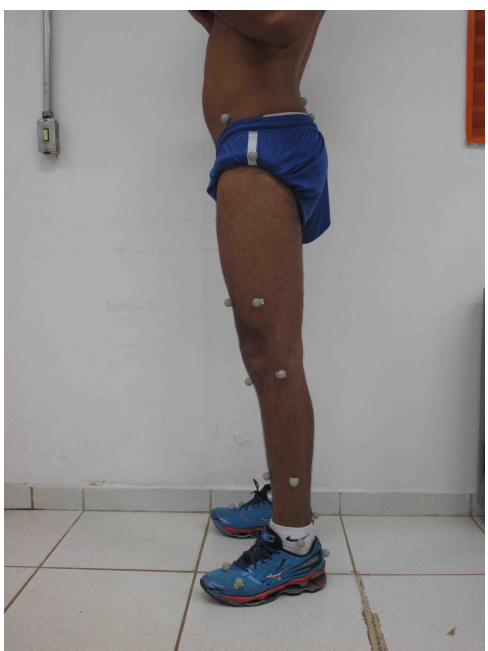

(f)

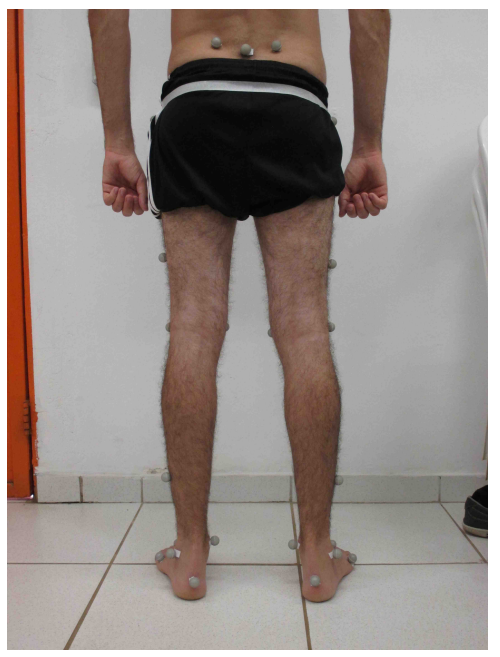

(d)

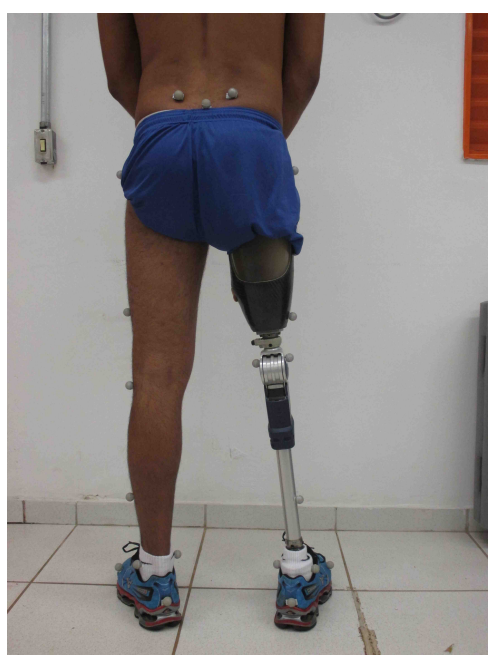

(g)

Figure 4.2: The experimental setup: (a) the walkway with three force platforms and eight cameras around it. The marker set used on the two groups: (b, e) frontal, (c, f) lateral, and $(\mathrm{d}, \mathrm{g})$ posterior view. 
Table 4.2: Mean values $( \pm S D)$ for the spatio-temporal parameters. A single gait cycle is defined as consecutive heel strike events of the same limb.

\begin{tabular}{cccc}
\hline \multirow{2}{*}{ Parameter } & Non-amputee & \multicolumn{2}{c}{ Amputee } \\
\cline { 3 - 4 } & & intact & prosthetic \\
\hline Walking speed $[\mathrm{m} / \mathrm{s}]$ & $1.15 \pm 0.084$ & \multicolumn{2}{c}{$1.001 \pm 0.065$} \\
\hline Step time $[s]$ & $0.565 \pm 0.048$ & $0.673 \pm 0.130$ & $0.672 \pm 0.034$ \\
\hline Double support time $[s]$ & $0.153 \pm 0.013$ & $0.223 \pm 0.024$ & $0.211 \pm 0.028$ \\
\hline Single support time $[s]$ & $0.416 \pm 0.040$ & $0.445 \pm 0.032$ & $0.401 \pm 0.025$ \\
\hline Step length $[\mathrm{m}]$ & $0.650 \pm 0.042$ & $0.601 \pm 0.089$ & $0.673 \pm 0.104$ \\
\hline
\end{tabular}

\subsection{Results}

\subsubsection{Spatio-temporal parameters}

Table 4.2 shows the spatio-temporal parameters for the two groups. These calculations correspond to the mean values of the walking trials performed by each subject. The results reveal small differences between the parameters from the two groups, more notable in the walking speed and in the step time, where the non-amputee group shows a slightly higher value in the walking speed, while the amputee group exhibits longer steps. Due to the number of the participants and the number of steps recorded per trial, it seems inappropriate to inference any trend between the two groups from these parameters.

However, previous studies have shown that differences in spatio-temporal parameters are more evident when the walking velocity is changing. For instance, Nolan et al. (2003) observed that transfemoral amputees present a longer stance time and a shorter swing time on their intact limb compared with non-amputee subjects. Moreover, they also noticed that these temporal asymmetries reduce as the walking speed increases. A similar result was also found in Jaegers et al. (1995), where more symmetric double support phases in both legs were found as the walking speed was increased from the self-selected value. Opposing results are reported in Schaarschmidt et al. (2012). The authors did not find significant differences in temporal asymmetries when increasing walking speed.

\subsubsection{Joint kinematics}

The resulting joint kinematics of the non-amputee group are presented in figure 4.3. The curves correspond to the mean values among all the able-bodied subjects. Besides the sagittal plane values, the frontal plane angle of the pelvis and the hip joints were also calculated, since a visual inspection of the amputee subjects while they were walking during the experiments, detected a predominant motion on these two locations. Generally speaking, the behavior of the joint angles 
is in accordance with what is found in the literature (Neumann, 2002; Perry, 1992; Michaud et al., 2000). The more notable characteristics can be summarized hereafter:

- Pelvis. On the frontal plane, the iliac crest elevates at the loading response on the trailing $\operatorname{side}^{1}$, followed by a minor fluctuation. Then it drops at the beginning of the swing phase, which coincides with the loading response of the leading leg, followed by another fluctuation until the next cycle.

- Hip. On the sagittal plane, the hip starts at a flexed position and, as the body moves forward, it extends up until the beginning of the swing phase, then it remains in flexion until the next step. On the frontal plane, this joint starts to move towards the middle line (adduction) as the pelvis elevates on the stance side. At $50 \%$ of the gait cycle, the hip returns to its neutral frontal position, to continue moving away the middle line (abduction) until the next heel strike.

- Knee. It is characterized by two moments of flexion and extension. At the initial contact the joint starts a little flexed, then it increases the flexion angle until the loading response. After that, the knee extends up right before the begin of the swing phase. The second moment of flexion-extension takes place at the swing phase, with the maximum angle value reached at mid-swing.

- Ankle. On the sagittal plane, the ankle joint is slightly plantarflexed at the beginning of the cycle. It increases the plantarflexion until the loading response. Then, it begins to dorsiflex until late stance. From this point the joint performs a plantarflexion, reaching the highest value at $60 \%$ of the stride. Finally the ankle dorsiflexes until the neutral position at terminal swing.

Particularly, the sagittal plane angles (flexion and extension) are the ones with less deviation from the mean curve. A greater deviation is seen on the pelvis obliquity (figure 4.3(a)) and the hip abduction/adduction angle (figure 4.3(c)). Besides their reduced range of motion compared to the sagittal plane angles, the pelvic-hip region might be prone to more variability caused by errors due to markers misplacement.

For the case of the three amputee volunteers, the joints angles exhibit some differences among subjects and between the limbs of each one of them. To facilitate the analysis, the angles are visualized on each side (see figure 4.4 and 4.5). The comparison with the outcome from the nonamputee group is done by choosing a reference subject who presented the smallest deviation of the walking speed in all the 10 trials. The observations from the three amputee subjects, based on the reference patterns for each angle, are presented in tables 4.3 and 4.4 .

\footnotetext{
${ }^{1}$ The trailing limb is the one which initiates the step, i.e., the stance leg. Conversely, the leading leg is the initial swing leg for the same gait cycle.
} 

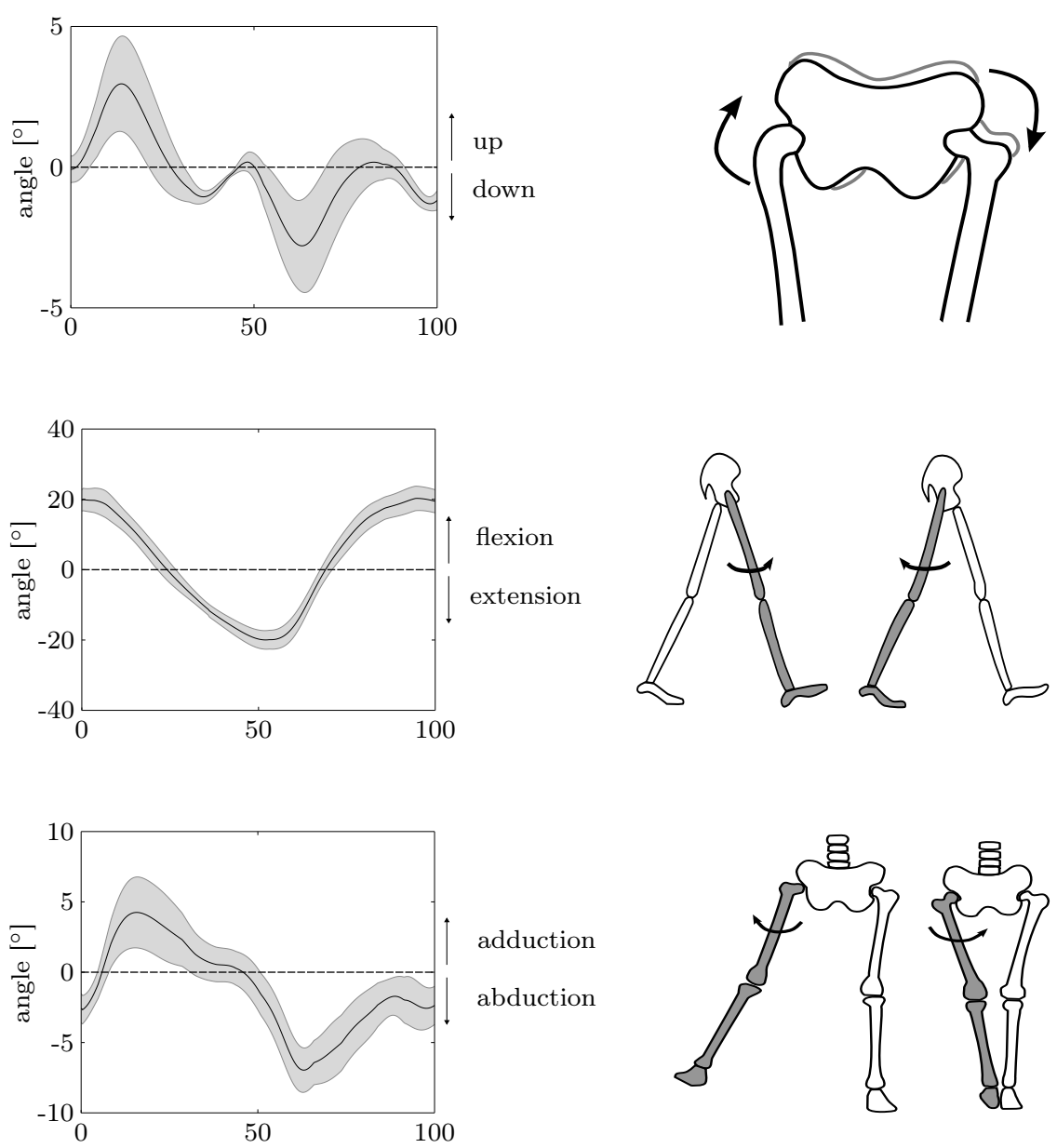

adduction

abduction
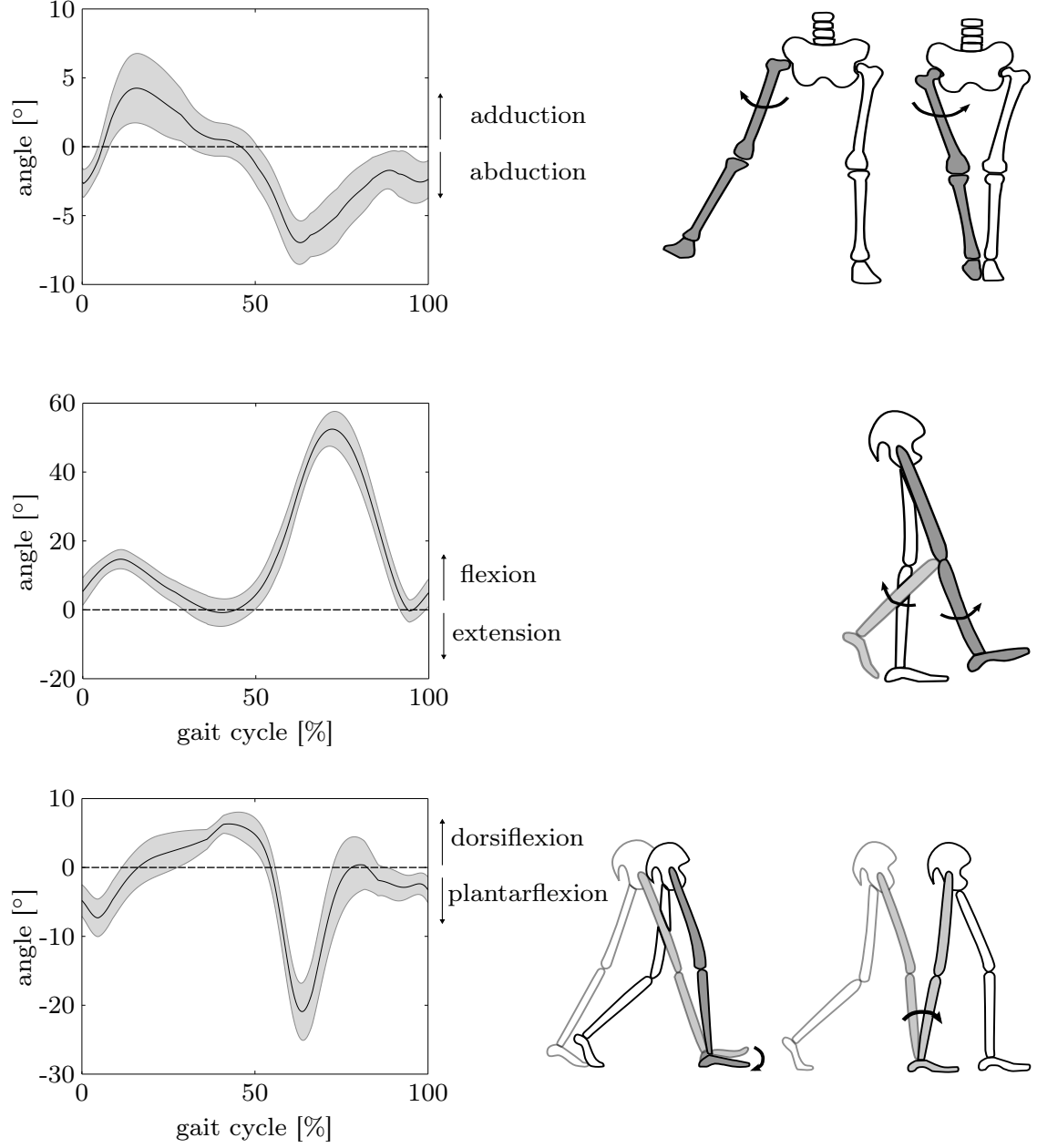

Figure 4.3: Kinematics of the non-amputee subjects (mean $\pm 1 S D$ ). (a) Pelvis obliquity; (b) hip flexion-extension; (c) hip abduction-adduction; (d) knee flexion-extension and (e) ankle plantarflexion-dorsiflexion. 

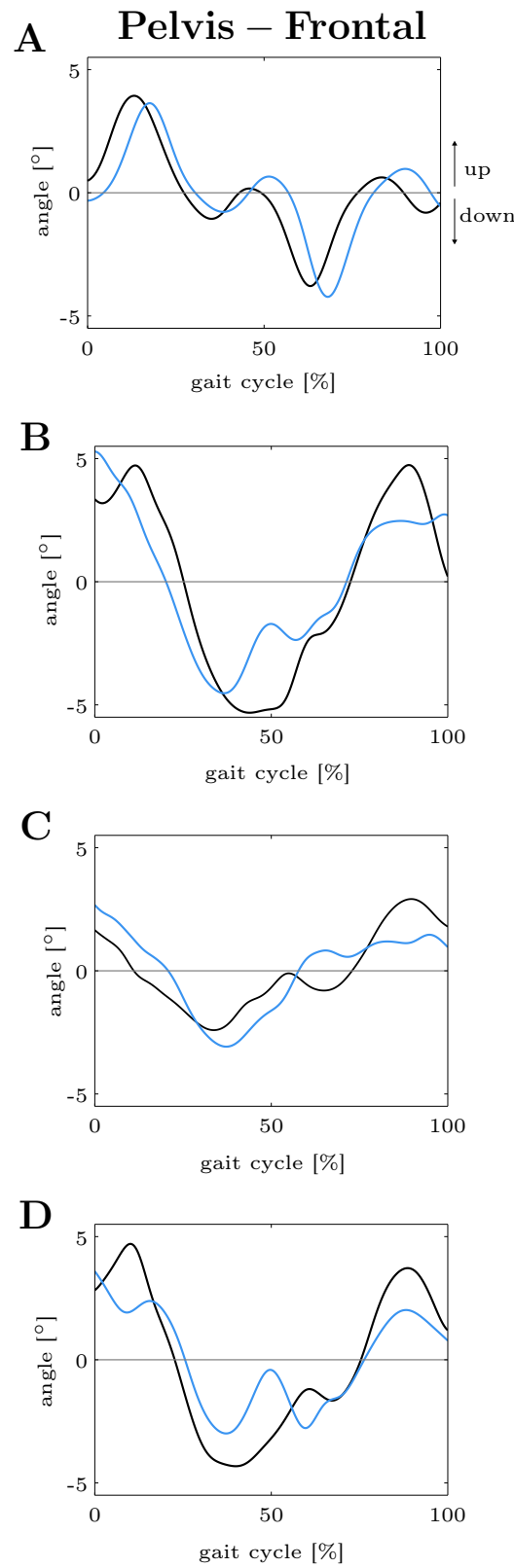
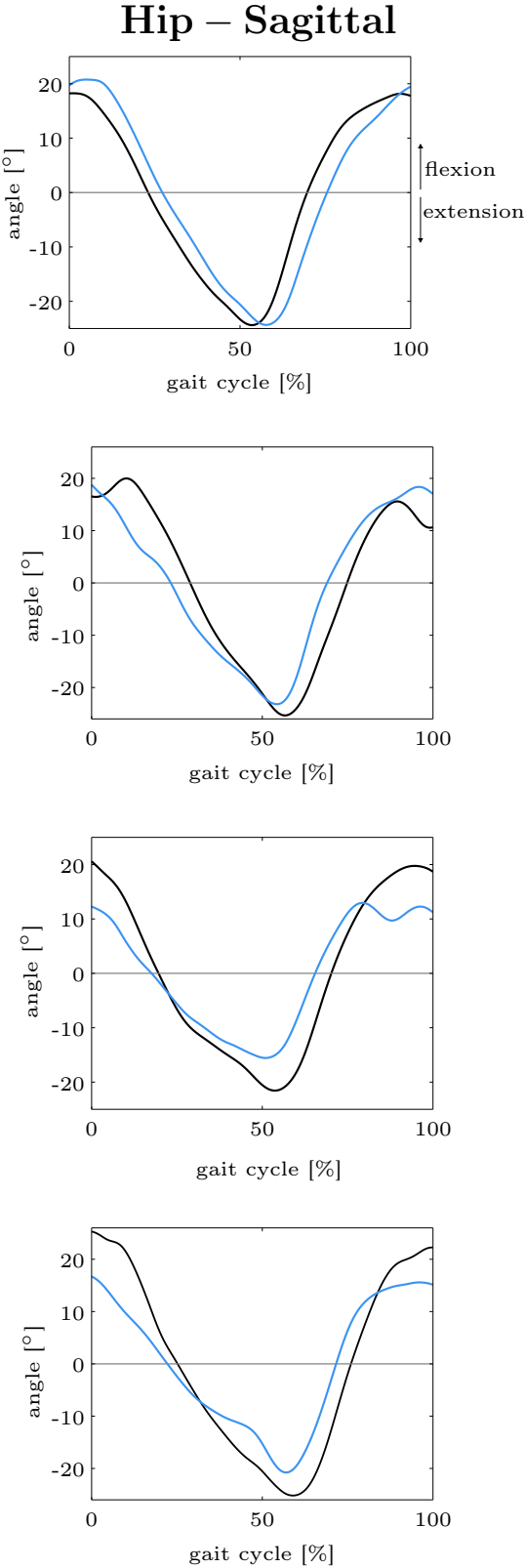

Hip - Frontal
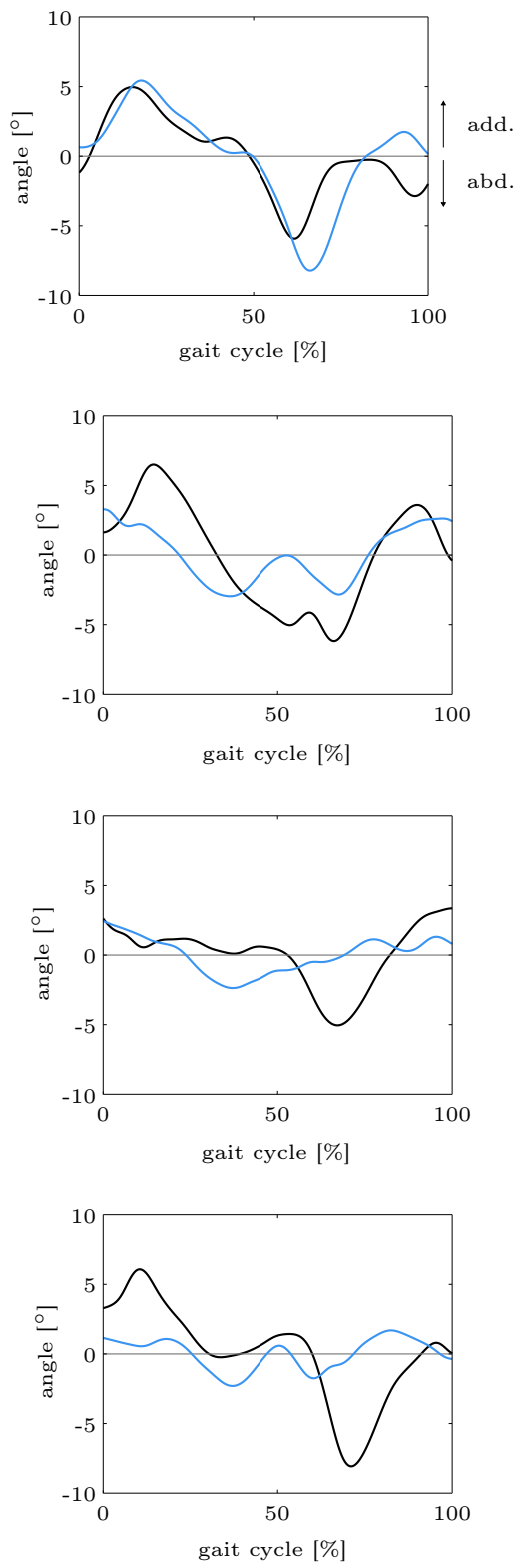

Figure 4.4: Pelvis and hip angles of the trailing leg (black line) against the leading leg (blue line). A: the reference subject; B, C, D: the amputee subjects. For the case of the amputee subjects the trailing leg corresponds the intact limb. 
Table 4.3: Main observations from the pelvis and the hip angles among the amputee subjects. The joint angles were compared against the non-amputee pattern. For each joint, the intact and the prosthetic side were analyzed during a gait cycle when each side began the stride (see figure 4.4 ). GC stands for gait cycle.

\begin{tabular}{|c|c|c|c|c|}
\hline \multirow{3}{*}{$\begin{array}{l}\text { Subject } \\
\mathrm{B}\end{array}$} & \multicolumn{2}{|c|}{ Pelvis obliquity } & \multicolumn{2}{|c|}{ Hip } \\
\hline & \multicolumn{2}{|l|}{ Intact side } & Intact side & Prosthetic side \\
\hline & $\begin{array}{l}\text { Its maximum value is } \\
\text { reached at loading re- } \\
\text { sponse. It drops from } \\
\text { mid-stance to initial } \\
\text { swing. Finally, the pelvis } \\
\text { elevates again at final } \\
\text { swing }\end{array}$ & $\begin{array}{l}\text { It begins at an elevated } \\
\text { position. The pelvis } \\
\text { reaches the lowest po- } \\
\text { sition at approximately } \\
40 \% \text { of the GC. It ele- } \\
\text { vates again from } 70 \% \text { un- } \\
\text { til the end of the GC. }\end{array}$ & $\begin{array}{l}\text { Sagittal: it initiates } \\
\text { with almost } 20^{\circ} \text { of flexion } \\
\text { and remains in this con- } \\
\text { dition most of the stance } \\
\text { phase. The extension an- } \\
\text { gle begins at } 30 \% \text { of the } \\
\text { GC until initial swing. } \\
\text { Then, it flexes again up } \\
\text { to the end of the stride. } \\
\text { Frontal: it has } 6.5^{\circ} \text { of } \\
\text { adduction at the loading } \\
\text { response. The hip goes } \\
\text { to abduction before the } \\
50 \% \text { of the GC occurs. } \\
\text { The maximum abduction } \\
\text { angle }\left(6.2^{\circ}\right) \text { happens at } \\
66 \% \text { of the GC. The hip } \\
\text { is on adduction again at } \\
\text { late swing. }\end{array}$ & $\begin{array}{l}\text { Sagittal: no relevant } \\
\text { changes from the intact } \\
\text { side. } \\
\text { Frontal: it begins in ad- } \\
\text { duction until } 21 \% \text {, then } \\
\text { this joint goes to abduc- } \\
\text { tion until initial swing. } \\
\text { Finally, the hip is on ad- } \\
\text { duction again until end } \\
\text { the stride. }\end{array}$ \\
\hline $\mathrm{C}$ & $\begin{array}{l}\text { It has an small eleva- } \\
\text { tion at initial contact. It } \\
\text { drops from loading re- } \\
\text { sponse to initial swing, } \\
\text { with a reduced range of } \\
\text { motion. The pelvis el- } \\
\text { evates during the stance } \\
\text { phase. }\end{array}$ & $\begin{array}{l}\text { During the stance phase } \\
\text { it has the same behavior } \\
\text { of the intact side. At the } \\
\text { swing phase, the pelvis } \\
\text { remains on a small up- } \\
\text { ward position. }\end{array}$ & $\begin{array}{l}\text { Sagittal: flexion and ex- } \\
\text { tension with a normal } \\
\text { range of motion. } \\
\text { Frontal: Small adduc- } \\
\text { tion during the stance } \\
\text { phase. Significant abduc- } \\
\text { tion at the beginning of } \\
\text { the swing phase. }\end{array}$ & $\begin{array}{l}\text { Sagittal: it begins with } \\
\text { a flexion angle of } 10^{\circ} \text {. } \\
\text { The maximum extension } \\
\text { of } 15^{\circ} \text { is reached at the } \\
\text { midpoint of the GC. The } \\
\text { hip ends in flexion with } \\
\text { the same initial angle. } \\
\text { Frontal: it initiates with } \\
\text { a small adduction of } 2^{\circ} \text {. } \\
\text { Abduction initiates at } \\
24 \% \text { of the GC until } \\
69 \% \text {. After this, there is } \\
\text { an small adduction angle } \\
\text { until the end of the GC. }\end{array}$ \\
\hline $\mathrm{D}$ & $\begin{array}{l}\text { The maximum elevation } \\
\text { angle }\left(4.6^{\circ}\right) \text { is at load- } \\
\text { ing response. The down- } \\
\text { ward position initiates at } \\
\text { of the GC, unil initial } \\
\text { swing. After that, the } \\
\text { pelvis elevates again to } \\
\text { reach a maximum angle } \\
\text { of } 3.7^{\circ} \text {. }\end{array}$ & $\begin{array}{l}\text { The elevation and de- } \\
\text { pression angles take } \\
\text { places at the same in- } \\
\text { stants of the intact side, } \\
\text { but with a smaller range } \\
\text { of motion and with a few } \\
\text { oscillations. }\end{array}$ & $\begin{array}{l}\text { Sagittal: no relevant } \\
\text { changes from the normal } \\
\text { pattern. } \\
\text { Frontal: adduction at } \\
\text { the loading response, } \\
\text { with a rapid transition } \\
\text { to abduction at the } 20 \% \\
\text { of the GC. The peak } \\
\text { of abduction }\left(-8.1^{\circ}\right) \text { is } \\
\text { reached at } 70 \% \text { of the } \\
\text { GC. }\end{array}$ & $\begin{array}{l}\text { Sagittal: the flexion } \\
\text { and extension angles take } \\
\text { places at the same in- } \\
\text { stants of the intact side, } \\
\text { but with a smaller range } \\
\text { of motion. } \\
\text { Frontal: the hip has a } \\
\text { little tendency of adduc- } \\
\text { tion during the entire cy- } \\
\text { cle. }\end{array}$ \\
\hline
\end{tabular}


A

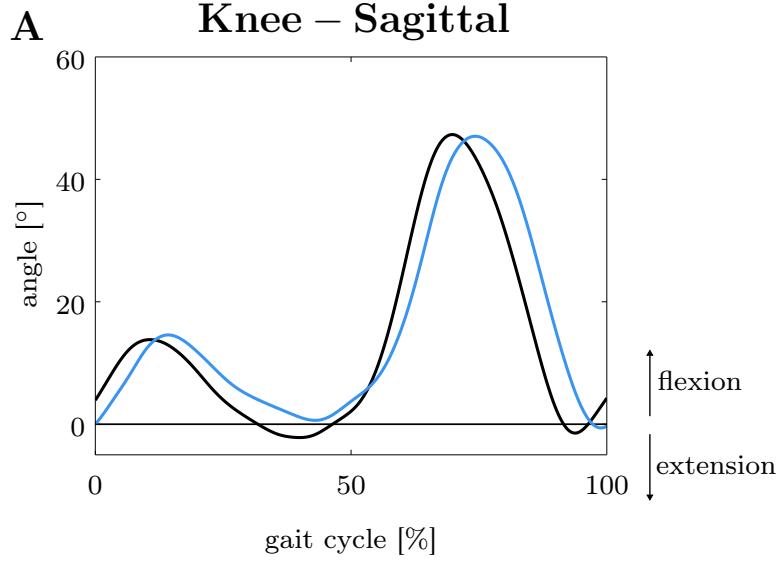

B

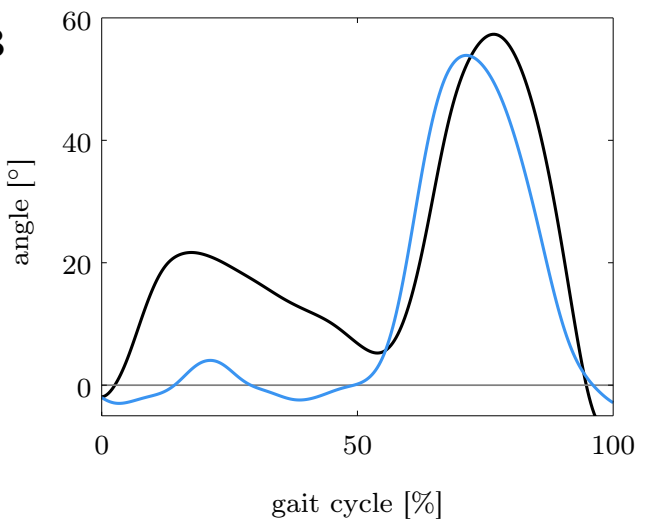

C

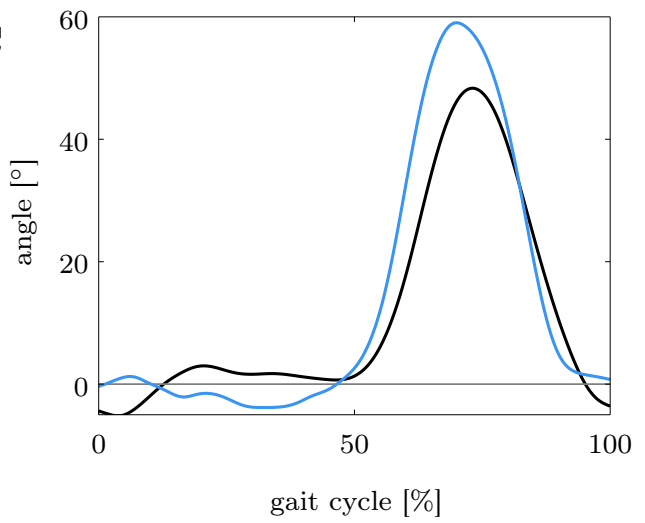

D

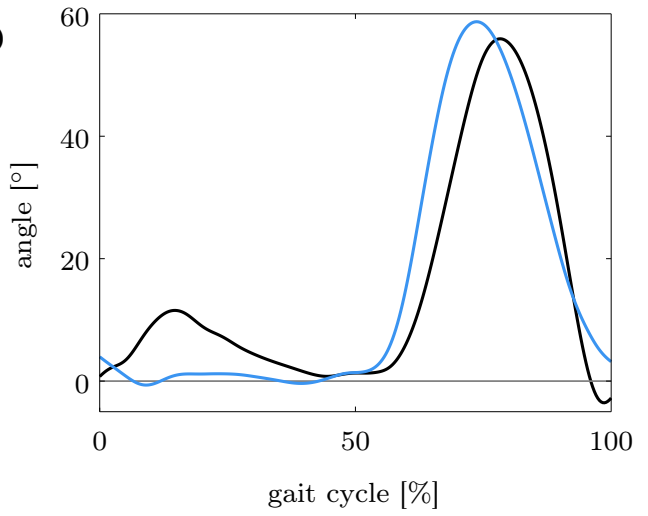

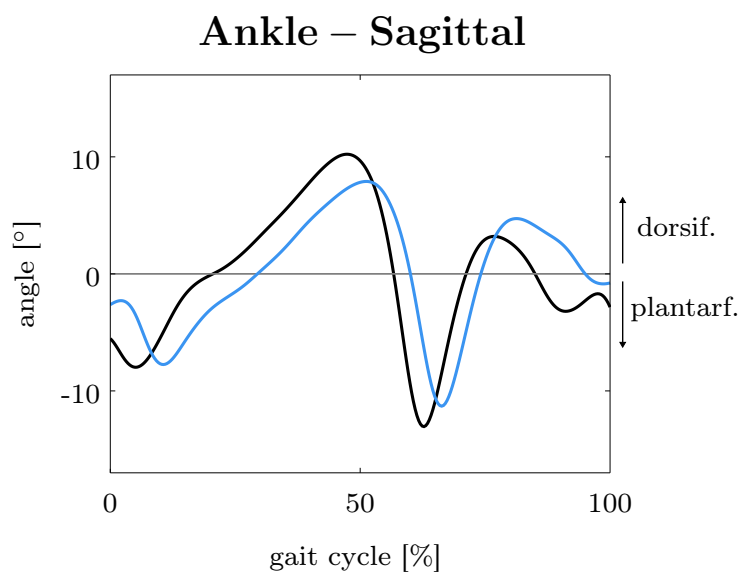
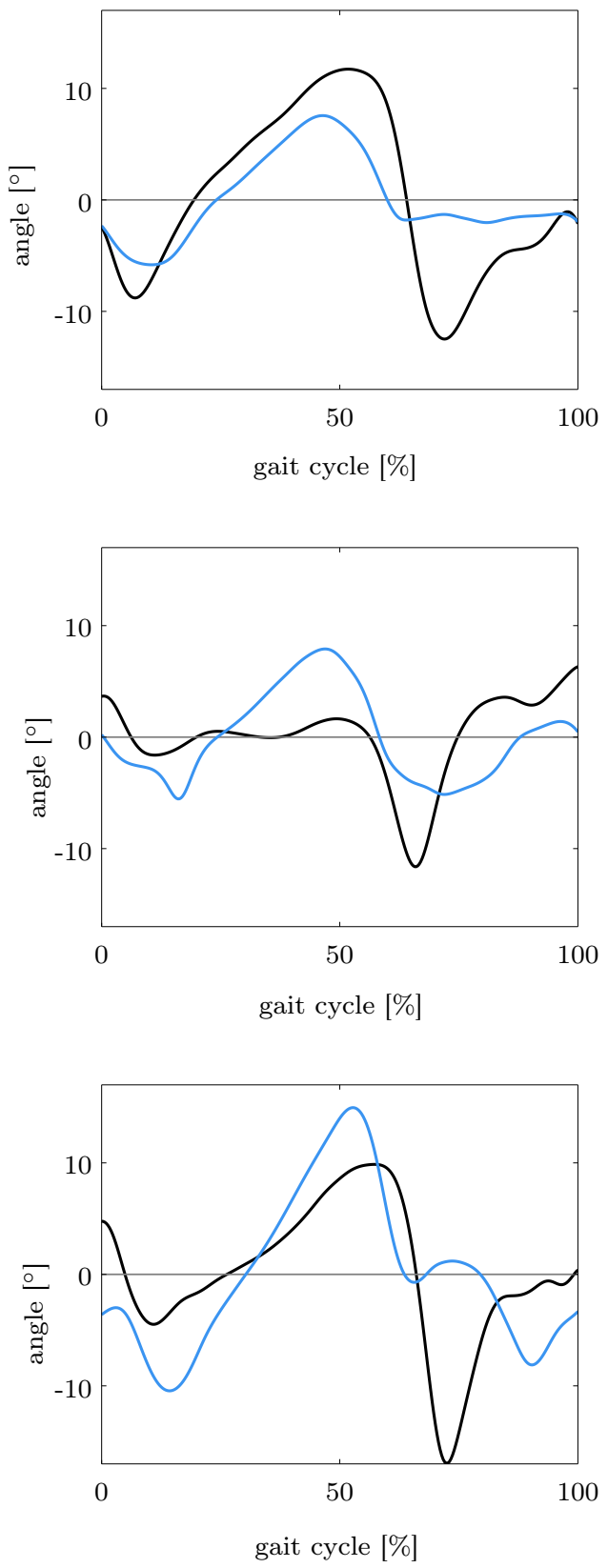

Figure 4.5: Knee and ankle angles of the trailing leg (black line) against the leading leg (blue line). A: the reference subject; B, C, D: the amputee subjects. For the case of the amputee subjects the trailing leg is the intact limb. 
Table 4.4: Main observations from the knee and ankle angles among the amputee subjects. The joint angles were compared against the non-amputee pattern. For each joint, the intact and the prosthetic side were analyzed during a gait cycle when each side began the stride (see figure 4.5).

\begin{tabular}{|c|c|c|c|c|}
\hline \multirow{2}{*}{ Subject } & \multicolumn{2}{|c|}{ Knee } & \multicolumn{2}{|c|}{ Ankle } \\
\hline & Intact side & Prosthetic side & Intact side & Prosthetic side \\
\hline B & $\begin{array}{l}\text { It presents a similar } \\
\text { pattern to the reference. } \\
\text { The stance extension } \\
\text { lasts until the beginning } \\
\text { of the swing phase. }\end{array}$ & $\begin{array}{l}\text { No initial flexion. At the } \\
\text { swing phase, the flexion- } \\
\text { extension motion is alike } \\
\text { to the intact side. }\end{array}$ & $\begin{array}{l}\text { The stance phase is sim- } \\
\text { ilar to the normal pat- } \\
\text { tern. No final dorsiflex- } \\
\text { ion at the swing phase. }\end{array}$ & $\begin{array}{l}\text { Moderate plantarflexion } \\
\left(-5.7^{\circ}\right) \text { and dorsiflex- } \\
\text { ion }\left(7.5^{\circ}\right) \text { at the stance } \\
\text { phase. Almost neutral } \\
\text { position at the swing } \\
\text { phase. }\end{array}$ \\
\hline $\mathrm{C}$ & $\begin{array}{l}\text { No initial flexion. The } \\
\text { pattern at the swing } \\
\text { phase is normal. The } \\
\text { maximum angle of the fi- } \\
\text { nal flexion is } 48^{\circ} \text {. }\end{array}$ & $\begin{array}{l}\text { It presents a negative } \\
\text { flexion during the stance } \\
\text { phase. The peak of the } \\
\text { flexion angle at the swing } \\
\text { phase is approximately } \\
10^{\circ} \text { higher than that of } \\
\text { the intact side. }\end{array}$ & $\begin{array}{l}\text { Almost neutral position } \\
\text { during the entire stance } \\
\text { phase. Plantarflexion } \\
\text { peak of }-11.5^{\circ} \text { at initial } \\
\text { swing and a final dorsi- } \\
\text { flexion of } 6^{\circ} \text {. }\end{array}$ & $\begin{array}{l}\text { Moderate plantarflexion } \\
\left(-5.5^{\circ}\right) \text { and dorsiflexion } \\
\left(7.8^{\circ}\right) \text { at the stance } \\
\text { phase. At the swing } \\
\text { phase, there is an ex- } \\
\text { tended plantarflexion, } \\
\text { with a maximum angle } \\
\text { of }-5.1^{\circ} \text {. }\end{array}$ \\
\hline $\mathrm{D}$ & $\begin{array}{l}\text { Very alike to the nor- } \\
\text { mal pattern. The stance } \\
\text { extension lasts until the } \\
\text { beginning of the swing } \\
\text { phase. }\end{array}$ & $\begin{array}{l}\text { No initial flexion. The } \\
\text { swing phase presents a } \\
\text { similar behavior to the } \\
\text { intact side. }\end{array}$ & $\begin{array}{l}\text { It initiates in a dorsi- } \\
\text { flexed position of } 4.6^{\circ} \text {, } \\
\text { then it goes to plan- } \\
\text { tarflexion until it reaches } \\
\text { its maximum }\left(-4.5^{\circ}\right) \text { at } \\
\text { loading response. The } \\
\text { maximum dorsiflexion } \\
\text { angle }\left(10^{\circ}\right) \text { occurs at } \\
\text { final stance. The plan- } \\
\text { tarflexion at initial swing } \\
\text { has a peak of } 17^{\circ} \text {. There } \\
\text { is no final dorsiflexion. }\end{array}$ & $\begin{array}{l}\text { The stance phase is alike } \\
\text { to the normal pattern, } \\
\text { with a plantarflexion } \\
\text { angle of }-10.4^{\circ} \text { and dor- } \\
\text { siflexion angle of } 14.9^{\circ} \text {. } \\
\text { At the swing phase, the } \\
\text { greatest plantarflexion } \\
\text { angle }\left(-8^{\circ}\right) \text { takes place } \\
\text { at the end of the stride. } \\
\text { No final dorsiflexion. }\end{array}$ \\
\hline
\end{tabular}

\subsubsection{Ground Reaction Forces}

The ground reaction force components in the vertical and the anterior-posterior direction were also measured. Figure 4.6 presents the mean values for the non-amputee group, while the bothsides pattern for each amputee subject and a non-amputee reference is presented in Figure 4.7. Concerning the GRF mean values of the non-amputee group, the anterior-posterior component is within the normal range and shape (Whittle, 2007). The anterior posterior GRF presents a posterior force at the first half of the stance phase, then it becomes an anterior force at the end of the step. Its magnitude generally doesn't exceed the $20 \%$ of the body weight, or $0.2 \mathrm{BW}$. The vertical GRF presents a well-known $M$-like shape with two peaks and a valley. The first peak at the loading response has a magnitude that can reach up to approximately $1.1 \mathrm{BW}$. At midstance, the vertical GRF decreases until $0.8 \mathrm{BW}$. The last peak is reached at terminal stance, usually with the same magnitude of the first peak.

Regarding the anterior-posterior component of the amputee group (see Figure 4.7), all three amputee subjects show greater peaks on the intact side if compared to their counterparts on the prosthetic side. On the intact side, the anterior average peak is $0.19 \mathrm{BW}$, against the one from 


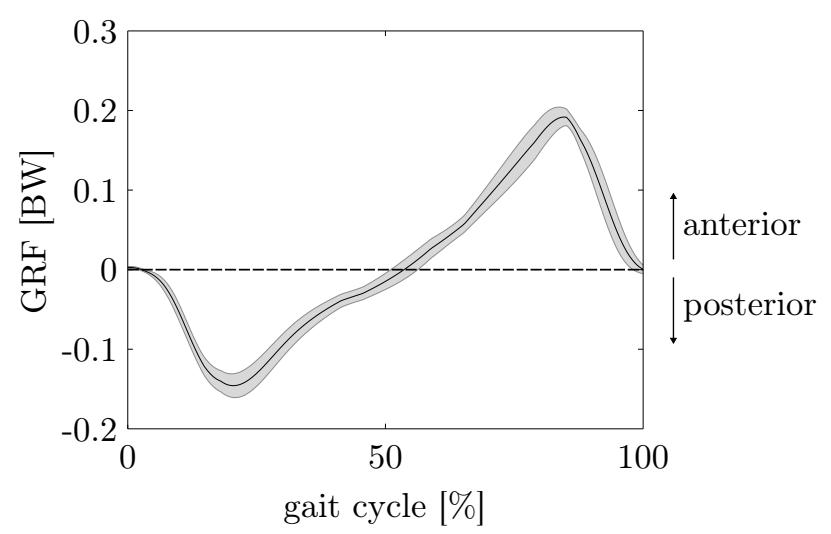

(a)

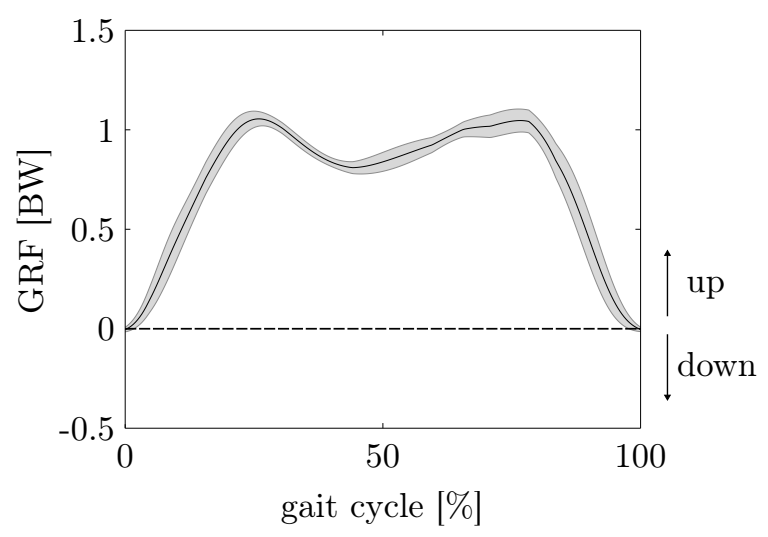

(b)

Figure 4.6: Ground Reaction Forces $($ mean $\pm 1 S D)$ of all the non-amputee subjects. (a) The anterior-posterior and (b) the vertical components.

the prosthetic side with a value of $0.07 B W$. For the case of the posterior GRF, its peak on the intact side has an average of $-0.14 B W$, while its counterpart on the prosthetic side is equal to $-0.09 B W$. Looking at the anterior-posterior patterns from subjects $\mathrm{C}$ and $\mathrm{D}$, it can be observed that the posterior forces are greater than the anterior forces on the prosthetic side.

The vertical component of the GRF exhibits differences between the three subjects. In subject $\mathrm{B}$ and $\mathrm{C}$ this component in both legs is quite similar. The peaks exceed the body weight on both legs, being the intact side the highest. The valley has an average magnitude of $0.87 \mathrm{BW}$ for both subjects. From subject D, the vertical GRF presents differences on both sides. On the intact side, the peaks do not exceed the body weight $(0.97 \mathrm{BW})$, while the force valley extends from $10 \%$ to $59 \%$ of the gait cycle. The prosthetic side exhibits an asymmetry around midstance $(G R F=0.8 B W)$, with a vertical difference between peaks of approximately $0.14 B W$.

From both GRF patterns it is also possible to observe a difference between the phases duration of each side. For the case of subject B and D the stance period of the intact limb lasts until the $70 \%$ of the gait cycle, compared to its counterpart which ends at $60 \%$. The difference in the stance duration of subject $\mathrm{C}$ is smaller, with a difference of approximately $5 \%$ between limbs. 
A
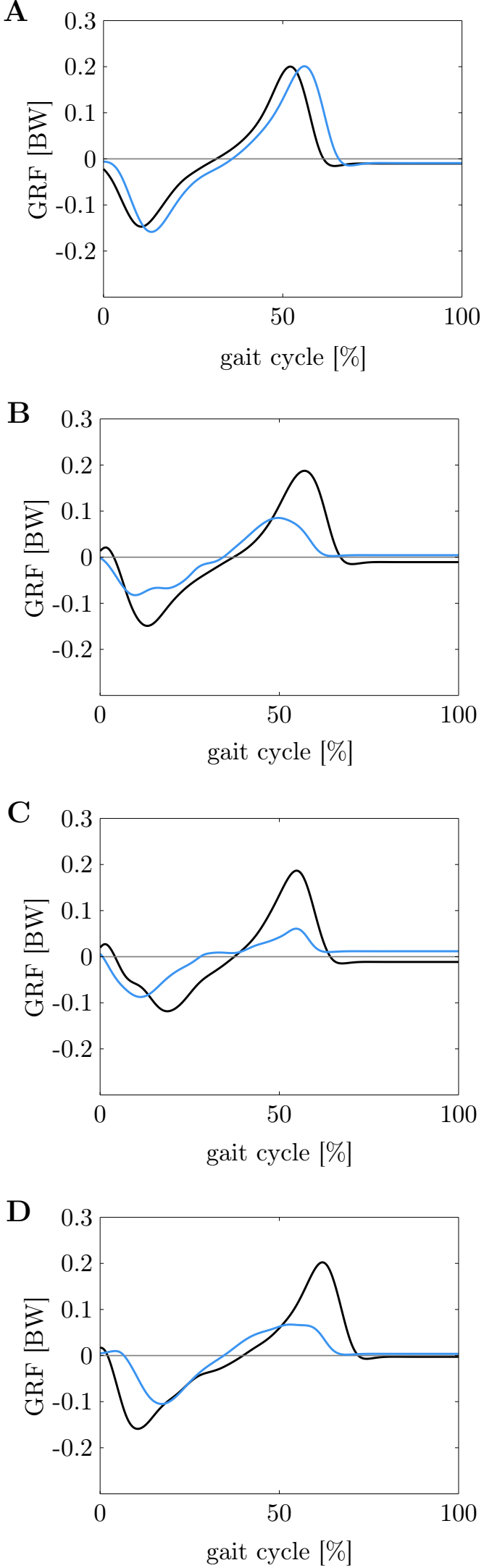
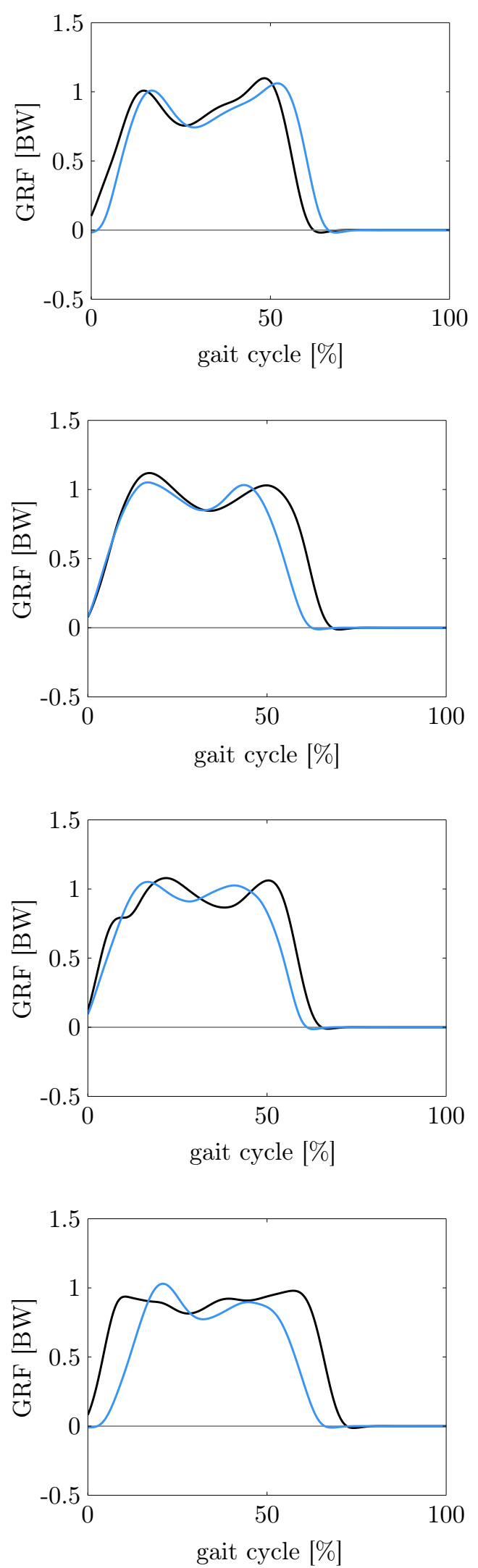

Figure 4.7: The anterior-posterior and the vertical GRF of the trailing leg (black line) against the leading leg (blue line). A: the reference subject. B, C, D: the amputee subjects. For the amputee subjects the trailing leg corresponds to the intact limb, while the prosthetic leg is the leading one. 


\subsubsection{CoM vertical trajectory}

The vertical trajectory of the body Center of Mass (CoM) is calculated directly from the trajectory of a marker placed on the second sacral vertebrae, which is the closest anatomical point to the location of the CoM. The pattern of the non-amputee group is shown in Figure 4.8. It clearly shows a periodic pattern with two periods corresponding to each step along the stride. The average excursion of the vertical CoM for the non-amputee group corresponds to $3.015 \mathrm{~cm}$. The highest value happens at midstance of the trailing leg, and it is repeated at the same instant in the contralateral limb (the leading leg). The lowest value takes place when the leading leg hits the ground at the second double support period.

In Figure 4.9 the vertical CoM of each amputee subject is presented, as well as the reference curve from a non-amputee subject. The time axis is divided in heel strike and toe-off events, which delimit the single support and the double support periods of the gait cycle. The analysis from each subject is detailed below.

- Subject B. The first step initiates with a deceleration of the CoM (negative slope) until the mid-point of the first double support period. After this, the step has a similar shape to the non-amputee reference. The transition between steps, at double support, does not attain the minimum height like the one obtained at the loading response. The vertical difference between these two minimum points is $1.12 \mathrm{~cm}$. The second step, which is done with the prosthesis, has a smaller vertical excursion than the first step, with a difference between peaks of $0.8 \mathrm{~cm}$

- Subject C. The first step is quite different from the second one. The transition between steps gets to a lower vertical position with respect to the value achieved at the initial double support, with a vertical difference of $2.3 \mathrm{~cm}$. The second step is a single wave, closer to the reference.

- Subject D. Like subject B, subject D presents two peaks at single support for both legs and two minimum points at the middle point of the double support periods, but similar to subject $\mathrm{C}$, the transition between steps is characterized by a CoM position lower than the first minimum with a vertical difference of $1.2 \mathrm{~cm}$.

Additionally, the duration of the double support and the single support periods were measured from the time difference between the heel strike and the toe-off events. Compared to the reference subject, the three amputee subjects have longer double support periods. Measured in percentage of the gait cycle, the amputee subjects have a double support period that lasts, in average, $16.8 \% G C$, against $12.8 \%$ GC from the reference subject. Naturally, this means less time during the single support period for the amputee gait. Moreover, it was also observed that subjects $\mathrm{B}$ and $\mathrm{C}$ have a initial double support (intact side) longer than the second double support (prosthetic side), with an average difference of $4 \% G C$. Conversely, subject $\mathrm{D}$ has the same duration for both double support periods $(19 \% G C)$, which are the longest of the amputee group. 


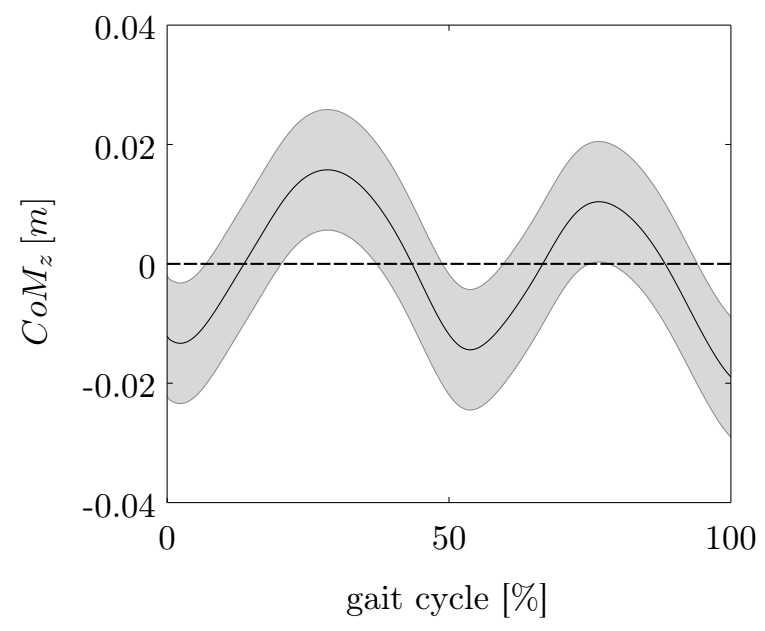

Figure 4.8: The CoM vertical excursion (mean $\pm 1 S D)$ of the non-amputee group.

\subsubsection{External mechanical power}

In this work, the external mechanical power from the reference subject and the three amputee subjects is calculated based on the equation (3.2). The power is made dimensionless by dividing it by $m g \sqrt{g l}$, where $m$ is the body mass, $g$ is the gravitational acceleration and $l$ is the length leg (Donelan et al., 2002b). Figure 4.10 presents the power curve during a single stride. The power profile exhibited in the reference subject is in accordance from what was found in the literature (Neptune et al., 2004; Adamczyk \& Kuo, 2009; Ellis et al., 2013). Looking at the curve described by the trailing leg (row A, black curve), it is possible to see similar contributions of positive and negative work during the single support period. A possible explanation of this behavior is the storage and the release of elastic energy from tendons (Donelan et al., 2002b) at the moment of the initial contact (storage) and midstance (release). During the initial double support, the trailing leg has a negative work because of the collision with the surface, while at the second double support the leg exerts a positive work at the moment of push-off. During step-to-step transition (between the HS2 and the TO1 events), it can be seen the simultaneous positive an negative work from both legs. In order to quantify the difference in mechanical power between subjects, the peak values at the step-to-step transition are given in Table 4.5. From these peak values it can be inferred that the three amputee subject present a smaller magnitude of collision and push-off work if compared to the reference. Following, the main observations from the three amputee subjects:

- Subject B. The work at the single support does not have the same contribution like the reference. The step-to-step transition starts just before the double support, but it ends at the same time of the mentioned period. The push-off work is smaller than that of the reference. Moreover, the magnitude of the collision work is smaller of the push-off work done by the trailing leg.

- Subject C. The negative work at the initial double support (first collision) starts at the midpoint of this period and it prolongs until the single support, when there is a similar 

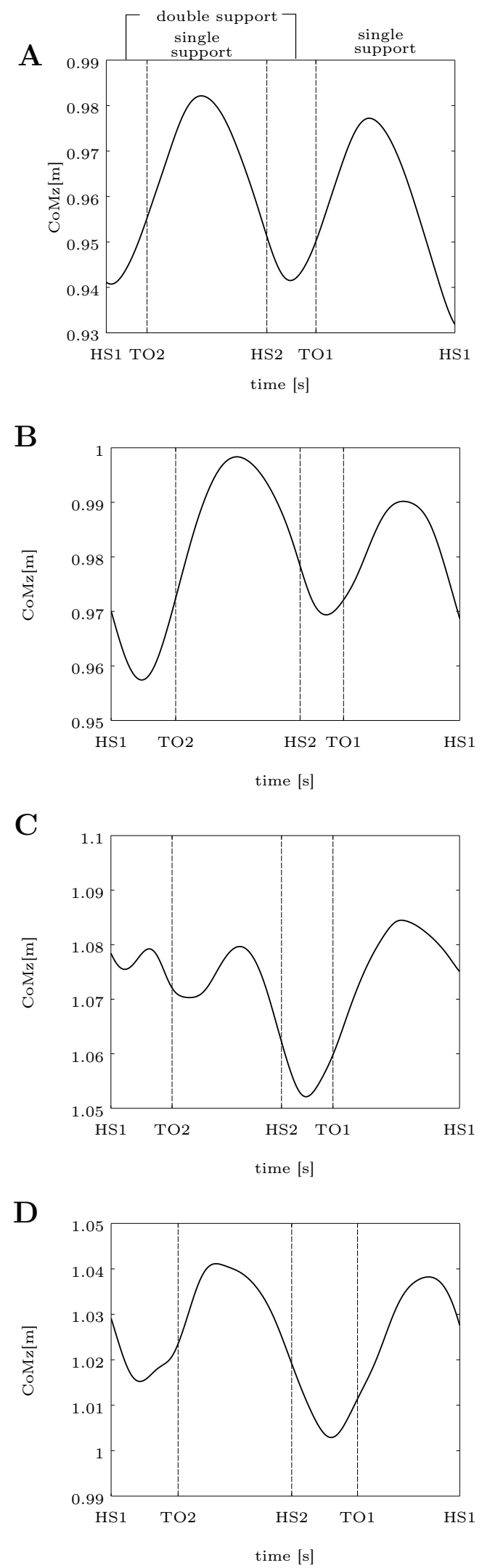

Figure 4.9: Vertical displacement of the CoM. A: the reference subject, B, C, D: the amputee subjects. $H S_{1}$ and $H S_{2}$ correspond to the heel strike events of the trailing and the leading leg, respectively. The $T O_{1}$ and $T O_{2}$ are the toe-off events for the same legs. For the case of the amputee subjects, the trailing leg corresponds to the intact leg. 
Table 4.5: Power peak values at the step-to-step transition, extracted from Figure 4.10.

\begin{tabular}{ccc}
\hline subject & push-off work & collision work \\
\hline A & 0.334 & -0.107 \\
\hline B & 0.207 & -0.147 \\
\hline C & 0.242 & -0.064 \\
\hline D & 0.270 & -0.080 \\
\hline
\end{tabular}

Table 4.6: $C O T_{\text {mech }}$ calculation based on the CoM power.

\begin{tabular}{cc}
\hline Subject & COT $_{\text {mech }}($ mean $\pm S D)$ \\
\hline $\mathrm{A}$ & $0.387 \pm 0.016$ \\
\hline $\mathrm{B}$ & $0.451 \pm 0.024$ \\
\hline $\mathrm{C}$ & $0.532 \pm 0.020$ \\
\hline $\mathrm{D}$ & $0.661 \pm 0.032$ \\
\hline
\end{tabular}

contribution of positive and negative work from the elastic energy exchange. At the step-tostep transition, the negative work is $26 \%$ of the positive work. This event takes place within the double support duration.

- Subject D. The initial negative work occurs during the whole double support. The positive work at the single support happens just before this period starts, while subsequent negative work starts before the midpoint of the single support. The collision work of the step-to-step transition corresponds to $30 \%$ of the push-off work.

\subsubsection{Mechanical Cost of Transport}

Table 4.6 shows the mechanical cost of transport, $C O T_{\text {mech }}$, for the reference subject $\mathrm{A}$ and the amputee subjects B, C and D. The calculation was performed using the expression given in Equation (3.3). In Kuo (2007) the $C O T_{\text {mech }}$ for humans is reported to be equal to 0.3 for normal walking. Another reference value is found in Gordon et al. (2009), where $C O T_{\text {mech }}=0.22 \pm 0.03$ for walking at a preferred step length. The value of subject A is close to these references, thus it can be used as a point for comparison with the results of the amputee group. From the values exhibited in Table 4.6, it is seen that the three amputee subjects perform more $C O T_{\text {mech }}$ if compared to the non-amputee reference, being the subject $\mathrm{B}$ who has the lowest value, while subject $\mathrm{D}$ has the highest $C O T_{\text {mech }}$ from the group. 

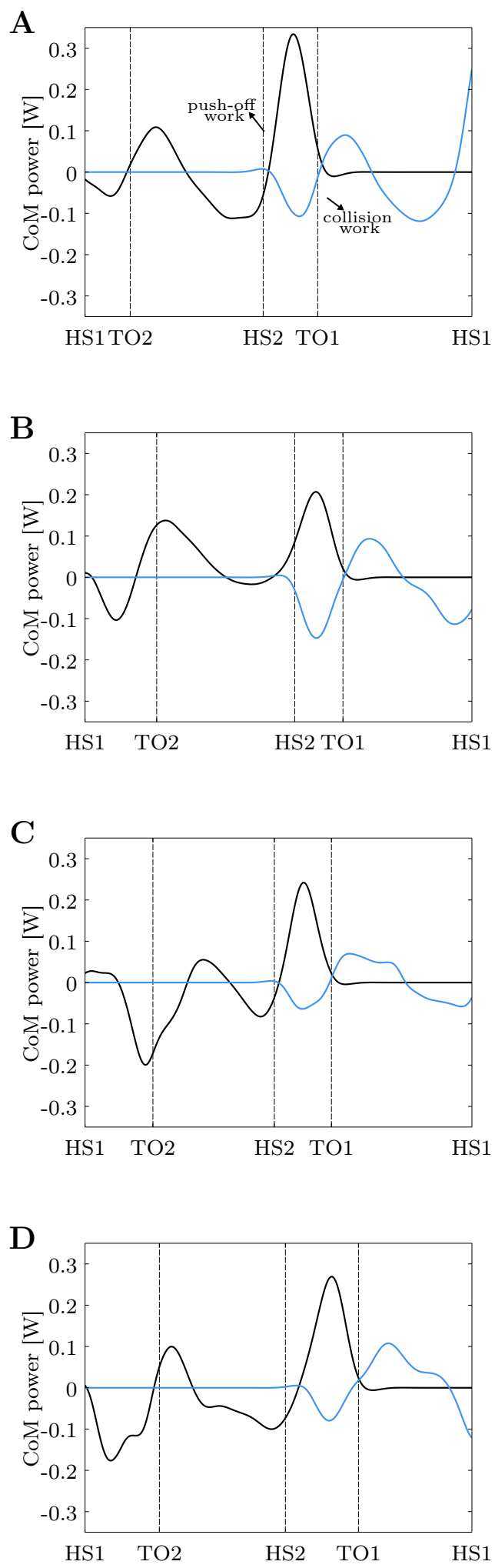

Figure 4.10: External mechanical power of the trailing leg (black line) and the leading leg (blue line) during a gait cycle. A: the reference subject; B, C, D: the amputee subjects. For the case of the amputee subjects, the trailing leg corresponds to the intact side. 


\subsection{Discussion}

\subsubsection{Joint kinematics}

The most notable differences are seen in the pelvis obliquity, the hip adduction/abduction angle and the ankle dorsiflexion/plantarflexion. The pelvis obliquity curves reveal a probable mechanisms of hip hiking on subjects $\mathrm{B}$ and $\mathrm{D}$, because of the final elevation of the pelvis at the swing phase on both sides, which does not exist in able-bodied subjects. As presented in section 3.3, the origin of hip hiking relies on the absence of dorsiflexion at late swing on the prosthetic side, as well as small posterior GRF values, also on this same side. Both characteristics are presented in subjects B and D. Surprisingly, subject C has an ankle dorsiflexion during the prosthesis swing, which could be one of the reasons why this subject does not exhibit hip hiking, even with a small anterior-posterior GRF.

Due to the close relation between the pelvis and the femur motion (Neumann, 2002), it is not unexpected that variations on the pelvis reflect an irregular behavior on the hip joint too. The hip adduction/abduction angle from the amputee group is also different from the reference. All the three subjects have a small range of adduction/abduction on the prosthetic side, with an average of $5^{\circ}$, against the average of $10^{\circ}$ in a normal case. On the intact side, the three subjects behaves differently. Perhaps the most notable characteristic is the great abduction angle of subject D at the end of the swing phase. Kark et al. (2012) hypothesized that differences in this angle between able-bodied subjects and lower limb amputees could be attributed to weak hip muscles, a widebased gait and leg-length discrepancies. Moreover, Gitter et al. (2002) attributed excessive hip abduction as a mechanism to enhance step length.

The mechanical restriction of the prosthetic foot used by the three amputee subjects bring out differences in the angle of the ankle joint in the sagittal plane. On the amputee side, the swing dorsiflexion is absent, due to the passive nature of the prosthetic foot. However, at the stance phase it can be seen an initial plantarflexion and dorsiflexion on the stance phase, possibly caused by the elastic effect of the leaf-spring elements of the foot. Continuing in the sagittal plane, the hip extension/flexion on the prosthetic side exhibits a smaller range of motion on subject $\mathrm{C}$ and D. The limitation on hip extension may be related to the prosthetic socket fitting. In order to minimize this mechanical constraint, the subject tends to tilt his/her pelvis in an anterior direction to avoid leg shortening on the intact side (Tranberg et al., 2011). Even though pelvic tilt was not measured in this work, a visual inspection from video records confirmed the pelvic tilt strategy on these two subjects. Finally, the knee angle on the sagittal plane shows no stance flexion on the prosthetic side of the three subjects. This issue was also discussed in section 3.3. An inadequate weight loading causes the stance prosthetic leg to remain in extended position. On the intact side, subject $\mathrm{B}$ exhibits stance flexion with a reasonable value, while in subject $\mathrm{D}$ this angle is smaller. Subject $\mathrm{C}$ shows no stance flexion on either both sides, which might explain the reduced pelvis obliquity seen in this subject. 


\subsubsection{GRFs}

The time difference between the stance phases of each limb is evidenced in the vertical GRF patterns of the amputee group. In all the three subjects, the stance phase of the intact limb lasts more than its counterpart on the prosthetic side. This is produced by the unequal weight loading, which makes the subject to spend more time on the intact limb. The anterior-posterior GRFs reveal another characteristics. The intact side has bigger forces than the prosthetic side, which might be also related to the weight loading constraint. This cause smaller collisions and push-off forces on the prosthetic side, increasing the efforts on the intact limb. Comparing to the reference, the magnitude on the intact side shows no notable differences.

\subsubsection{CoM, external mechanical power and $C O T_{\text {mech }}$}

The different patterns of the vertical CoM from the amputee group could be thought as the manifestation of the gait constraints and the compensatory mechanisms of each one of the subjects. The most distinguished characteristic of the vertical CoM among subjects is the asymmetry of the vertical excursion from one step to the other. The differences between the minimum points during each double support period may be related to the unequal duration of the vertical GRFs along each step. On the other hand, the differences between the peaks coincide with the differences in weight loading onto each leg; the higher the peak the more the body weight is bore onto the leg. In subjects B and D this situation is clearly visible: the first peak of the vertical CoM is higher than the second one because the first step is performed with the intact limb. Conversely, for subject $\mathrm{C}$ the CoM pattern does not reflect this phenomenon, there are more than two peaks during the first step, which also correspond to the intact leg. It is possible that other compensatory mechanisms have influenced the pattern of the vertical CoM on this subject.

By using the measurements of the CoM and the GRFs, the external power was calculated. The value of the external power is linearly proportional to the overall metabolic cost of walking (Donelan et al., 2002b), thus its calculation can give us an idea of the energy expenditure. The pattern of the reference subject shows approximately equal contributions of work at the single support phase, meaning an efficient exchange between the stored and the released energy caused by the initial contact. At the moment of the step-to-step transition, push-off work is higher than the collision work, meaning that more energy has to be released to redirect the CoM trajectory from a downward to an upward direction. Regarding the amputee group, all the three subjects have unequal work contribution during the single support period of the stance phase from the intact side, that is possibly related to the stance phase duration asymmetry between limbs. Moreover, the difference in magnitude between the push-off work done by the intact limb and the collision work from the prosthesis may be produced by the weight loading asymmetry. Finally, as a metric that could represent somehow the mechanical energy expenditure of walking, the COT was estimated from the notion of the external power. The value of COT for the three amputees is higher than that of the reference, which comes as no surprise since it is well-known that compensatory mechanisms represent a more costly walking for this population. The COT values from subjects B, C and D exceed the COT value of the reference in $17 \%, 37 \%$ and $66 \%$, respectively. This calculation only 
confirms the previous statement, but it does not go further to relate any compensation with the increase of the mechanical cost of walking.

In summary, all the measured variables evidence the existence of compensatory mechanisms developed by each amputee subject, as well as gait constraints caused by the leg prosthesis. However, still is unclear how the lost of the knee and the ankle-foot complex induced to specific compensations, and how each one of these mechanisms increase the energy cost of walking.

\subsection{Conclusions}

This chapter presented the experimental part of this work and the subsequent gait analysis from the extracted data. The main purpose here is to have a closer look to the problem of amputee gait by the comparison of the results from a reduced number of amputee subjects, with the ones obtained from a non-amputee group. In fact, the measurements of the kinematic and the kinetic variables on both limbs during a gait cycle confirmed the presence of asymmetries in the studied amputee subjects. These asymmetries make the values of the affected variables to deviate from the normal patterns measured in the non-amputee population.

From all the gait variables, the frontal plane angles of the pelvis and the hip joint, along with the ankle angle in the sagittal plane showed an important difference between sides. Some common characteristics between the amputee subjects could be extracted. It is also worth to point out the different patterns of the vertical CoM for all the three amputee subjects, all distant from the one obtained for the reference subject. In addition, the mechanical cost of transport associated to each subject showed that the amputee group has a less efficient walk that a able-bodied subject, which could be related to the characteristics identified in the gait variables.

The asymmetries between limbs are caused by compensatory mechanisms, most of them related to prolonged use of a certain type of prosthesis. The fact that all three volunteers use the same passive prosthesis for many years might be related to some of the common mechanisms found in the amputee group, even thought a clear relationship cannot be established just by looking at the gait data. A deeper knowledge of the prosthesis is required in order to find the effect of its operation on the gait developed by each user. 



\section{SYMmetry ANALYSIS}

Beyond the visual inspection of the kinematics and kinetics variables measured and exhibited in sections 4.2 .2 to 4.2 .5 , it would be interesting to quantify how similar the gait parameters are between the subjects' limbs and between the amputee subjects and the reference. The symmetry analysis in walking has been a matter of discussion in many clinical papers, but still there are different points of view regarding how it can be accurately measured. In this chapter, two different indices for measuring limb symmetry are employed. The results for the different gait variables measured in our experiments are presented and discussed.

\subsection{MEASURING LIMB SYMMETRY}

As stated by Sant'Anna et al. (2011), limb symmetry can be computed using discrete methods, which compare data points at specific gait instants, or using continuous methods that analyze a complete gait signal and compare it to its counterpart on the contralateral limb. The former methods are simpler to calculate and mainly are indices which measure the difference between the feature values from the left and the right side at a specific time. One of the most used discrete method is the symmetry index (SI), proposed by Robinson et al. (1987). The SI calculation takes one of the sides as a reference and simply calculates the difference between the two values and divide it by their average. A symmetry condition is obtained when $S I=0$. Some variation of this index has been proposed by other authors. For instance, Vagenas \& Hoshizaki (1992) divides the difference by the maximum value between the right and the left side so the index output is limited between \pm 1 , where the sign indicates the superiority of one side to the other. Another index is the ratio index (RI) (Sadeghi et al., 2000a), which takes the ratio from the right and the left side values. Higher or lower RI values than one indicates asymmetries. The expressions of each one of the discrete indices are specified in Table 5.1.

The continuous methods, on the other hand, analyze the entire sequence from each side in order to establish a similarity between the two signals. The signal can be, for example, EMG, trajectories from joints or special body points, acceleration, forces. These techniques may included the use of correlation coefficients (Miller et al., 1996), principle components (Sadeghi et al., 2000b) or frequency domain analyses (Crowe et al., 1995).

To compare the results of the kinematic and kinetic variables measured in this work, some continuous methods are used. The following sections will detail their implementations, as well as the obtained results. 
Table 5.1: Some discrete indices expressions used across the literature. $R$ and $L$ stands for the parameter value in the right and the left side, respectively.

\begin{tabular}{cc}
\hline Discrete Index & Expression \\
\hline \hline Robinson et al. (1987) & $S I=\frac{|R-L|}{0.5(R+L)}$ \\
\hline Vagenas \& Hoshizaki (1992) & $S I=\frac{|R-L|}{\max (R, L)}$ \\
\hline Sadeghi et al. (2000a) & $R I=\frac{R}{L}$ \\
\hline
\end{tabular}

\subsection{THE CROSS-CORRELATION COEFFICIENT}

To introduce the concept of the cross-correlation coefficient, first it is necessary to explain the cross-correlation function. Given two sequences $x[n]$ and $y[n]$, the cross-correlation function, $R_{x y}[m]$, is the averaged product of the sequence $x[n]$ with the time-shifted version of $y[n]$,

$$
R_{x y}[m]=\frac{1}{N} \sum_{n=0}^{N-m-1} x[n] y[n+m], \quad m=1, \ldots, 2 N-1
$$

where $N$ is the number of samples of both sequences and $m$ is the relative time shift, also known as lag, between $x[n]$ and $y[n] . R_{x y}[m]$ will have a maximum value at a specific lag when $x[n]$ and $y[n]$ best match. In this sense, the main purpose of the cross-correlation is to seek for similarities between $x[n]$ and $y[n]$ as a function of the time shift. Sometimes it is more convenient to express the cross-correlation function in terms of the cross-correlation coefficient, $\rho_{x y}[m]$, defined as the cross-correlation of the two sequences normalized by their auto-correlation functions at zero lag,

$$
\rho_{x y}[m]=\frac{R_{x y}[m]}{\left[R_{x x}[0] R_{y y}[0]\right]^{1 / 2}}
$$

where $R_{x x}$ and $R_{y y}$ in 5.2 are the auto-correlation of $x[n]$ and $y[n]$, respectively. The crosscorrelation coefficient lies between $\pm 1 ; \rho_{x y}=1$ means that the signals $x[n]$ and $y[n]$ are positive correlated, while $\rho_{x y}=-1$ indicates that the two signals are negatively correlated. $\rho_{x y}=0$ means no correlation between them.

The cross-correlation function is used in the work of Miller et al. (1996) to analyze EMG signals from different muscles of the lower limbs during locomotion. The authors employed the correlation function to synchronize different trials from the same measurement, facilitating their comparison in terms of shape. This work also proposed a bilateral symmetry measurement by means of the cross-correlation coefficient. The symmetry magnitude, $S_{M}$, corresponds to the cross-correlation coefficient between the signals taken from the same muscle on both limbs, while the phase symmetry $S_{P}$ is the time shift between the two signals when the cross-correlation is maximum. These two parameters are expressed as follows

$$
\begin{gathered}
S_{M}=\max \left\{\rho_{x y}(m)\right\} \\
S_{P}=m, \max \left\{\rho_{x y}(m)\right\}
\end{gathered}
$$


Table 5.2: $S_{M}$ index for the joint kinematics. The mean values were calculated from the amputee group.

\begin{tabular}{|c|c|c|c|c|c|}
\hline \multirow{2}{*}{ Subject } & \multirow{2}{*}{ Pelvis } & \multicolumn{2}{|c|}{ Hip } & \multirow{2}{*}{ Knee sagittal } & \multirow{2}{*}{ Ankle sagittal } \\
\hline & & Sagittal & Frontal & & \\
\hline A & 0.975 & 0.974 & 0.907 & 0.986 & 0.933 \\
\hline B & 0.902 & 0.933 & 0.695 & 0.895 & 0.848 \\
\hline $\mathrm{C}$ & 0.788 & 0.950 & 0.608 & 0.973 & 0.611 \\
\hline D & 0.903 & 0.949 & 0.499 & 0.947 & 0.575 \\
\hline $\mathrm{Mea}_{a m p} \pm \mathrm{SD}$ & $0.864 \pm 0.066$ & $0.944 \pm 0.01$ & $0.601 \pm 0.1$ & $0.938 \pm 0.04$ & $0.678 \pm 0.1483$ \\
\hline
\end{tabular}

These indices are also used in Gouwanda \& Senanayake (2011) to detect gait symmetry in walking from signals obtained by gyroscopes. A related approach is employed by Moe-Nilssen \& Helbostad (2004), who used the auto-correlation in an acceleration signal measured in the trunk to estimate gait cycle parameters like cadence, stride and step regularity. In Yoneyama et al. (2013), the cross-correlation coefficient is employed to detect the period of the gait signals obtained from an accelerometry-based system.

Here, the $S_{M}$ index is calculated for all the kinematic and kinetic information presented in chapter 4. Tables 5.2 and 5.3 show the results of the symmetry index for the angles, the GRFs and the vertical CoM trajectories. For the case of the vertical CoM, the signals to be compared correspond to the steps performed by each limb during a gait cycle. The phase symmetry index, $S_{P}$, is not calculated here because it does not reflect a real phase difference between the two signals for our dataset. Since the two-sides curves are already synchronized for comparison, as they were presented in chapter 4 , the value of $S_{P}$ would not necessarily mean that one side is delayed or advanced in time with respect to the other. If the two sequences were measured at the same trial, which was not the case here, then we would have the real time information when the two sequences (i.e., the gait variables in the two sides) take place and the cross-correlation lag would give us indeed information of the time difference between the signals.

From the previous cited works, the value of the cross-correlation coefficient above 0.9 seems to be a good criteria for similarity detection, then this value is used in this work to separate the gait variables between high and low symmetry. The results from the reference subject show a $S_{M}$ higher than 0.90 for all the variables. For the case of the amputee group, the $S_{M}$ values above 0.90 are found in the hip and the knee angle in the sagittal plane, as well as in the vertical component of the GRF. The lowest symmetry can be found in the hip frontal angle, the ankle sagittal angle and the vertical CoM trajectory, which also has the highest variability of $S_{M}$ among the amputee subjects. The pelvis angle in the sagittal plane and the anterior-posterior GRF have reasonable values. 
Table 5.3: $S_{M}$ index for the GRFs and the vertical CoM.

\begin{tabular}{cccc}
\hline \multirow{2}{*}{ Subject } & \multicolumn{2}{c}{ GRF } & CoM \\
\cline { 2 - 3 } & Anterior-Posterior & Vertical & \\
\hline A & 0.998 & 0.978 & 0.956 \\
\hline B & 0.956 & 0.955 & 0.556 \\
C & 0.821 & 0.954 & 0.501 \\
D & 0.744 & 0.834 & 0.950 \\
Mean $_{a m p} \pm \mathrm{SD}$ & $0.864 \pm 0.066$ & $0.914 \pm 0.07$ & $0.67 \pm 0.245$ \\
\hline
\end{tabular}

Additionally, an inter-subject comparison between each amputee subject and the reference was also made. The results for the intact and the amputee side against one side from the reference are presented in Tables 5.4 and 5.5. The angles in the frontal plane, i.e., the pelvis the hip angle are the ones with lowest index values on both sides, below 0.7. Low $S_{M}$ values are also found in the ankle angle and the vertical CoM. The rest of the variables (GRFs, hip and knee angles) have values above 0.9 .

\subsubsection{Discussion}

The values of the $S_{M}$ index are in accordance with what was found in the gait analysis performed in chapter 4 . The fact that the $S_{M}$ exhibited superior values in all the measured variables for the case of the non-amputee subject supports the selection of this particular subject as the reference for all the performed analyses.

Regarding the behavior of the amputee group, the variables which showed lower values of the cross-correlation coefficient are the ones previously identified with the highest asymmetries in the gait analysis (see discussion in section 4.3). The hip in the frontal plane and the ankle in the sagittal plane are the angles with low $S_{M}$ values in the intra-subject and in the inter-subject comparisons. This means that these angles have different behaviors on each side of the amputee subjects and they are also different if compared to the reference patterns. On the contrary, the pelvis angle in the frontal plane shows a moderate value of symmetry between limbs, but exhibits a low value in the inter-subject comparison, thus this parameter can be considered symmetric within the amputee subjects, but has a different pattern if compared to the reference. Furthermore, the $S_{M}$ value from the vertical CoM trajectory is low in all the three amputee subjects in both comparisons.

Finally, observing the individual values of each amputee subject, it can be seen that subject C is the one with the lowest $S_{M}$ values in the CoM and the pelvis angle, while subject D shows this same trend for the hip angle in the frontal plane and the ankle angle. In general, subject B has superior values of cross-correlation in all the gait variables, compared to the other amputee subjects. This may be the reason why this subject has a lower mechanical cost of transport ( see Table 4.6) during walking. 
Table 5.4: Inter-subject comparison of the joint kinematics, between the three amputee subjects and the reference subject.

\begin{tabular}{|c|c|c|c|c|c|c|c|c|c|c|}
\hline \multirow{3}{*}{ Subject } & \multicolumn{2}{|c|}{ Pelvis } & \multicolumn{4}{|c|}{ Hip } & \multicolumn{2}{|c|}{ Knee sagittal } & \multicolumn{2}{|c|}{ Ankle sagittal } \\
\hline & \multirow[b]{2}{*}{ Int. } & \multirow[b]{2}{*}{ Amp. } & \multicolumn{2}{|c|}{ Sagittal } & \multicolumn{2}{|c|}{ Frontal } & \multirow[b]{2}{*}{ Int. } & \multirow[b]{2}{*}{ Amp. } & \multirow[b]{2}{*}{ Int. } & \multirow[b]{2}{*}{ Amp. } \\
\hline & & & Int. & Amp. & Int. & Amp. & & & & \\
\hline $\mathrm{B}$ & 0.613 & 0.623 & 0.935 & 0.993 & 0.676 & 0.597 & 0.914 & 0.940 & 0.779 & 0.806 \\
\hline $\mathrm{C}$ & 0.493 & 0.621 & 0.932 & 0.982 & 0.526 & 0.676 & 0.898 & 0.920 & 0.489 & 0.674 \\
\hline $\mathrm{D}$ & 0.598 & 0.705 & 0.895 & 0.946 & 0.586 & 0.564 & 0.944 & 0.919 & 0.842 & 0.738 \\
\hline $\operatorname{Mean}_{a m p} \pm$ & $0.568 \pm$ & $0.65 \pm$ & $0.921 \pm$ & $0.974 \pm$ & $0.596 \pm$ & $0.612 \pm$ & $0.92 \pm$ & $0.926 \pm$ & $0.703 \pm$ & $0.739 \pm$ \\
\hline $\mathrm{SD}$ & 0.065 & 0.048 & 0.022 & 0.025 & 0.076 & 0.058 & 0.023 & 0.012 & 0.19 & 0.066 \\
\hline
\end{tabular}

Table 5.5: Inter-subject comparison of the GRF, the vertical CoM and the CoM power.

\begin{tabular}{|c|c|c|c|c|c|}
\hline \multirow{3}{*}{ Subject } & \multicolumn{4}{|c|}{ GRF } & \multirow{3}{*}{$\mathrm{CoM}$} \\
\hline & \multicolumn{2}{|c|}{ Anterior-Posterior } & \multicolumn{2}{|c|}{ Vertical } & \\
\hline & Int. & Amp. & Int. & Amp. & \\
\hline $\mathrm{B}$ & 0.983 & 0.956 & 0.942 & 0.987 & 0.613 \\
\hline $\mathrm{C}$ & 0.986 & 0.824 & 0.919 & 0.969 & 0.533 \\
\hline $\mathrm{D}$ & 0.835 & 0.929 & 0.831 & 0.936 & 0.750 \\
\hline $\begin{array}{c}\text { Mean } n_{a m p} \pm \\
\text { SD }\end{array}$ & $0.935 \pm 0.086$ & $0.903 \pm 0.07$ & $0.90 \pm 0.059$ & $0.964 \pm 0.026$ & $0.632 \pm 0.11$ \\
\hline
\end{tabular}

\subsection{CoM SPECTRAL ANALYSIS}

Many experiments across the literature have shown the periodical nature of the trajectory of the center of mass during a normal gait cycle. Concerning the vertical excursion of the CoM, this signal can be compared to a sinusoidal function whose period coincides to the period of the gait cycle. On the other hand, the performance of the vertical CoM on amputee subjects (see figure 4.9) reveals other characteristics different from a "perfect" sinusoidal function, but that still preserves the periodicity of the signal between strides.

This periodic characteristic of the CoM trajectory has led researches to use the discrete Fourier series (DFS) to mathematically represent the performance of this parameter during a gait cycle. According to the DFS formulation, a discrete periodic sequence $x[n]$ with a period of $N$ samples can be represented as a sum of sinusoidal functions whose frequencies are multiple of the fundamental frequency $\omega_{0}=2 \pi / N$. In this sense, the Discrete Fourier Series (DFS) of the sequence $x[n]$ can 
be expressed as ${ }^{1}$

$$
x[n]=\frac{1}{N} \sum_{k=1}^{N} a_{k} e^{j k(2 \pi / N) n}
$$

In the same manner, the DFS coefficients can be written as

$$
a_{k}=\sum_{k=1}^{N} x[n] e^{-j k(2 \pi / N) n}
$$

As the sequence $x[n]$ has a period of $N$ samples, its spectrum can only have components that are located in frequencies multiple of $\omega_{0}$. This means that the DFS coefficients will appear in frequencies defined as

$$
\omega_{k}=k \omega_{0}, \quad k=1,2,3, \ldots, N
$$

To define how many DFS coefficients are necessary in order to have a good approximation of $x[n]$, the energy calculation of the signal is a useful criterion. The energy in the frequency domain can be calculated in terms of the DFS coefficients, as follows

$$
E_{T}=\sum_{k=1}^{N}\left|a_{k}\right|^{2}
$$

where $\left|a_{k}\right|^{2}$ is known as the average power of the $k t h$ component of the DFS.

The DFS formulation has already been used in the literature of gait analysis. Crowe et al. (1995) estimated the CoM trajectory from GRF measurements, which were expanded in terms of the DFS for each force component. The authors showed results from normal gaits in different experimental conditions and suggested the analysis of the DFS coefficients as an alternative to characterize human gait. A more recent attempt is the work of Minetti et al. (2011). They analyzed consecutive strides at different velocities during walking and running. From these datasets, expressions of the DFS of the 3D CoM trajectory were obtained at each velocity condition. In Betker et al. (2006), the CoM vertical trajectory is estimated from a sum-of-sines function whose input is the acceleration measured at the trunk segment, instead of time information. The authors validated this proposal with $\mathrm{CoM}$ values calculated from kinematic data and additionally compared the algorithm performance with other models (a neural network and an adaptive fuzzy system) that also estimate the CoM trajectory in the sagittal plane.

In this work, the Fourier analysis is used to represent the vertical CoM trajectory in terms of the DFS components. Figure 5.1 presents the magnitude spectrum of the DFS of the vertical excursion of the CoM from subjects A to D, as well as the individual sinusoidal components in time domain. The number of the DFS coefficients calculated for each vertical CoM is related to a energy

\footnotetext{
${ }^{1}$ Here, instead of sines or cosines functions, the expression for the DFS is given in terms of complex exponentials, which is also a periodic function and it is related to the former by the Euler formula $\left(e^{j x}=\cos x+j \sin x\right)$.
} 
criterion, i.e., the reconstruction of the CoM waveform includes the DFS coefficients that represent at least the $99 \%$ of the total energy signal defined in (5.7). Additionally, Figure 5.2 exhibits the reconstruction of the vertical CoM from the calculated DFS coefficients; the distortion between the original and the reconstructed signal is also provided. Table 5.6 summarize the number of DFS coefficients and their contribution to the overall signal energy.

Regarding the reference subject A (first row), his vertical CoM in time domain presents two oscillations with almost the same amplitude and duration in the course of the gait cycle. The magnitude spectrum of this subject reveals two main coefficients for $k=1$ and $k=2$. The first one constitutes approximately the $5 \%$ of the total signal energy, while the component in $k=2$ has an energy of $94 \%$. The latter oscillates at a frequency very close to the inverse of the step period

of this subject $\left(t_{\text {step }}=0.58\right)$. The rest of the coefficients are not considered since they represent only the $1 \%$ of the signal power.

From the amputee group, subjects B and D have a similar behavior; the signal energy is concentrated in two DFS coefficients in $k=1$ and $k=2$, which have approximately $20 \%$ and $79 \%$ of the total signal energy, in frequencies that coincide with one and twice the frequency of the gait cycle (see Table 5.6). A different behavior is observed in subject C; the energy signal is spread out into four coefficients, with the first two having almost the same contribution in terms of energy. Additionally, the reconstructed signals from the selected DFS components (see Figure 5.2) have a small distortion in all the subjects, bounded between the limits of $\pm 2.5 \mathrm{~mm}$.

\subsubsection{DFS-based symmetry index}

As analyzed in previous sections, the vertical CoM trajectory also reflects the symmetry condition between the lower limbs, since the two oscillations of this parameter during a single gait are the consequence of the two leg contacts with the surface, which are expected to be similar in a symmetric gait. For normal condition where the vertical CoM exhibits a periodic pattern, its waveform behaves like an even function with respect to the vertical axis at a time equals to the step time. In the context of the Fourier analysis, a symmetric pattern of the vertical CoM expressed in the DFS components will contain only even DSF coefficients.

In order to quantify the symmetry of the vertical CoM, an index that measures this condition can be thought in terms of the ratio between the energy from the even DFS components and the total signal energy. Considering that the even components make equal contribution to each vertical oscillation (one per step) of the CoM during a gait cycle, the presence of odd components will represent asymmetries on this signal. Based on this, Minetti et al. (2011) suggested an index of symmetry based on the DFS coefficients that synthesized the vertical CoM trajectory

$$
S_{C o M}=\frac{\sum_{i}\left|a_{i}\right|^{2}}{\sum_{k}\left|a_{k}\right|^{2}}, \quad i=2,4,6, \ldots, N \text { and } k=1,2,3, \ldots, N
$$

where $a_{i}$ are the even components, while $a_{k}$ are the overall DFS components for the studied waveform. A value of $S_{C o M}$ equals to 1 means perfect symmetry, i.e., the vertical CoM during the 
Table 5.6: Coefficient frequencies and its energy contribution to the DFS of the vertical CoM.

\begin{tabular}{ccc}
\hline Subject & Coefficient Frequency $[H z]$ & Coefficient Energy $\left[\% E_{T}\right]$ \\
\hline \multirow{2}{*}{$\mathrm{A}$} & $f_{1}=0.856$ & $P_{1}=5.204$ \\
\cline { 2 - 3 } & $f_{2}=1.712$ & $P_{2}=93.359$ \\
\hline \multirow{2}{*}{$\mathrm{B}$} & $f_{1}=0.839$ & $P_{1}=19.328$ \\
\cline { 2 - 3 } & $f_{2}=1.678$ & $P_{2}=79.320$ \\
\hline \multirow{2}{*}{$\mathrm{C}$} & $f_{1}=0.767$ & $P_{1}=43.684$ \\
\cline { 2 - 3 } & $f_{2}=1.534$ & $P_{2}=39.450$ \\
\cline { 2 - 3 } & $f_{3}=2.301$ & $P_{3}=14.000$ \\
\hline \multirow{2}{*}{$\mathrm{D}$} & $f_{4}=3.067$ & $P_{4}=2.409$ \\
\cline { 2 - 3 } & $f_{1}=0.812$ & $P_{1}=19.753$ \\
\hline & $f_{2}=1.623$ & $P_{2}=78.033$ \\
\hline
\end{tabular}

Table 5.7: Symmetry index based on the DFS of the vertical CoM.

\begin{tabular}{cc}
\hline Subject & $S_{C o M}$ \\
\hline $\mathrm{A}$ & 0.959 \\
\hline $\mathrm{B}$ & 0.804 \\
\hline $\mathrm{C}$ & 0.421 \\
\hline $\mathrm{D}$ & 0.788 \\
\hline
\end{tabular}

first step is equal to the one produced during the next step. Table 5.7 shows the values for all the subjects. The reference subject, as expected, has the highest value. For the case of the amputee group, the $S_{C o M}$ values in decreasing order correspond to subject B, D and C.

\subsubsection{Discussion}

In a purely mechanical perspective, the trajectory of the center of mass reflects the interaction between different body segments in order to execute motion. As a global parameter that represents the overall characteristics of gait, the estimation of its performance can give us some clues about the effect of the different compensation mechanisms executed by the amputee subjects who participated in this study.

The fact that this parameter exhibits a periodic behavior supports the use of consolidated mathematical techniques which make the interpretation of waveforms with this behavior easier. 
A

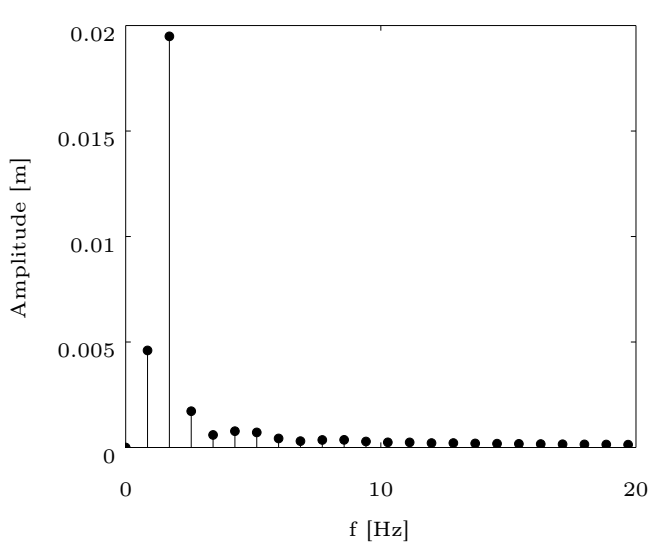

B

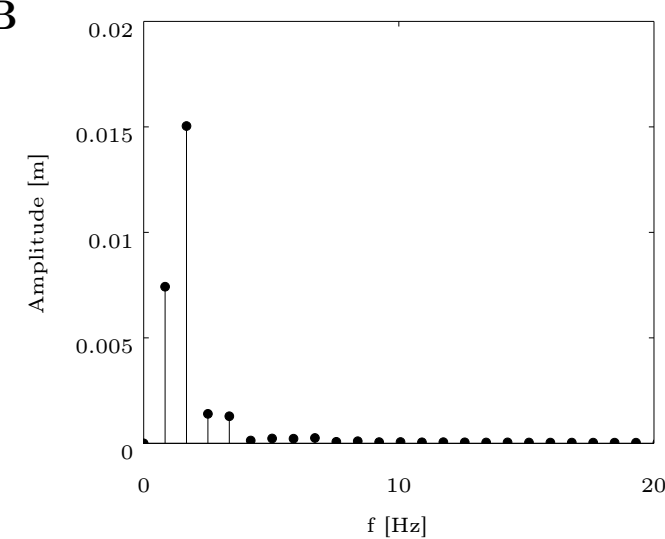

C

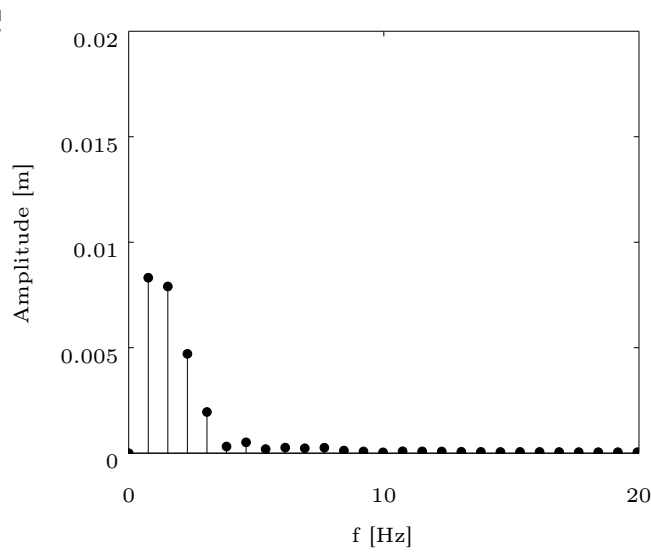

D

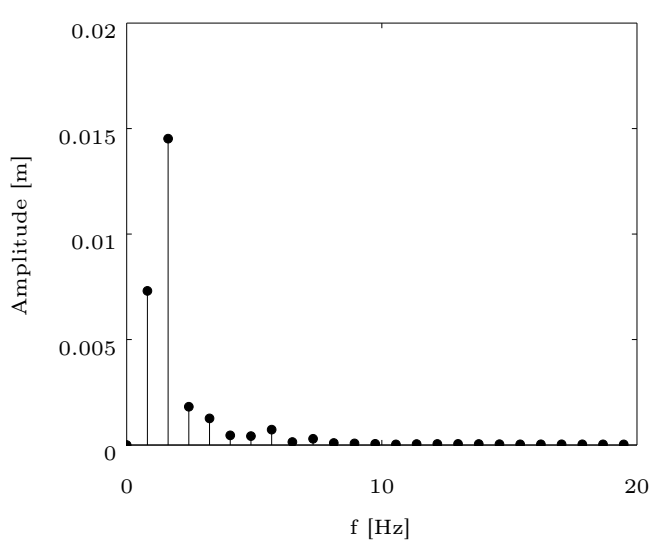

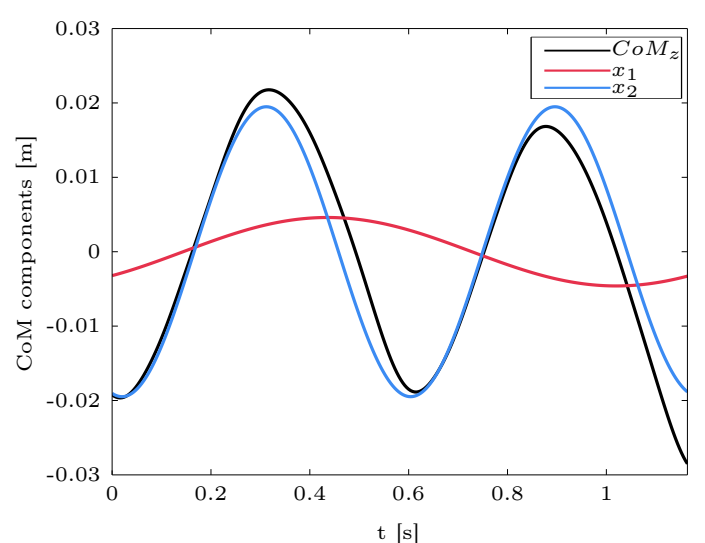
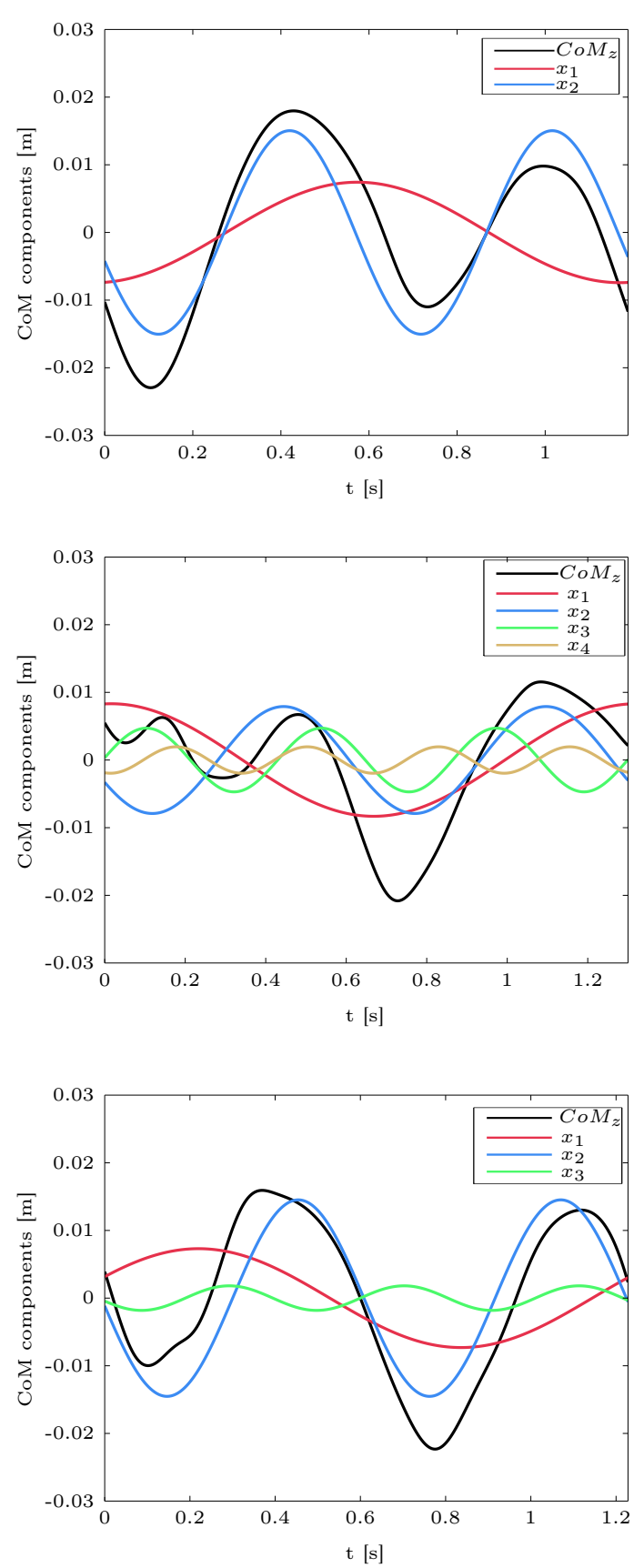

Figure 5.1: Magnitude spectrum (first column) and decomposition of the vertical CoM signal into its harmonics, the black curve is the original waveform. 

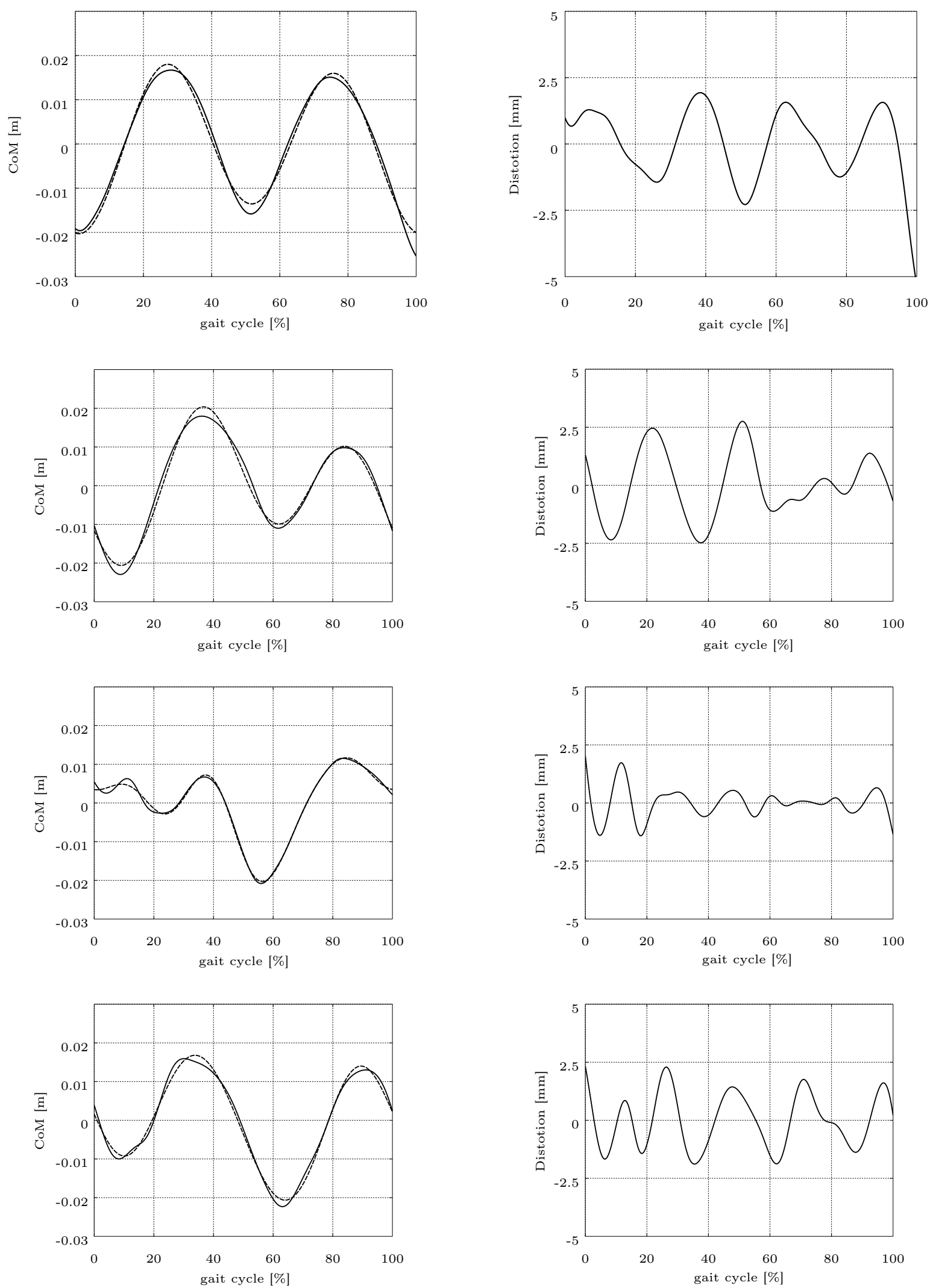

Figure 5.2: Left column: original signal (solid line) and its reconstruction (dashed line). Right Column: distortion in $\mathrm{mm}$ between the two signals. 
Specifically, the vertical excursion of the CoM describes two oscillations per gait cycle, which are expected to be similar given the fact that both limbs are supposed to behave in the same manner. Bearing this in mind, a symmetry index defined as a ratio between the energy of the even coefficients, responsible for the symmetry behavior of the signal, and the total energy of the resultant DFS, will measure the level of symmetry of walking in terms of the vertical CoM.

In our experiments, the vertical $\mathrm{CoM}$ of the reference subject does not exhibit perfect symmetric pattern, since the second oscillation has a lower amplitude than the first one, then the resultant DFS is formed by two coefficients. Nevertheless, the symmetry index for this subject is high $\left(S_{C o M}=0.959\right)$, meaning that the two consecutive steps in the gait cycle are very similar to each other. The reconstruction of the vertical CoM from only two components was also the result of Crowe et al. (1995). They called the first harmonic the Fundamental Extrinsic Harmonic (FEH), since it contributes to the asymmetric characteristics of the vertical CoM. On the other hand, the second harmonic belongs to the Fundamental Intrinsic Harmonics (FIH), that reflects the symmetry aspects of the signal.

For the case of subject B, the fundamental frequency, which coincides to the frequency of the gait cycle, is responsible for a component that presents one oscillation that might be related to the difference in amplitude and duration between the steps. The second component, in turn, oscillates at a frequency twice the frequency of the gait cycle, close to the frequency of each step; this component shows a perfect even symmetry between the consecutive steps. The value of $S_{C o M}$ reflects the contribution of the fundamental odd coefficient in the reduction of the symmetry condition.

Considering that the second coefficient is the one that reflects the symmetric behavior of the vertical CoM, for the case of subject $\mathrm{C}$ the rest of the resultant coefficients distorts this pattern in great amount. The first component is responsible for some of the vertical displacement of the resultant waveform, while the third and fourth components produce the initial undulations at the first instants of the gait cycle, as well as the pronounced vertical excursion at the step-tostep transition moment. The sum of these individuals components gives as a final result a very asymmetric pattern of the vertical CoM, with the lowest $S_{C o M}$ value of all the analyzed subjects.

Subject D has a similar situation of subject B, two coefficients concentrates most of the energy signal. For our case, the energy criterion of $99 \%$ included a third coefficient. This last coefficient only contributes with $1.22 \%$ of the total energy signal, so it can be simply discarded for the purpose of the present analysis. The first coefficient is responsible for the distortion of the symmetric pattern given by the second coefficient, in terms of a phase difference and a decrease of the CoM position at the step-to-step transition. 


\subsection{ConClusions}

This chapter presented two techniques to analyze limb symmetry. The first one is an index which measures the difference in magnitude of two time sequences; for this case, any of the measured variables from the two limbs. The magnitude index, $S_{M}$, is based on the cross-correlation coefficient and it is intended to look for similarities between two signals, one time-shifted with respect to the other one. At a time when the two sequences best match, the cross-correlation coefficient will approach to one. From our experiments, the results of the $S_{M}$ index are consistent from the observations made in the gait analysis chapter. Highest asymmetric behaviors between limbs, looking at the joint angles, were found at the hip angle in the frontal plane and at the ankle angle in the sagittal plane. These values are probably the result of the hip hiking mechanism and the absence of actuation of the ankle joint in the prosthetic leg. The vertical CoM is also different from each amputee subject. Additionally, the index also exhibited differences between each amputee subject and the reference subject; the above mentioned angles and the pelvis angle showed the lowest values and the vertical CoM also presented an important difference in this comparison. It is worth to point out that when compared each side of the amputee subject with one side of the reference, the $S_{M}$ values were similar for each comparison, in other words, the intact side has also a different behavior if compared to a normal pattern. This makes sense due to the fact that the intact limb tends to maximize its capabilities to counteract the absence of the contralateral limb, reflecting patterns that differ from a normal situation, mostly in terms of magnitude, which is precisely one of the characteristics measured by the cross-correlation coefficient.

The second part of this chapter presented the use of the Fourier analysis to represent the vertical CoM trajectory in terms of the DFS. This analysis revealed the presence of several DFS components multiple of the gait cycle frequency for the case of the amputee subjects, in contrast with the two DFS components of the reference case. From the assumption of even symmetry of the CoM waveform in a normal situation, the presence of odd components were then related to the distortion in the resultant CoM from the selected components. This relationship was established by means of a symmetry index, $S_{C o M}$, which is defined as the ratio between the energy from the even components and the total signal energy. As expected, the reference subject exhibited the highest value, while the amputee group results reflected low levels of symmetry.

The results from both techniques confirm the presence of asymmetries on the gait of all the amputee subjects in a quantitative manner. Even though a direct association can not be made between the analysis presented here and the compensatory behaviors that affect this type of gait, these results can be used to identify the most influential parameters to assess limb symmetry in a condition of unilateral transfemoral amputation. From the variables measured along the experiments, the trajectory of the CoM seems to be a good choice to summarize the overall characteristics of gait. 


\section{GAIT MODELING}

Walk, run, swim and fly, among many others, represent different types of gait that can be found in nature. From an engineering perspective, trying to imitate these ways of locomotion represent a real challenge, not only because the constructed mechanism must emulate the animal anatomy, but also because of the complexity of representing the locomotion behavior that will command the movements of this machine.

Despite of the level of resemblance, gait models based on biological systems are intended to describe the main functions related to the locomotion generation. Holmes et al. (2006) classified gait models according to three main approaches. First, the neurobiological approach studies how the central pattern generator $(\mathrm{CPG})^{1}$ and the spinal reflexes produce and modulate the different types of locomotion patterns without sensory feedback. The reflex-driven approach focuses on the role of the proprioceptive feedback and the coordination between limbs in order to perform a certain way of locomotion. Finally, the biomechanical approach takes into account the limb dynamics and the way they change according to the environmental conditions.

In this chapter, a gait model based on the trajectory of the center of mass will be used to study the basic aspects of human walking. Different solutions from its basic formulation will be generated in order to understand how the modification of the systems parameters and the initial conditions could generate different walking patterns that may represent different human conditions. The issue of limb asymmetry is also represented by this model, and from a small variation of the original formulation, some simulations are also carried out to observe how particular combination of asymmetric characteristics on the legs could lead to different solutions. Furthermore, based on the characteristics of the subjects who participated in our study, a comparison between the model output and experimental data is performed. Comparisons for non-amputee and amputee situations are presented. To conclude this chapter, a proposal for a model-based estimation for one of the model parameter is made using an extended Kalman filter.

\subsection{Dynamic Walking}

Dynamic walking is a conceptual framework that exploits the natural dynamics of the legs to produce walking in legged robots (Remy, 2011). Different from other approaches which mostly rely on actuation to promote motion, dynamic walking machines are able to walk with small

\footnotetext{
${ }^{1}$ The CPG is a set of neurons located at the spinal cord, which provides a rhythmic activity to the muscles groups involved in locomotion (Geyer \& Herr, 2010).
} 
intervention of actuators. The control strategy is mostly oriented to the production of a cyclic motion which preserves the stability of the system along walking.

One of the first attempts to model human walking by means of simple mechanisms is elucidated in the famous work of McGeer (1990). He could demonstrate that his "passive dynamic walker" (see Figure 6.1) generated a bipedal walking without any energy input or active control on the machine. The constructed device consisted of two stiff legs with semicircular feet connected by a hing at the hip joint. It had two degrees of freedom: the two legs rotate around an axis perpendicular to the sagittal plane placed on the hip. Putting it on a gentle slope, the walking machine was capable of generating consecutive steps just by the effects of gravity and inertia. According to this approach, when one of the legs is swinging, its movement is similar to a free pendulum, and when the stance phase takes place, the contact leg exhibits an inverted pendulum-like dynamics.

From the initial work of McGeer, many other researchers have used this concept to model gait dynamics. Garcia et al. (1998) proposed a two-link model based on the passive dynamic walker, but with point-masses at the feet. The model showed stable walking patterns, which mainly depend on the ramp slope value. In Wisse et al. (2004), an upper body is added to the model presented in Garcia et al. (1998). The upper body was characterized by a massless stick which rotates around the hip joint by means of a point mass attached to it. The authors demonstrated theoretically that the presence of the upper body resulted in a better energy efficiency and in a slightly better robustness against disturbances. This latter model is implemented in Wisse et al. (2007), where the authors presented Denise, a passive-based biped robot capable of performing a stable walking using two foot contact switches as sensors and an on/off pneumatic actuator (Figure 6.1).

In this same line of model simplicity, other approaches include the elastic characteristics of the vertebrate limbs. The effective mechanisms developed by animals to take advantage of this elastic behavior was initially studied by Cavagna et al. (1977). They found common mechanisms of storing and recovering energy during the animal locomotion and compared them with two simple and well-studied mechanical systems: a swinging pendulum and a bouncing ball. According to the author's findings from force and velocities records, there is an alternate exchange between the potential gravitational energy and the kinetic energy during walking, like in a pendulum. On the other hand, in running this energy exchange is almost null, but the energy conservation remains, which suggest the presence of an elastic characteristic in this type of gait, hence Cavagna et al. (1977) modeled it like a bouncing ball. Those remarkable findings represented the starting point for many other studies which explored the elastic characteristics of animals in order to propose compliant gait models.

Blickhan (1989) was the first to study an elastic system as a way of representing the mechanical properties of hopping and running in humans. Specifically, he considered the entire musculoskeletal system as a simple spring-mass system. The body was modeled as a point mass bouncing passively on a massless spring without viscous losses and the gait was characterized by alternating contact and aerial phases (see Figure 6.2). He called this model the spring-loaded inverted pendulum (SLIP). On his work, he found interesting relationships between the systems parameters and the model behavior. He could also calculate appropriate parameter spaces which result in hopping and 

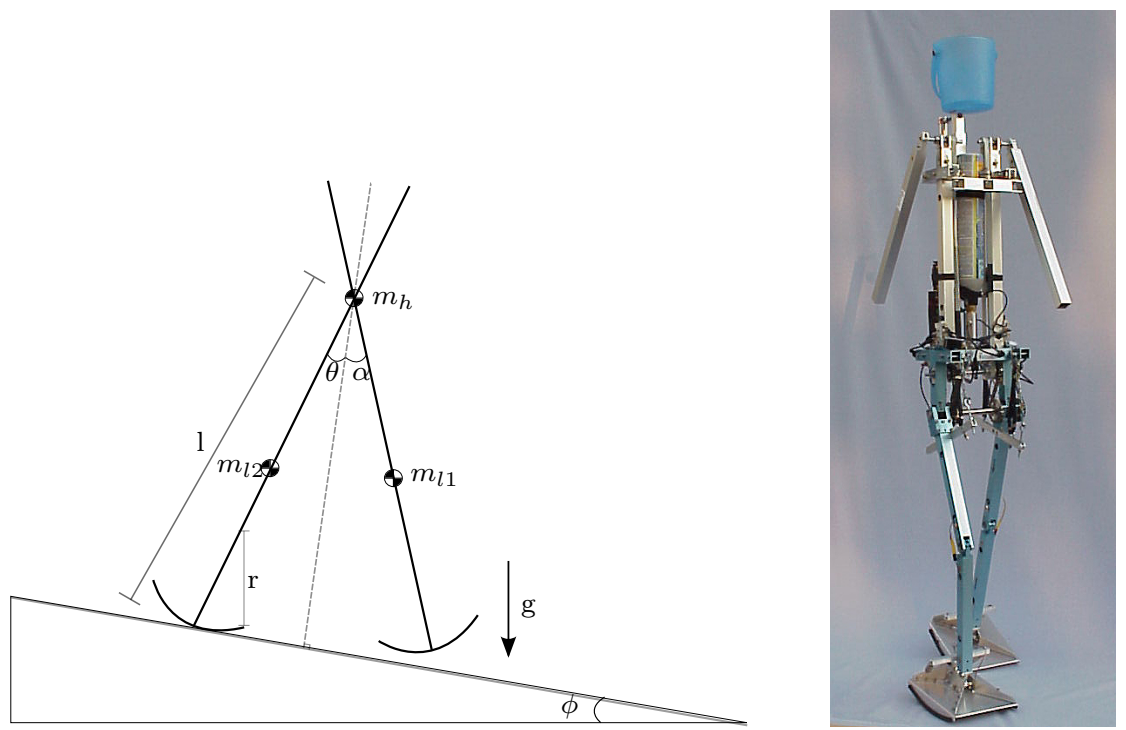

Figure 6.1: McGeer's passive dynamic walker (adapted from McGeer, 1990). The parameter of this model are: the upper body mass $m_{h}$, concentrated at the hip joint, the leg masses, $m_{l 1}$ and $m_{l 2}$, the leg angles $\theta$ and $\alpha$, leg length $l$, the foot radius $r$ and the ramp slope $\phi$. Based on this model, Wisse et al. (2007) built Denise, a passive biped walker robot.

running patterns like the ones done by humans.

After Blickhan's introductory work, other studies used this model for representing legged locomotion. Farley \& Gonzalez (1996) studied the relationship between leg stiffness, the angle swept by the leg, and the stride frequency for different running speeds. Seyfarth et al. (2002) investigated the periodicity and stability of different solutions of the spring-mass system for different leg adjustments during running. Their results agreed with experimental observations.

Encouraged by previous experimental findings about the inconvenience of modeling walking by stiff legs (Lee \& Farley 1998), Geyer et al. (2006) demonstrated that it is also valid to represent walking using the SLIP model proposed by Blickhan (1989). In their work, a bipedal spring-mass model for walking is proposed with double support and single support periods. They were able to prove that this model produces a ground reaction force pattern very close to the one produced by humans as they walk. Next section is devoted to explain the bipedal SLIP model for walking, the chosen model in this work for representing this type of gait.

\subsection{BIPEDAL SLIP MODEL FOR WALKING}

Figure 6.3 shows a representation of the bipedal version of the SLIP model and its corresponding phases for walking in the sagittal plane. The body is represented by a point mass $m$ located at the CoM, $\mathbf{r}=\left[\begin{array}{ll}x_{C o M} & y_{C o M}\end{array}\right]^{T}$. Each leg is represented by massless linear springs with fixed rest length $L_{0}$ and stiffness $k_{0}$. During stance, the forces $\mathbf{F}_{\mathbf{1 , 2}}$ are generated from each spring, directed from the foot points $\mathbf{r}_{\mathbf{F P}}=\left[\begin{array}{ll}x_{F P} & y_{F P}\end{array}\right]^{\mathrm{T}}$ to the body mass. The swing leg doesn't affect the 


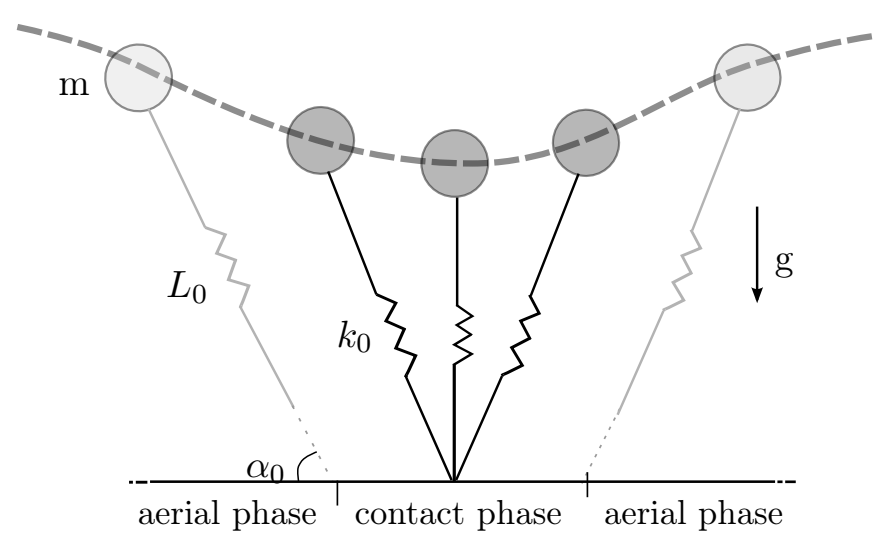

Figure 6.2: SLIP model for running and hoping (adapted from Blickhan, 1989). The point mass $m$ represented the whole body mass. The leg is a massless and linear spring, with rest length $L_{0}$ and stiffness $k_{0}$. At the aerial phase, the leg has an inclination with respect to the ground equals to $\alpha_{0}$.

dynamics of the whole system, since it is massless and generates no force.

A single step is defined by alternating single support and double support phases. The step in the SLIP model initiates at midstance, when the leg is vertically oriented with respect to the ground, which is also known as Vertical Leg Orientation (VLO) (Rummel et al., 2010) or apex height (Geyer et al., 2006), since the CoM reaches its highest point in this condition. The beginning of the double support phase is given by the touch-down (TO) event, which is the instant when the swing leg hits the ground, describing an angle of attack $\alpha_{0}$ with the surface. When both legs are identical, the parameters of SLIP model for walking are the body mass $m$, the leg's rest length $L_{0}$, the angle of attack $\alpha_{0}$, the leg stiffness $k_{0}$ and the system energy $E_{s}$. The equation of motion describing the CoM trajectory along the stance phase is given by

$$
m \ddot{\mathbf{r}}=\mathbf{F}_{1}+\mathbf{F}_{2}-m \mathbf{g}
$$

where $\mathbf{r}=\left[\begin{array}{ll}x_{C o M} & y_{C o M}\end{array}\right]^{T}$ is the position of the CoM and $\mathbf{g}=\left[\begin{array}{ll}0 & g\end{array}\right]^{T}$ corresponds to the gravity vector. The force of any of the two legs $\mathbf{F}_{\mathbf{1 , 2}}$ during stance is

$$
\mathbf{F}_{\mathbf{1}, \mathbf{2}}=k_{0}\left(\frac{L_{0}}{\left\|\mathbf{r}-\mathbf{r}_{\mathbf{F P}}\right\|}-1\right)\left(\mathbf{r}-\mathbf{r}_{\mathbf{F P}}\right)
$$

Specific equations describing the single or the double support phase are derived from (6.1) and (6.2) by setting $\mathbf{F}_{\mathbf{1}}$ or $\mathbf{F}_{\mathbf{2}}$ to zero, according to the current state of the system. The transitions from stance to swing is detected when any leg force has decreased to zero, i.e., when any of the two legs is on the lift-off ( $\mathrm{LO}$ ) event. The swing-to-stance transition is reached when the current swing leg has touched the floor, so the difference $y_{C o M}-y_{T D}=0, y_{T D}$ is the touch-down height and it is defined as $y_{T D}=L_{0} \sin \left(\alpha_{0}\right)$. The initial conditions of the SLIP model are chosen such that the CoM is at the VLO position, when the CoM is at its maximum height $\left(y_{0}=y_{V L O}\right)$, while $x_{0}=x_{F P 1}$, i.e., the $\mathrm{x}$-coordinate of the CoM coincides to that of the foot point. The velocity of 


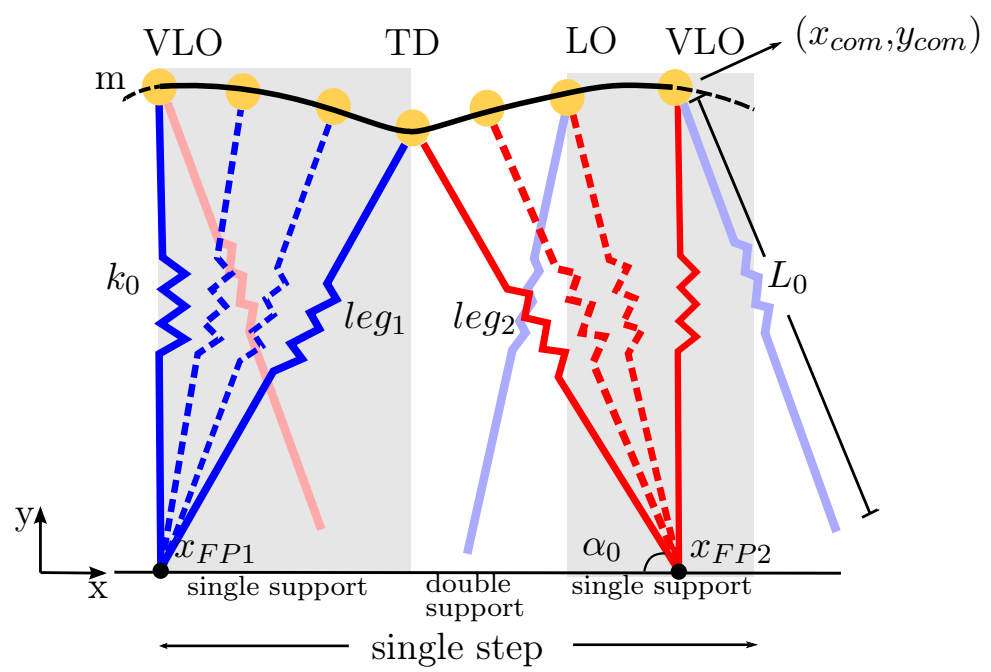

Figure 6.3: Bipedal SLIP model. A single step is defined by two single support phases and a double support phase. The transition between these phases are given by the touchdown (TD) and the lift-off (LO) events. The system parameters are the body mass $m$, the leg length $L_{0}$, the angle of attack $\alpha_{0}$, the leg stiffness $k_{0}$ and the system energy $E_{s}$. The beginning of a step happens when the stance leg is at the vertical leg orientation (VLO) event.

the CoM for this initial moment depend on the system parameter at the initial height $y_{0}$

$$
\left|\dot{\mathbf{r}}_{0}\right|^{2}=\frac{2}{m}\left(E_{s}-m g y_{0}-\frac{k}{2}\left(L_{0}-y_{0}\right)^{2}\right)
$$

The CoM velocity direction can be expressed as the angle between the horizontal and the vertical component, as follows

$$
\theta_{0}=\arctan \left(\frac{\dot{y}_{0}}{\dot{x}_{0}}\right)
$$

In this way, the initial conditions are reduced to know the initial vertical position of the CoM, $y_{0}$, and the initial velocity direction $\theta_{0}$. Depending on the values of the initial conditions and the model parameters, different kind of solutions can be obtained; the searching of their appropriate values are subject to generate periodic and stable solutions for the SLIP model. In Rummel et al. (2010), an extended study of the SLIP model was performed. Periodicity was studied using the Poincaré return maps, where the instant of the VLO event was chosen as the Poincaré section, then the system states at this point must remain fixed from one step to the next in order to guarantee periodicity. Maps of initial conditions with different parameter values were constructed to find the suitable combinations that lead to periodic solutions. Stability was also examined on the periodic solutions by calculating the eigenvalues of the Poincare maps. The work of Rummel et al. (2010) is used here as a reference for choosing the initial conditions and the parameter values to generate different SLIP solutions that satisfy periodicity and stability.

For this work, the SLIP model was implemented in Matlab. The integration method used to 
solve the model dynamics was Runge-Kutta with a variable step (ode45). Figure 6.4 shows the result of a SLIP solution for a certain combination of parameters and initial conditions. It can be observed the periodic and symmetric pattern of the vertical CoM ( $\left.y_{C o M}\right)$ with respect to the vertical axis at the moment of the VLO event, which coincides to midstance in a real gait cycle. The total vertical excursion for this solution is $1.84 \mathrm{~cm}$, which is very small if compared to the human pattern. The reason for this small CoM vertical motion is related to the value of $\alpha_{0}$. An stepper angle of attack directly influences the touch-down height $y_{T D}=L_{0} \sin \left(\alpha_{0}\right)$, which prevents the CoM to "go down" to a lower point. Furthermore, the two components of the GRF also reflects symmetry around the VLO event. The vertical GRF $\left(G R F_{y}\right)$ exhibits the m-like shape for both legs; the maximum points do not exceed the body weight $(0.78 \mathrm{BW})$, while the minimum point at VLO is equal to $0.6 B W$. The amplitude of the anterior-posterior component $\left(G R F_{x}\right)$ lies between the limits of $\pm 0.12 B W$. The mechanical power is calculated using the expression in Equation (3.2). This pattern resembles the curves presented in section 4.2.5. It shows the positive and the negative contribution of work during the stance phase of each leg, which for the SLIP solution are equal in magnitude, reflecting the energy conservation of this model. As well as it was done for the experimental data, the mechanical cost of transport, $C O T_{\text {mech }}$, was also calculated for the SLIP solutions, using the Equation (3.3). For this case $C O T_{\text {mech }}=0.144$, which reflects the small work done on the COM to produce a small vertical trajectory.

In contrast, the solution in figure 6.5 presents a bigger excursion in the vertical CoM and in the GRF components. Adding more energy to the system $\left(E_{s}=824.04 J\right)$ in combination with a flatter $\alpha_{0}$ produces more vertical motion of the CoM. For this solution, the total vertical excursion is $6.36 \mathrm{~cm}$. The GRF components also show higher and lower points than those of the previous solution. $G R F_{y}$ reaches $1.1 \mathrm{BW}$, while the minimum point corresponds to $0.48 \mathrm{BW}$. The anteriorposterior GRF values are between $\pm 0.28 \mathrm{BW}$. In consequence, the mechanical power also has a bigger amplitude. Finally, The cost of transport for this solution is equal to $C O T_{\text {mech }}=0.22$.

The SLIP solutions presented in Figures 6.4 and 6.5 are just two examples of the great variety of walking patterns that can be accomplished with this model. The compliant behavior of the legs, along with the pendular motion of the overall system produce a CoM vertical motion that resembles the human pattern. In addition, the waveforms of the GRF components are also similar to those seen in section 4.2.3. So far, the legs are assumed to have the same characteristics of length, stiffness and angle of attack. The asymmetry between legs could generate other types of solutions that can be compared to special conditions in human walking. 


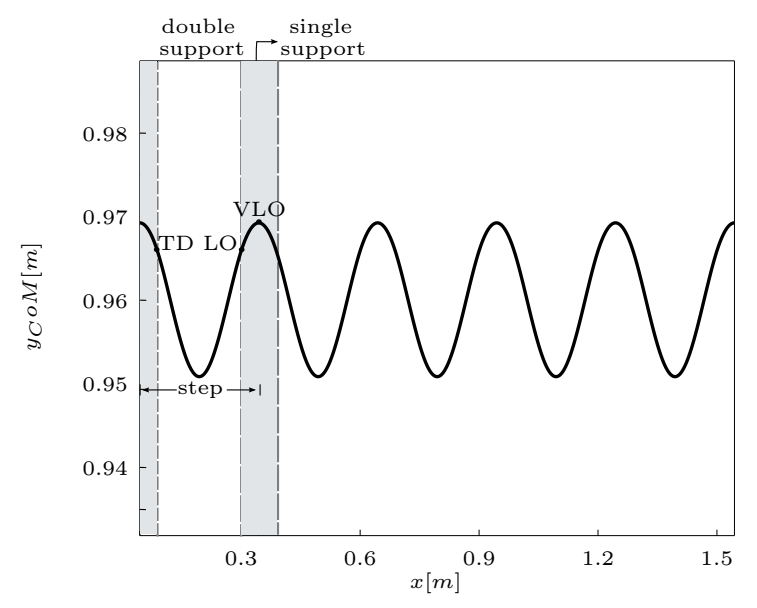

(a)

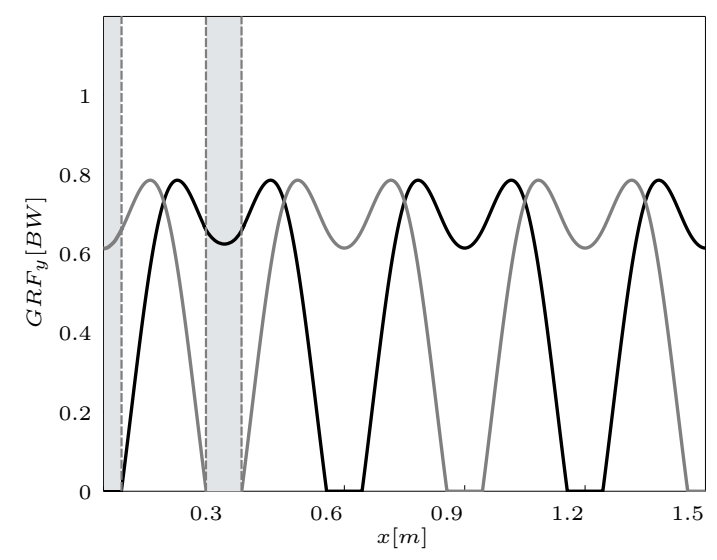

(c)

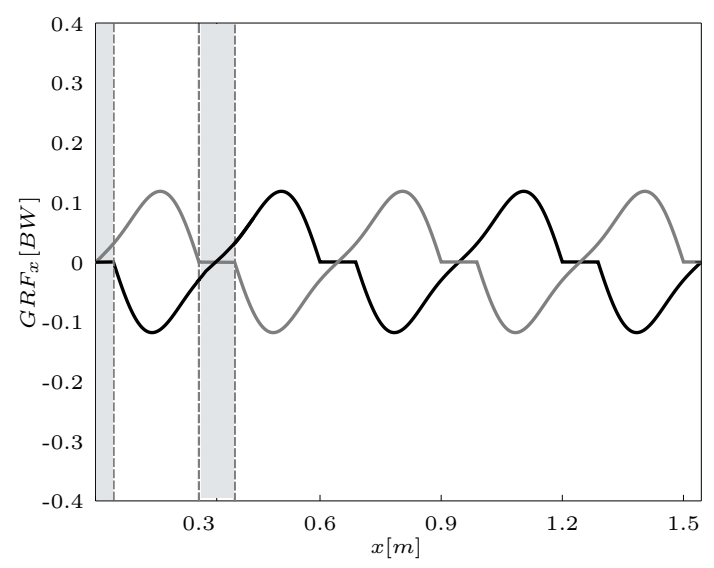

(b)

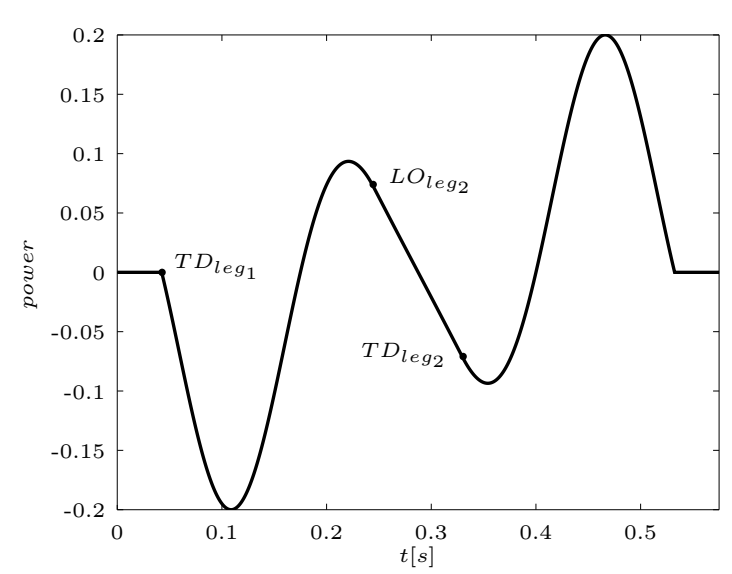

(d)

Figure 6.4: SLIP solution for $m=80 \mathrm{~kg}, L_{0}=1 \mathrm{~m}, k_{0}=15696 \mathrm{~N} / \mathrm{m}, \alpha_{0}=75^{\circ}$ and $E_{s}=$ 812.27 J. (a) The vertical trajectory of the CoM. (b) The anterior-posterior GRF and (c) the vertical GRF of both legs. (d) The mechanical power is calculated for one leg. A single step is defined between two consecutive VLO events. The double support takes place between the TD and the TO event, while the single support happens between the TO and the VLO event. 


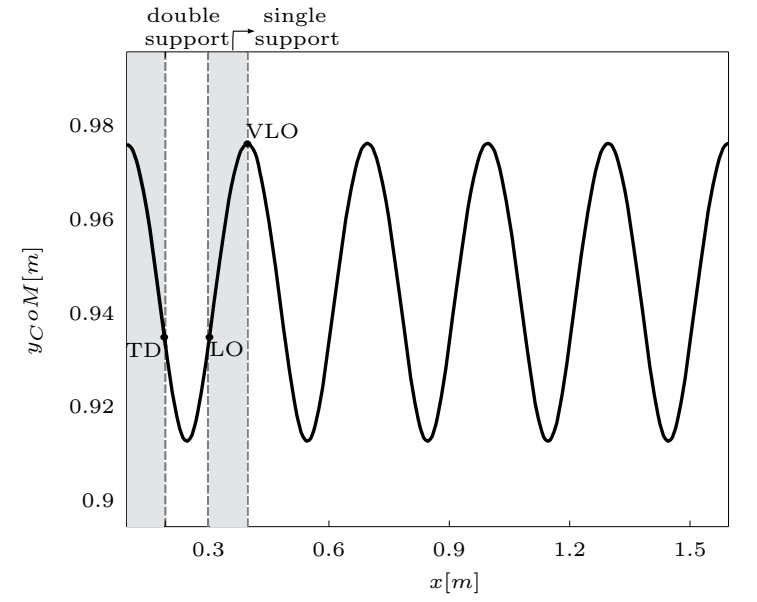

(a)

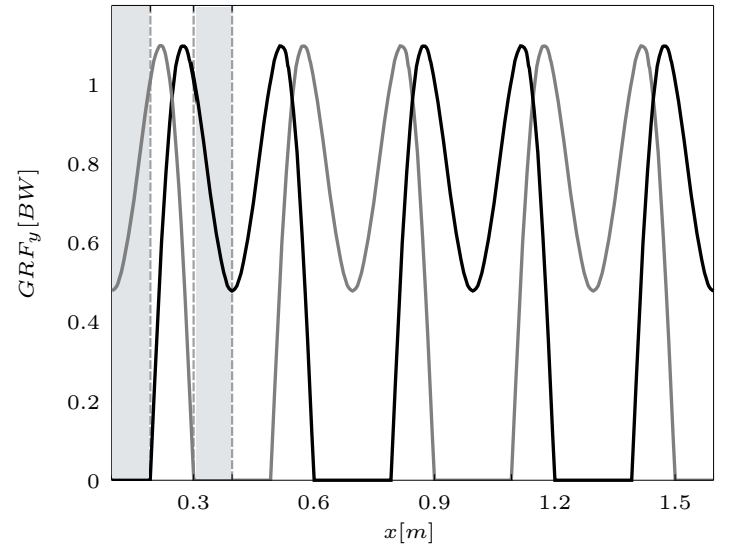

(c)

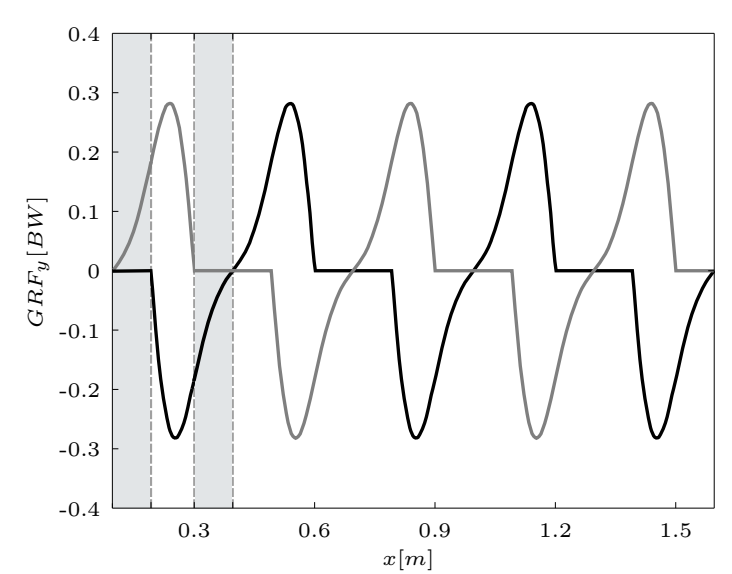

(b)

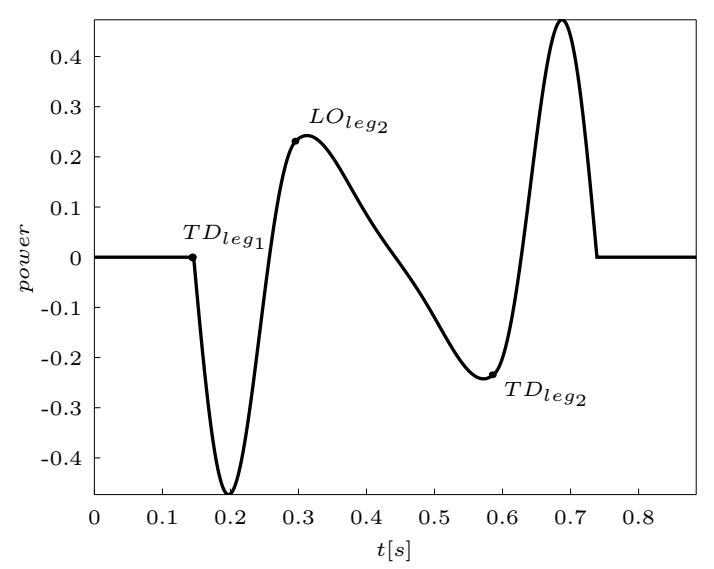

(d)

Figure 6.5: SLIP solution for $m=80 \mathrm{~kg}, L_{0}=1 \mathrm{~m}, k_{0}=15696 \mathrm{~N} / \mathrm{m}, \alpha_{0}=69^{\circ}$ and $E_{s}=$ 824.04 J. (a) The vertical trajectory of the CoM. (b) The anterior-posterior GRF and (c) the vertical GRF of both legs. (d) The mechanical power is calculated for one leg. 


\subsubsection{SLIP model with asymmetric legs}

To study the effects of the asymmetry between legs on the SLIP solutions, Merker et al. (2011) introduced the difference between the leg parameters as perturbations parameters $\varepsilon_{\alpha}, \varepsilon_{k}$ and $\varepsilon_{L}$ that affect the control parameters $\alpha_{0}, k_{0}$ and $L_{0}$. For one of the legs, the perturbations are added from the control parameters

$$
\alpha_{1}=\alpha_{0}+\varepsilon_{\alpha} \quad k_{1}=k_{0}+\varepsilon_{k} \quad L_{1}=L_{0}+\varepsilon_{L}
$$

while on the other, the perturbations are subtracted

$$
\alpha_{2}=\alpha_{0}-\varepsilon_{\alpha} \quad k_{2}=k_{0}-\varepsilon_{k} \quad L_{2}=L_{0}-\varepsilon_{L}
$$

In this way, the dynamics and stability of the SLIP model are investigated in Merker et al. (2011), given each condition of asymmetry. In this work, the formulation given in the Equations (6.5) and (6.6) is used to represent the differences between the legs. Each asymmetry condition is analyzed separately. The solutions presented here were considered successful if the corresponding simulation reached a minimum of 50 consecutive steps.

\subsubsection{Asymmetry in $\alpha_{0}$}

Figure 6.6 exhibits two solutions for the case of asymmetry in the angle of attack $\alpha_{0}$. Both solutions have a periodicity every two steps, i.e., the conditions of the first step (from VLO$O_{1}$ to $\mathrm{VLO}_{2}$ ) are repeated on the third step (from $\mathrm{VLO}_{3}$ to $\mathrm{VLO}_{4}$ ), while the second step is similar to the fourth step. For the first solution $\alpha_{0}=72^{\circ}$ and the parameter perturbation corresponds to $\varepsilon_{\alpha}=2^{\circ}$. The first step is done with leg 1 , which is the one with the stepper angle, $\alpha_{1}=74^{\circ}$. This step presents a smaller vertical excursion of the CoM $(2.27 \mathrm{~cm})$, if compared to the one from the second leg, with $\alpha_{2}=70^{\circ}$ and a vertical trajectory of $4.54 \mathrm{~cm}$. The asymmetry between the legs are also evident in the duration of the single and double support periods. For the step performed with leg 1 , the single support lasts $0.06 s$ and the double support time corresponds to $0.18 s$. For the next step, the single support time is $0.14 \mathrm{~s}$, while the double support lasts $0.16 \mathrm{~s}$. The two components of the GRF also reflect differences on the maximum and minimum values. Both components have a vertical asymmetry around VLO.

The angle of attack for the second solution (Figure 6.6, row B) is equal to $\alpha_{0}=73.8^{\circ}$. The perturbation value is equal to first solution, as well as the rest of the system parameters. The particular characteristic of this solution is that the steps do not begin at the highest point of the vertical CoM, in other words, the VLO events do not correspond to the highest point. For the case of leg 1 being the leading leg, the touch-down height is above this point; the opposite happens for the step initiated by leg 2 . This makes the single supports of the same step have different durations. Moreover, the vertical asymmetries of the GRF components are also more pronounced than that of the first solution. 


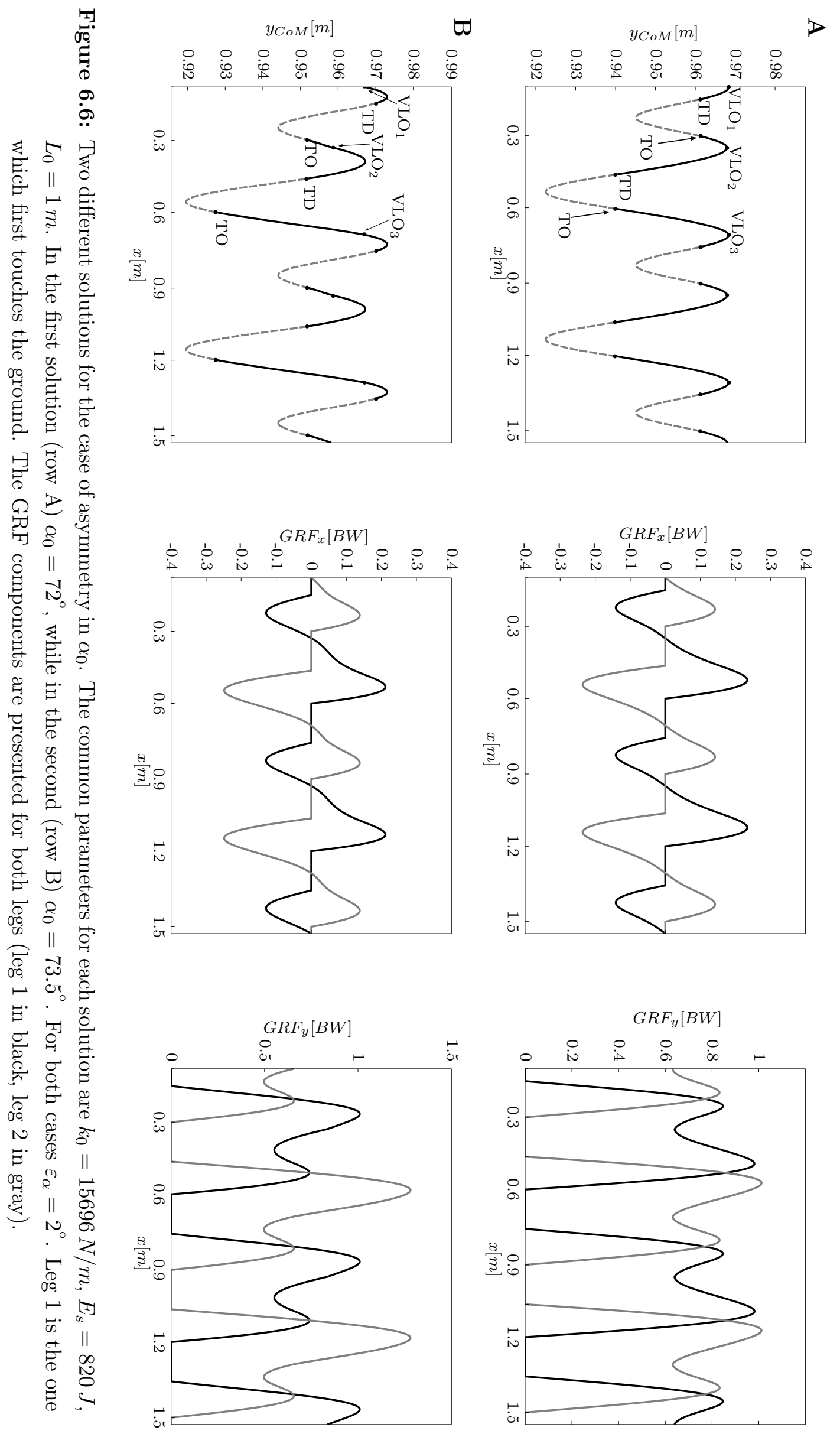




\subsubsection{Asymmetry in $k_{0}$}

The difference on the leg stiffness of both legs are illustrated in the two solutions presented in Figure 6.7. For both SLIP solutions, $k_{0}=15696 \mathrm{~N} / \mathrm{m}$ and $\varepsilon_{k}=2000 \mathrm{~N} / \mathrm{m}$. The difference on the system parameters of each case lies on the angle of attack. The first solution (Figure 6.7, row A) shows a big difference between the VLO points of each step. The first step has a vertical excursion of $1.6 \mathrm{~cm}$, while the corresponding value to the second step is $4 \mathrm{~cm}$. Leg 1 is stiffer than leg 2 , which means that at the moment of touch-down, leg 1 touches the ground with a high stiffness, preventing the CoM to attain a very low position. On the contrary, when leg 2 lifts off the ground, the CoM can go higher and the VLO event for this leg is above than that of the contralateral side. The anterior-posterior component of the GRF has practically the same magnitude for the anterior and the posterior part in each leg. For the case of $G R F_{y}$, the pattern of leg 1 is vertically symmetric around VLO, while its counterpart in leg 2 does not exhibit two well-defined peaks.

The same value of $k_{0}$ and the parameter perturbation is used for the second solution (row $\mathrm{B}$ ), but with a difference of a stepper angle of attack $\left(\alpha_{0}=73^{\circ}\right)$. In general, this solution shows higher amplitudes in the vertical CoM and in the GRF components, if compared to the first solution. Additionally, there are also differences in the vertical trajectory of the CoM during each leg. For the first step the vertical excursion is $7.5 \mathrm{~cm}$, while for the second step this value corresponds to $8.4 \mathrm{~cm}$. However, the first solution still shows a higher asymmetry with respect to the vertical CoM. It seems that the effect of the asymmetry in $k_{0}$ is compensated somehow with a stepper angle of attack in both legs. The $G R F_{x}$ components for both legs have the same behavior of the first solution, but with greater values. The vertical GRF, on the contrary, is asymmetric around VLO. The peaks for leg 1 achieved values of $1.54 B W$ and $1.23 B W$, while for leg 2 these values are equal to $1.19 \mathrm{BW}$ and $0.88 \mathrm{BW}$.

\subsubsection{Asymmetry in $L_{0}$}

The last case of parameter asymmetry is the difference in the leg length. According to the stability analysis performed in Merker et al. (2011), the stable solutions exists up to $\varepsilon_{L}=9 \mathrm{~mm}$. Using this reference, the solutions in Figure 6.8 are obtained for $\varepsilon_{L}=7 \mathrm{~mm}$ for both cases. The angle of attack are different for each solution, while the rest of the parameters are maintained equal. Like the previous solutions, the differences in the vertical CoM trajectory are visible from one step to the next. For the first solution (Figure 6.8, row A), the vertical excursion is equal to $2.6 \mathrm{~cm}$ for the step with leg 1 , whereas for the second leg this values is $5.3 \mathrm{~cm}$. The second solution has a bigger range of motion in the vertical sense, in which the excursion values of the CoM are $4.4 \mathrm{~cm}$ and $6.6 \mathrm{~cm}$ for the step of leg 1 and the one performed with leg 2, respectively. The waveforms of the GRF are similar to those from previous solutions. In both cases the vertical GRF is asymmetric around the VLO event, with a more extreme behavior for the second solution. In both solutions, the anterior-posterior components have smaller values for the second leg in comparison with those from leg 1. 


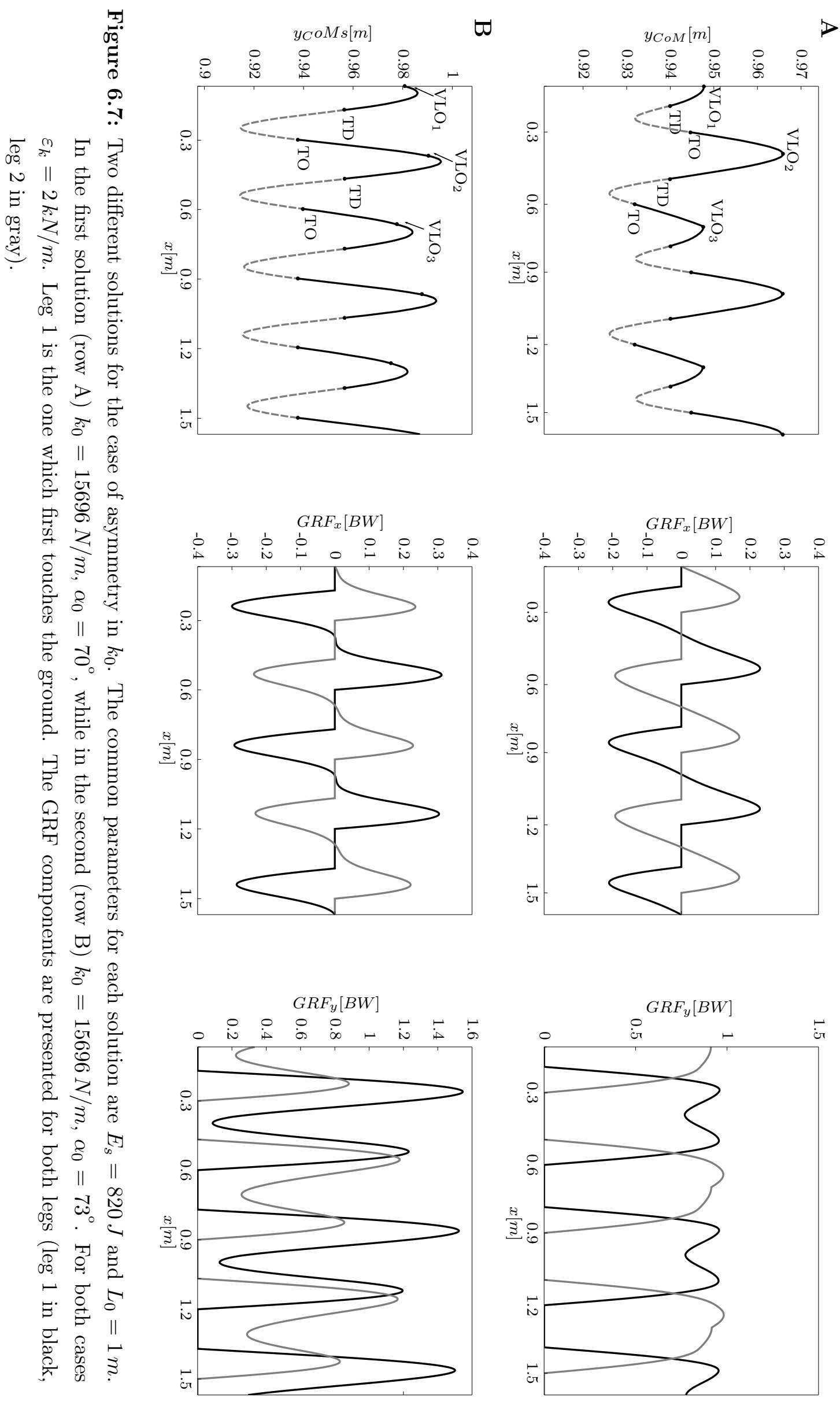




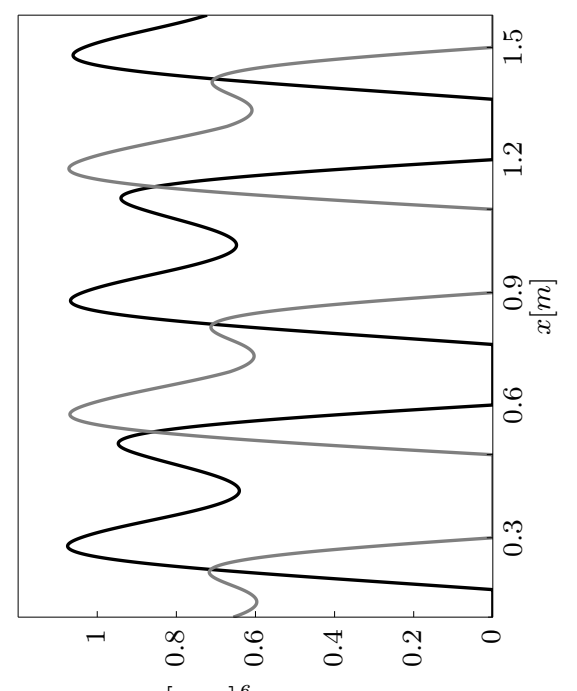

$[\mathrm{Mg}]^{n}$ НЧ⿰

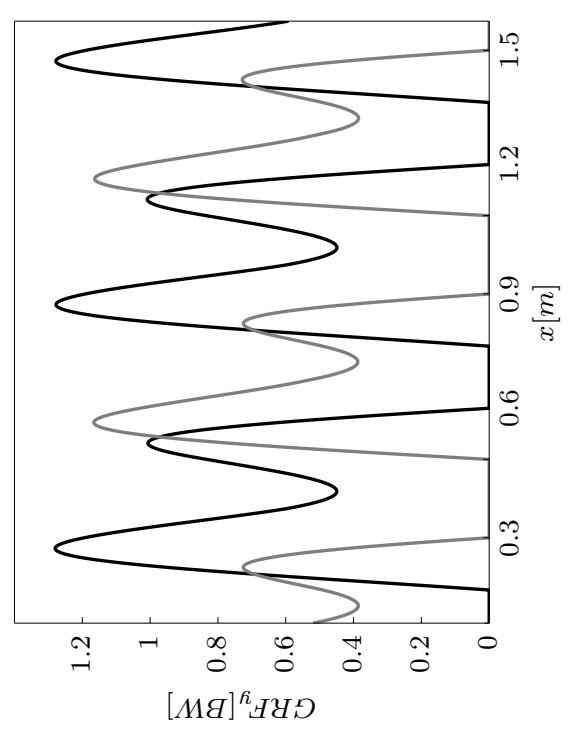

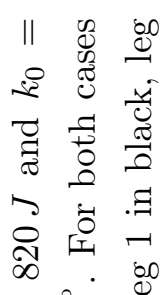

1 is

xi

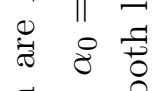

है

에 11 d

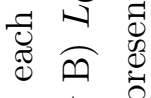

它
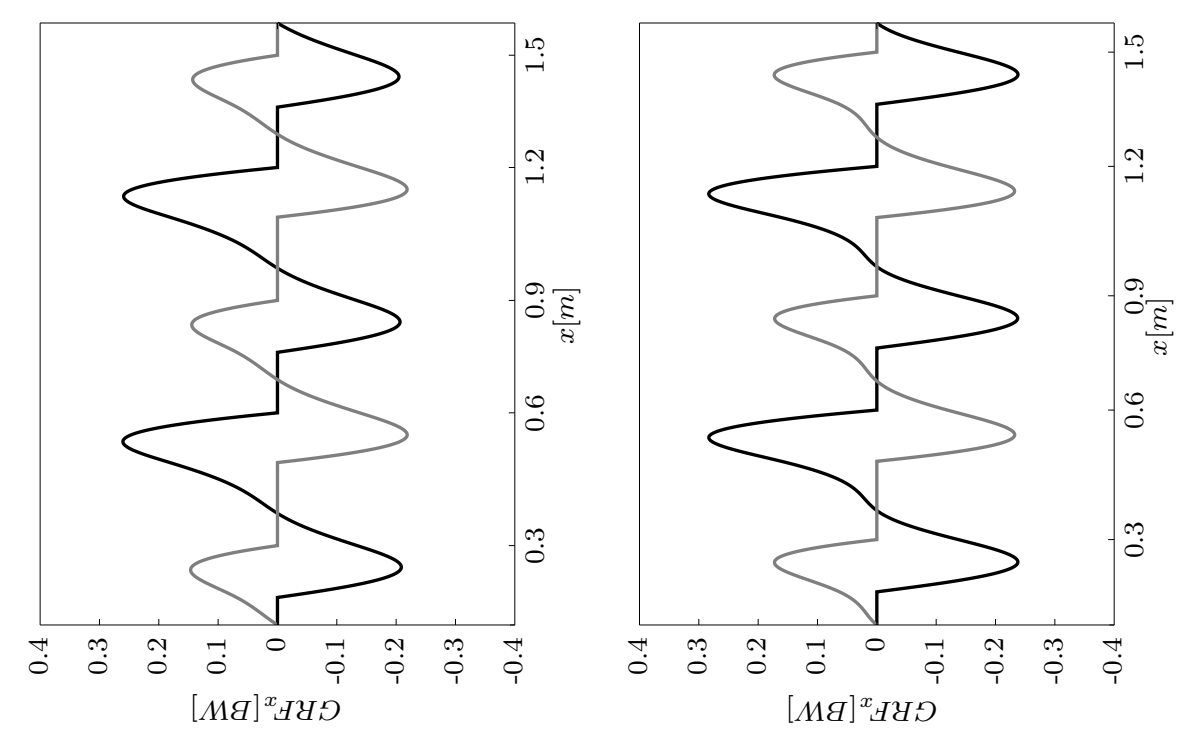

过

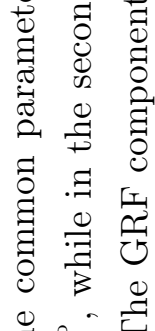

E 0

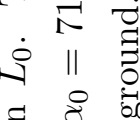

.$\nexists 8$ के

ह ह

द्व 11 है

공 용

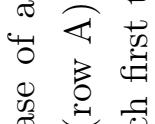
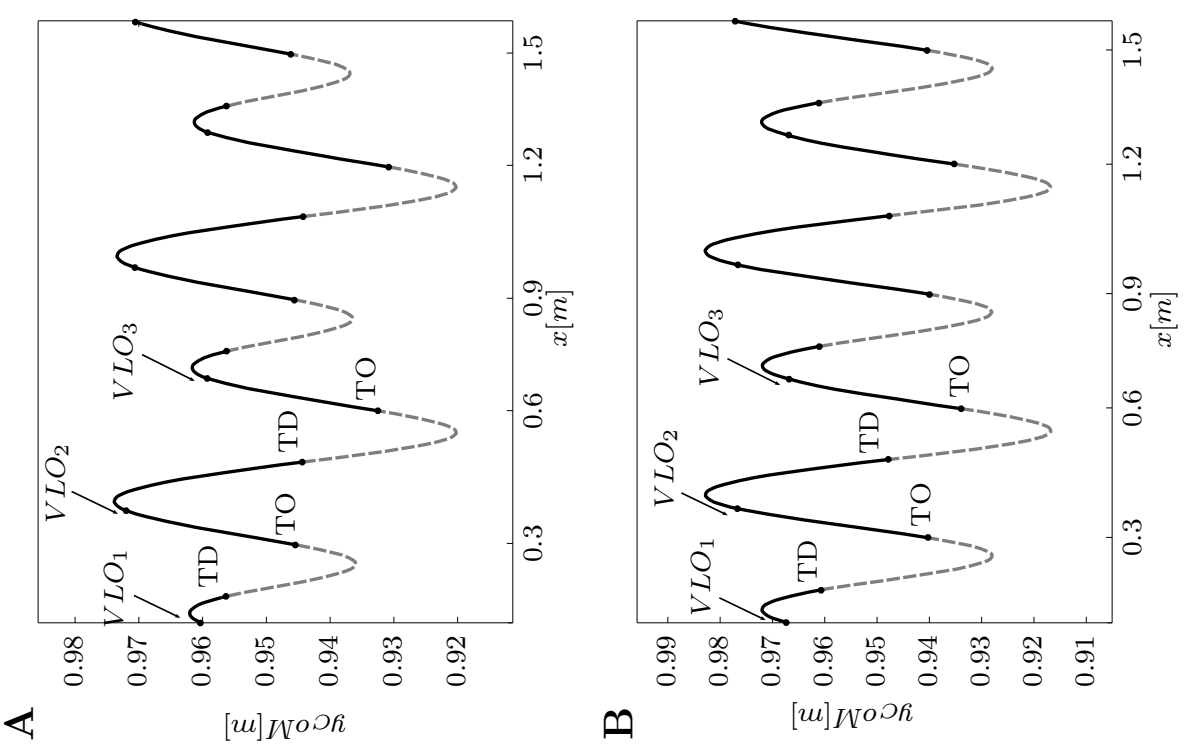

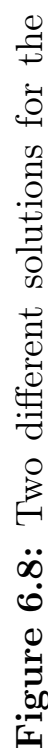

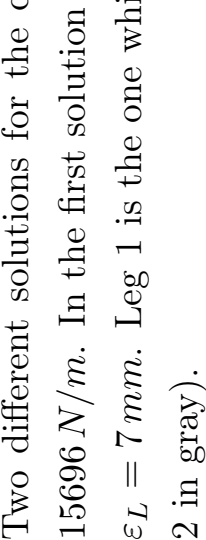


Table 6.1: Parameters and initial conditions extracted from each subject.

\begin{tabular}{|c|c|c|c|c|c|c|c|c|}
\hline \multirow{2}{*}{ Parameter } & \multicolumn{2}{|c|}{ Ref. } & \multicolumn{2}{|c|}{ Subj. B } & \multicolumn{2}{|c|}{ Subj. C } & \multicolumn{2}{|c|}{ Subj. D } \\
\hline & Leg 1 & Leg 2 & Leg 1 & $\operatorname{Leg} 2^{\star}$ & Leg 1 & $\operatorname{Leg} 2^{\star}$ & $\operatorname{Leg} 1^{\star}$ & Leg 2 \\
\hline$L_{0}[m]$ & 0.989 & 0.982 & 0.983 & 0.996 & 1.072 & 1.091 & 1.082 & 1.046 \\
\hline$k_{0}[k N / m]$ & 16.424 & 12.924 & 34.703 & 24.170 & 151.49 & 19.507 & 11.827 & 19.316 \\
\hline$\alpha_{0}\left[^{\circ}\right]$ & 68.7 & 73 & 73 & 76 & 71 & 75 & 76.5 & 75.5 \\
\hline$m[k g]$ & \multicolumn{2}{|c|}{73} & \multicolumn{2}{|c|}{80} & \multicolumn{2}{|c|}{72} & \multicolumn{2}{|c|}{82.5} \\
\hline \multicolumn{9}{|c|}{ Initial conditions } \\
\hline$y_{V L O}$ & \multicolumn{2}{|c|}{0.982} & \multicolumn{2}{|c|}{0.97} & \multicolumn{2}{|c|}{1.087} & \multicolumn{2}{|c|}{1.029} \\
\hline$\dot{x}_{V L O}$ & \multicolumn{2}{|c|}{1.002} & \multicolumn{2}{|c|}{1.025} & \multicolumn{2}{|c|}{0.916} & \multicolumn{2}{|c|}{1.136} \\
\hline$\dot{y}_{V L O}$ & \multicolumn{2}{|c|}{0} & \multicolumn{2}{|c|}{-0.191} & \multicolumn{2}{|c|}{0} & \multicolumn{2}{|c|}{0.203} \\
\hline
\end{tabular}

( $\star$ Amputee leg.

\subsubsection{The SLIP model compared to experimental data}

The simulation results presented in section 6.2.1 show the capacity of the SLIP model to represent basic characteristics of human walking, like the CoM motion and the GRF patterns, even in situations where the legs characteristics are different. However, it would be interesting to compare the SLIP solutions to real data extracted from subjects with symmetric and asymmetric characteristics.

Table 6.1 presents the SLIP parameters extracted from the anthropometric characteristics of the reference subject A and the three amputee subjects B C and D. For the case of the leg length $L_{0}$, the definition of a virtual leg is necessary due to the difference of the SLIP leg and the real human leg. The virtual leg is defined as the distance between the marker placed on the sacral vertebrae and the marker located on the calcaneus bone of each foot. $L_{0}$ is measured at initial contact, where the leg is more relaxed. The angle of attack $\alpha_{0}$ is calculated as the angle between the virtual leg and the surface at initial contact. Finally, the leg stiffness is estimated as the ratio between the maximum value of the vertical GRF and the maximal leg compression during stance (Geyer, 2005)

$$
k_{0}=\frac{\max \left(G R F_{y}\right)}{\max (\Delta L)}
$$

$\max (\Delta L)$ is calculated as the difference between $L_{0}$ and the virtual leg length at midstance, where the leg is maximally compressed. Regarding the initial conditions, the SLIP step begins at midstance or VLO event, thus the initial state of the CoM $\left[\begin{array}{llll}x_{V L O} & y_{V L O} & \dot{x}_{V L O} & \dot{y}_{V L O}\end{array}\right]^{T}$ is extracted from this moment in the experimental data. For simplicity, $x_{V L O}=0$ at the beginning of the simulation, so the initial conditions are reduced to $\left[\begin{array}{lll}y_{V L O} & \dot{x}_{V L O} & \dot{y}_{V L O}\end{array}\right]^{T}$ (see Table 6.1). 


\subsubsection{Symmetric solutions}

The first case corresponds to the reference subject, who exhibited an almost symmetric behavior from the gait analysis experiments and the limb symmetry calculations carried out in chapters 4 and 5. The first simulation assumed symmetry in legs, thus the system parameters are extracted only using the characteristics from leg 1 . The simulation result, along with real data from this subject, are exhibited in Figure 6.9. In order to make a comparison from the real data and the SLIP results, the vertical CoM is normalized to a gait cycle, while the GRF components and the mechanical power are normalized to the stance phase duration. For the vertical CoM, the mean has been extracted from both curves to facilitate the comparison of the vertical excursion. The GRF components are normalized to the body weight (BW). The power is dimensionless, like the case of the calculations carried out in section 4.2.5.

From a simple visual inspection it can be observed that there are differences between the SLIP simulation and the real data. Using the cross-correlation coefficient $S_{M}$ (see section 5.2), a quantitative evaluation of the difference in magnitude between waveforms can be made. The $S_{M}$ value is above 0.9 for the vertical CoM and the GRF components, whereas the mechanical power shows an index value of $S_{M}=0.793$. Besides the differences in magnitude, the single support and the double support durations of both cases are distinct. For the SLIP walking solution, the double support and the single support periods are equal for each step, since this solution is symmetric. Specifically, the double support duration is equal to $18.11 \% G C$, while the single support duration corresponds to $31.88 \%$ GC. For the case of the reference subject, there is a slight difference in these periods duration on each step. The first double support lasts $11.68 \%$ GC and the subsequent single support duration is $34.71 \% G C$. In the second step the double support takes place during $13.65 \%$ GC, while the single support lasts $39.86 \%$ GC. Summarizing, the SLIP solution has longer double supports and shorter single supports compared to the real case. The duration of the gait events in the SLIP model depends on the transition conditions between the stance and the swing phase. A premature TD event, compared to the real TD, can be the cause of a shorter duration of the single support period. Nevertheless, it seems that the small differences in the leg characteristics of the reference subject are more related to the discrepancies between the SLIP solution and the experimental data.

\subsubsection{Asymmetric solutions}

The SLIP model with asymmetric legs is used as an attempt to obtain a better approximation of the real data, considering that the legs are not exactly the same. For the reference subject, two solutions were obtained, one considering solely asymmetry in $\alpha_{0}$ and the second taking into account asymmetry in $k_{0}$. To facilitate the comparison between each asymmetric solution and the one obtained for the symmetric case (Figure 6.9), Table 6.2 exhibits the result of the $S_{M}$ index for $y_{C o M}, G R F_{x}, G R F_{y}$ and the mechanical power.

In order to obtain periodic and stable solutions (more than 50 successful consecutive steps), the original initial condition for this subject (see Table 4.1) had to be modified to meet both 


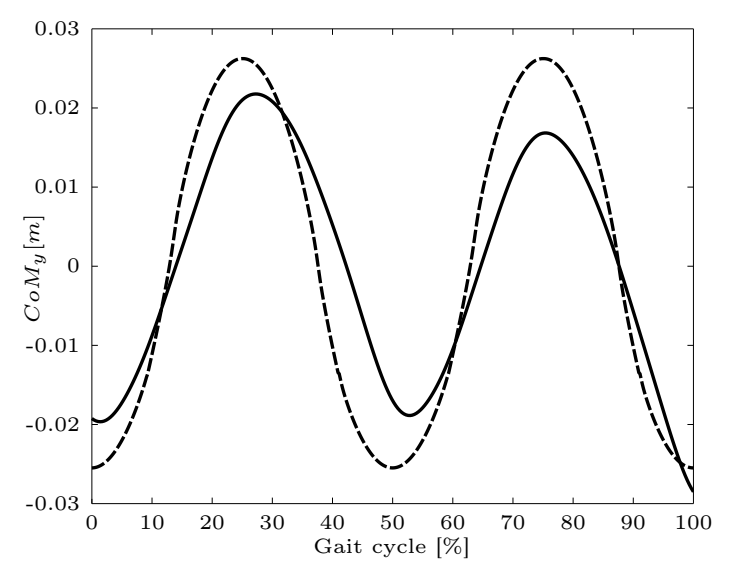

(a)

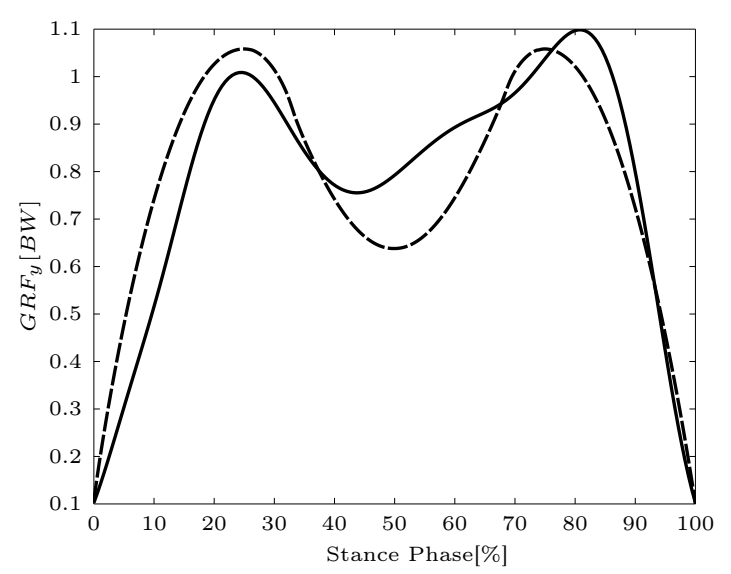

(c)

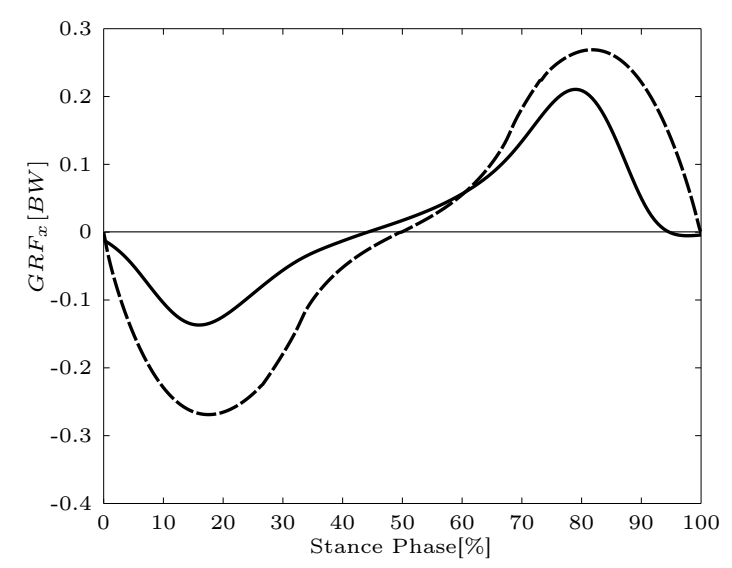

(b)

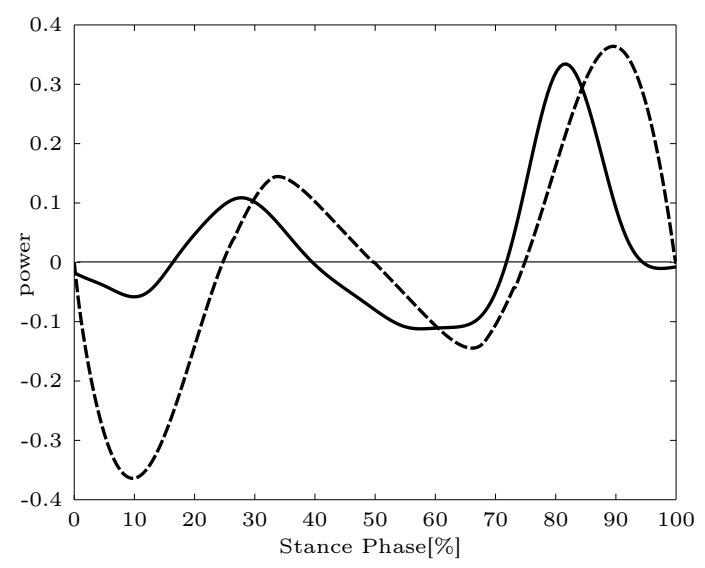

(d)

Figure 6.9: The SLIP solution (dotted lines) and the real data waveforms (solid lines) from the reference subject. (a) The vertical CoM. (b) The anterior-posterior GRF. (c) The vertical GRF and (d) the mechanical power. The cross-correlation coefficient for each pair of curves are (a) 0.943, (b) 0.960, (c) 0.901 and (d) 0.793 .

Table 6.2: $S_{M}$ values for the different walking solutions for the reference subject case.

\begin{tabular}{cccc}
\hline Parameter & Symm Sol. & Asymm Sol. A & Asymm Sol. B \\
\hline$y_{C o M}$ & 0.943 & 0.942 & 0.976 \\
\hline$G R F_{x}$ & 0.960 & 0.966 & 0.965 \\
\hline$G R F_{y}$ & 0.901 & 0.819 & 0.937 \\
\hline Power & 0.793 & 0.847 & 0.795 \\
\hline
\end{tabular}


conditions. The initial conditions at VLO (values for $y_{V L O}$ and $\theta_{V L O}$ ) for the case of asymmetry in $\alpha_{0}$ (solution A) are reduced in range as the difference between $\alpha_{1}$ and $\alpha_{2}$ gets bigger (Merker et al., 2011). Since the difference on the angle of attack between the legs of the reference subject is almost $5^{\circ}$, a periodic and stable solution is achieved increasing the initial velocity of the system to the value of $\dot{x}_{V L O}=1.15 \mathrm{~m} / \mathrm{s}$. The leg length parameter for both legs is practically the same, while the leg stiffness is set to the value of $k_{1}$. The B solution, with asymmetry in $k_{0}$, also has a few modifications on the initial conditions, specifically in $y_{V L O}$, which is reduced to $0.964 \mathrm{~m}$. The angle of attack used for this simulation is $\alpha_{1}$.

Solution A (see Figure 6.10) does not represent major improvements in the resultant waveforms compared to the symmetric solution; the $S_{M}$ values reflect a significant superiority only in the mechanical power. Regarding solution $\mathrm{B}$, the $S_{M}$ values show differences in all the gait variables, with the major index value for the vertical CoM, followed by $G R F_{y}$. Looking at the real data and the overlapped SLIP curves for this solution, even with differences in magnitude, the simulated and the real waveforms are more synchronized for the case of $y_{C o M}$ and $G R F_{y}$, which may explain the values of $S_{M}$ for these variables. In all three cases the mechanical power has the worst approximation. The initial negative work, which is a consequence of the initial contact, is overestimated in the SLIP solution. Due to the conservation of energy of the system, the positive and the negative contribution in the total mechanical power for the stance leg are equal in all the obtained solutions, even for the case of asymmetry.

For the case of the amputee group, the only periodic and stable solution based on the anthropometric characteristics of the three subjects was obtained for subject B. Like in the case of the reference subject, the initial conditions had to be altered. The seek for the appropriate initial conditions for specific parameter values is based on previous studies (Geyer, 2005; Rummel et al., 2010; Merker et al., 2011). Any of them considered values greater than $1 \mathrm{~m}$ for the leg length, or body mass superior to $80 \mathrm{~kg}$, which is the case of subject C and D (see table 6.1). This makes the task of adjusting the initial conditions in a coherent way to generate SLIP solutions for these two subjects difficult. Even though some attempts were carried out in order to generate possible solutions, none of them were periodic and stable.

In Figure 6.11 the solution for subject B is presented. As mentioned before, the initial conditions had to be modified. Specifically, the initial velocity in both direction were changed to $\dot{x}_{V L O}=$ $1.5 \mathrm{~m} / \mathrm{s}$ and $\dot{y}_{V L O}=0$, so the CoM velocity at VLO was completely horizontally oriented. The initial height was remained unchanged, as well as the parameters from both legs. For this solution all the asymmetries were introduced at the same time. The highest cross-correlation coefficient value corresponds to the anterior-posterior GRF, while the poorest value is from the vertical CoM (see the values in Figure 6.11). The initial peak of the vertical GRF is almost absent, which might causes the strange result of the mechanical power in this same instant. Although the vertical CoM presents a clear time difference with its real counterpart, it reproduces the asymmetry in amplitude between the steps. This time difference is related to the increase in the initial CoM velocity. 


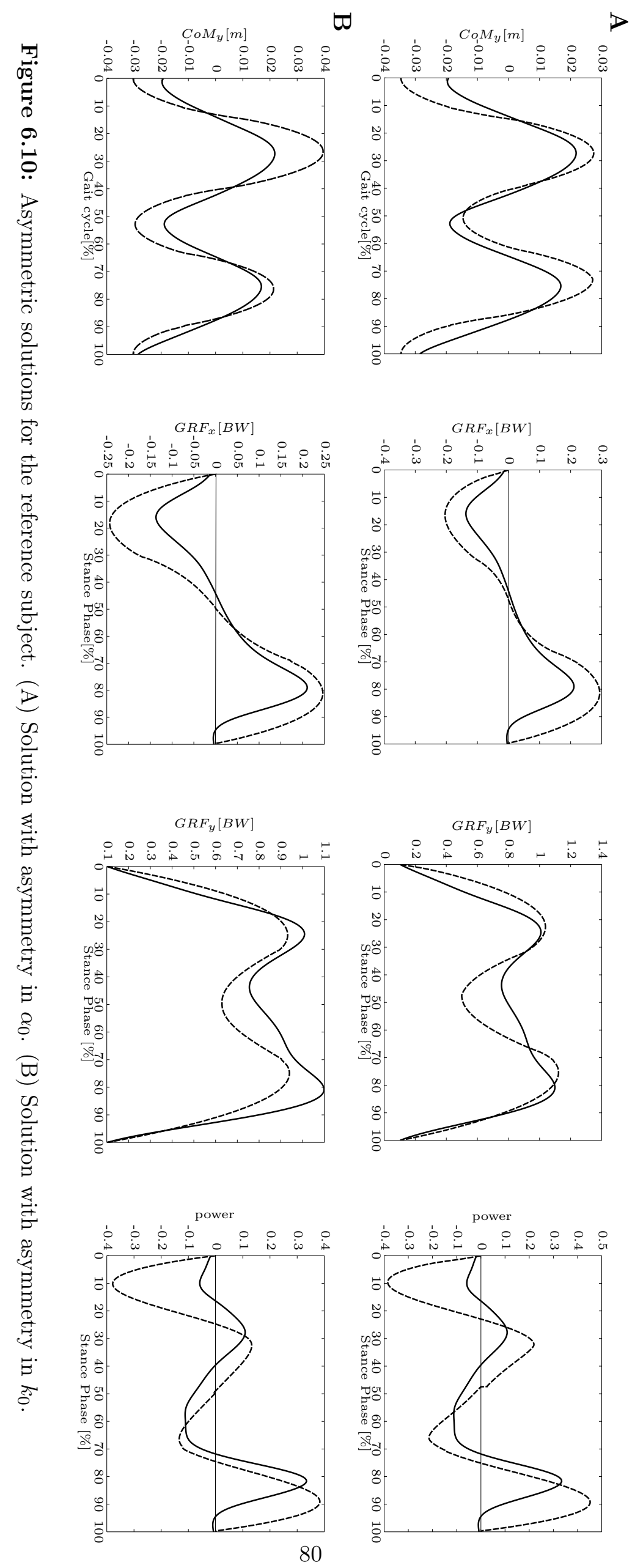




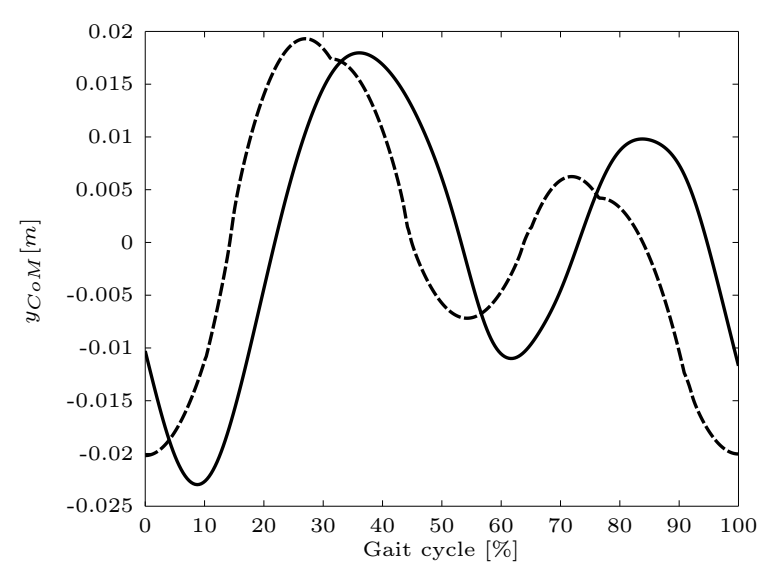

(a)

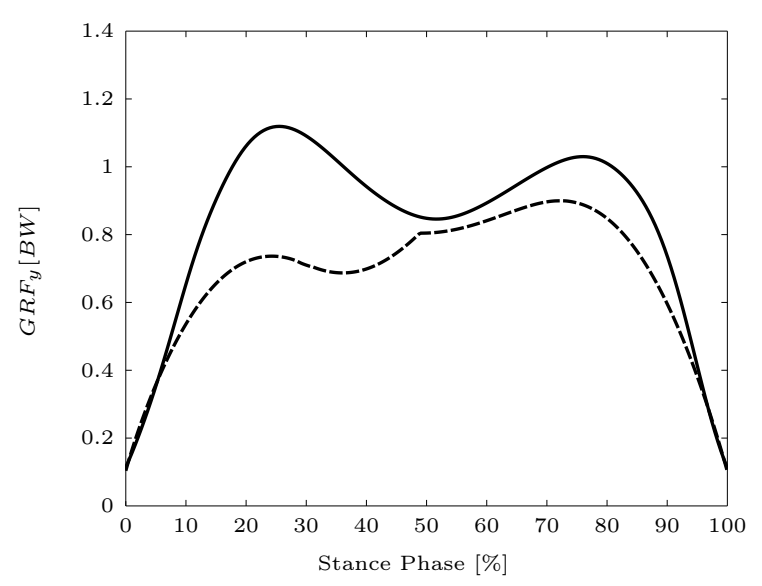

(c)

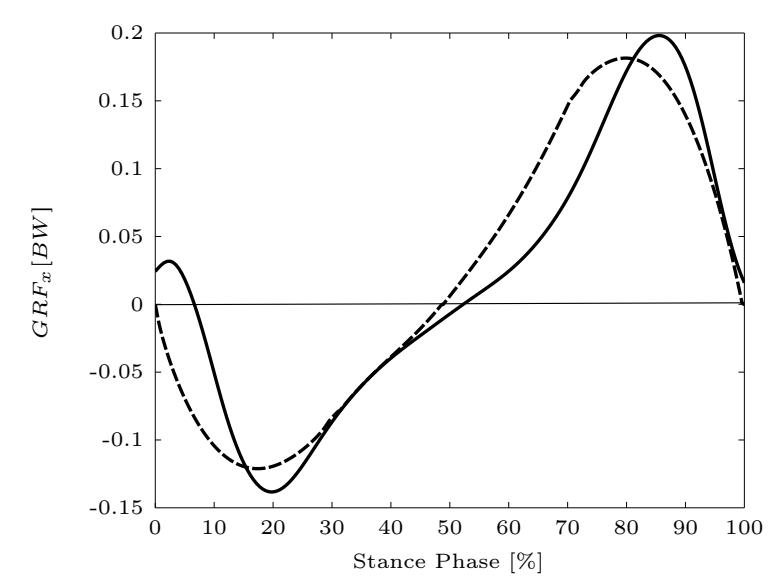

(b)

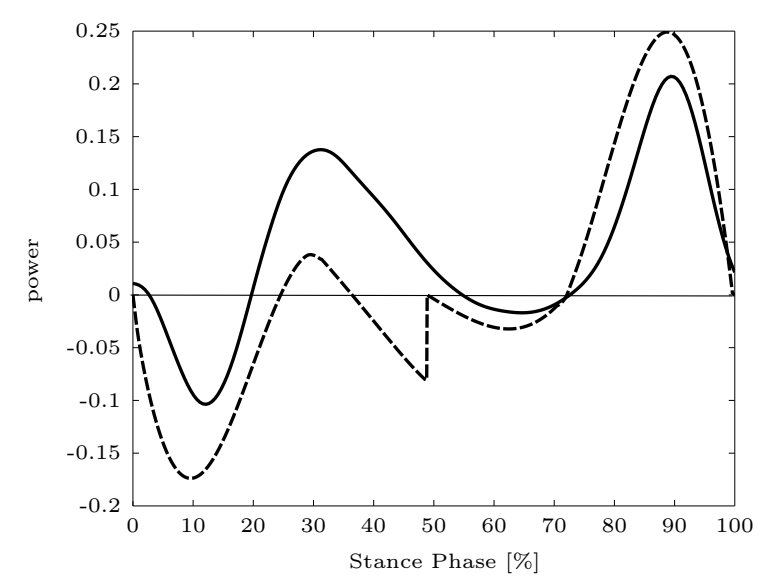

(d)

Figure 6.11: The SLIP solution (dotted lines) overlapped with the real data waveforms (solid lines) from subject B. (a) The vertical CoM. (b) The anterior-posterior GRF. (c) The vertical GRF and (d) the mechanical power. The cross-correlation coefficient for each pair of curves are (a) 0.814, (b) 0.976, (c) 0.889 and (d) 0.834 . 


\subsection{LEG STIFFNESS ESTIMATION}

Most of the SLIP parameter have a real physical meaning and can be extracted in almost a direct way, except for the leg stiffness. The value of $k_{0}$ has been determined in different ways, besides the expression given in (6.7). The assumption of a linear elasticity is used in Lipfert et al. (2012) in order to fit force-length curves extracted from real legs in a linear least squared sense, and from this the leg stiffness can be extracted. The other methods mainly differ on the definition of the leg compression $\triangle L$, which may lead to different stiffness values. In the work of Blum et al. (2009), five different methods to calculate leg stiffness in different conditions of running were compared. The comparison was made using predictions of the SLIP model based on the estimated $k_{0}$ from each method. The SLIP solutions exhibited differences, showing the discrepancies between methods. On the other hand, the definition of the leg stiffness comes from the concept of the SLIP model, then it seems reasonable that the estimation of this parameter should be based on the SLIP model itself. This section presents the proposal of an alternative leg stiffness estimation method using an extended Kalman filter.

\subsubsection{The EKF-based approach to estimate leg stiffness}

The Kalman filter $(\mathrm{KF})$ is an optimal solution for the estimation of states in a linear stochastic system, where its dynamics can be represented by models which describe its process and measurements (Simon, 2006). The Extended Kalman Filter (EKF) is an extension of the original KF for nonlinear systems. Besides estimating the system states, these filtering techniques could also be applied for parameter estimation, where the unknown parameter is considered as an additional state to be estimated.

Formulating the SLIP equations (6.1) and (6.2) using the state-space representation, we have

$$
\begin{aligned}
x_{i} & =\mathbf{F}_{i-1}^{\theta} x_{i-1}+w_{i-1} \\
y_{i} & =\mathbf{H}_{i} x_{i}+v_{i}
\end{aligned}
$$

Equation (6.8) represents the process function. The state vector is defined as

$$
x=\left[\begin{array}{lllll}
x_{C o M} & y_{C o M} & \dot{x}_{C o M} & \dot{y}_{C o M} & k_{0}
\end{array}\right]^{T}
$$

where the last state corresponds to $k_{0}$, the parameter to be estimated. For this formulation, measurements of the CoM trajectory and its velocities are considered available, thereby

$$
y=\left[\begin{array}{llll}
x_{C o M} & y_{C o M} & \dot{x}_{C o M} & \dot{y}_{C o M}
\end{array}\right]^{T}
$$

Process and measurements noises, $w$ and $v$, are considered zero-mean white noise with covariances $\mathbf{Q}$ and $\mathbf{R}$, respectively. Since the SLIP dynamics change during each phase, the definition of the process function matrix also changes. The superscript $\theta$ in the $\mathbf{F}$ matrix denotes this behavior, 
where $\theta$ can takes values of 1 or 2 , depending if the current phase of the system is the double or the single support, respectively. The transition events that drive the system to each phase are determined by the foot contact vector $\mathbf{r}_{F P}$, which is considered to be known.

To verify the convergence of the filter, some simulations were performed. Three walking solutions with three different values of $k_{0}$ were generated. The stiffness values, as well as the other system parameters, were chosen in order to have periodic stable solutions. For the three proposed solutions the body mass was set to $80 \mathrm{~kg}$ and the leg length was adjusted to $L_{0}=1 \mathrm{~m}$. The chosen $k_{0}$ values correspond to $k_{1}=11.8 \mathrm{kN} / \mathrm{m}, k_{2}=15.7 \mathrm{kN} / \mathrm{m}, k_{3}=23.5 \mathrm{kN} / \mathrm{m}$. The SLIP solutions provide the measurements to the filter, as well as the position of the foot for each simulated step. The initial estimate of $k_{0}$ was intentionally set at a high value, $k_{0}=28 \mathrm{kN} / \mathrm{m}$, in all the three walking scenarios.

Figure 6.12a shows one of the SLIP solutions, while in Figure $6.12 \mathrm{~b}$ a single step for each solution is presented. As $k_{0}$ goes higher, the vertical oscillations of the CoM are smaller, and consequently, the step period is shorter. The results of the stiffness estimation for the three walking solutions can be seen in figure $6.12 \mathrm{c}$. For the three cases, the $k_{0}$ estimation solutions converge to a value close to the corresponding true stiffness. The estimation error evolution is shown in figure $6.12 \mathrm{~d}$. The RMS errors for each estimation are $e_{1}=0.47 \mathrm{kN} / \mathrm{m}, e_{2}=0.06 \mathrm{kN} / \mathrm{m}$ and $e_{3}=1.157 \mathrm{kN} / \mathrm{m}$.

\subsection{Discussion}

The implementation of the SLIP model demonstrated its usefulness to represent the basic characteristics of human walking. The original formulation produces different walking patterns depending on the initial conditions and the systems parameters values. From the initial solutions shown in Figure 6.4 and 6.5, it is possible to observe the dependency that exists between the system parameters in order to produce particular walking patterns. Specifically, for the case of these two solutions, if the leg stiffness and the leg length are unaltered, changes in the energy system and the angle of attack will impact on the oscillations of the vertical CoM and on the values of the GRF components. Bigger oscillations are obtained for higher values of $E_{s}$ and $\alpha_{0}$, if the rest of the parameters are maintained unchanged. This does not mean that the same effect cannot be obtained by other combinations of parameters and initial conditions. One of the appealing characteristics of the SLIP model is its flexibility in terms of the parameter choices to obtain different kinds of walking solutions.

The introduction of asymmetries in the leg characteristics also demonstrated the possibility of representing this condition using the SLIP model. The equations of motion did not need to be modified, so the implementation was straight forward. The three asymmetry scenarios already proposed in Merker et al. (2011) was the reference point for the simulations carried out in section 6.2.1. The solutions obtained by the three types of asymmetry generated differences among steps, not only in the amplitude of the vertical CoM or the GRF components, but also in the duration of the single support and double support periods, like occur in an amputee gait.

The simulation results for symmetric and asymmetric legs encouraged us to compare the ex- 


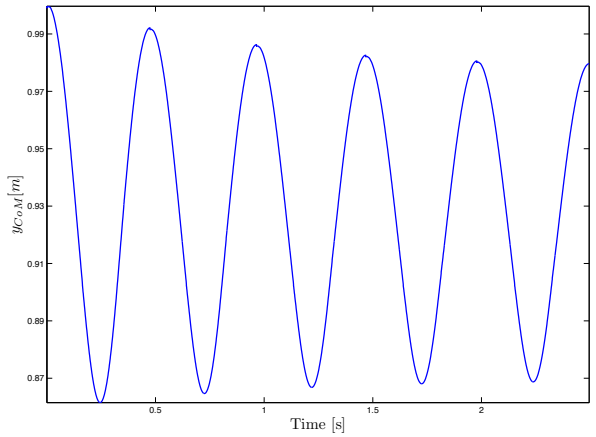

(a)

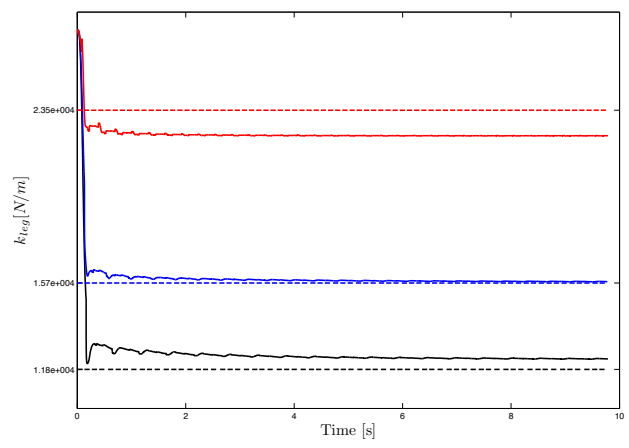

(c)

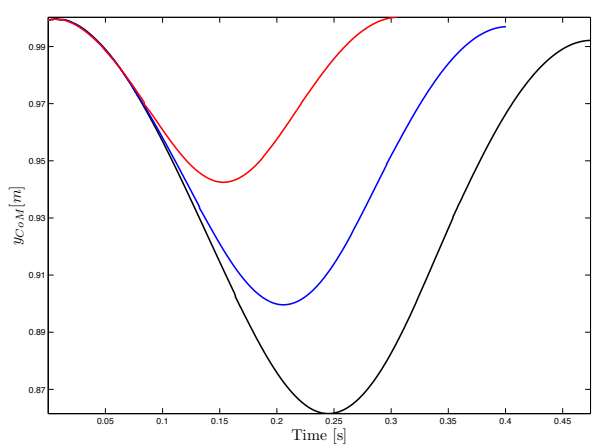

(b)

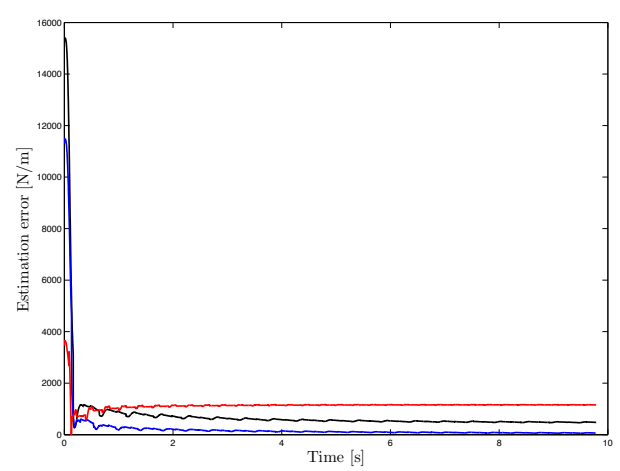

(d)

Figure 6.12: Leg stiffness estimation: (a) Vertical CoM for one of the SLIP solution used as measurements for the EKF filter. (b) A single step extracted for each solution. It can be observed the differences between vertical excursions of the CoM for the three values of $k_{0}$. (c) The $k_{0}$ (a.k.a. $k_{\text {leg }}$ ) estimation for the three walking solutions. (d) The corresponding estimation error. Black curve corresponds $k_{1}$, while the blue and the red ones belongs to $k_{2}$ and $k_{3}$, respectively. 
perimental results obtained in our study with the SLIP solutions obtained from the characteristics of the reference subject and the amputee group. Regarding the reference subject, the first attempt was to considered the leg characteristics as equal for both limbs, even though the values shown in Table 6.1 exhibited some discrepancies between each leg. The symmetric solution showed a reasonable agreement between the simulation and the real waveforms, but evidenced that the small differences in the leg characteristics of this subject may impact the SLIP solution. The results for the asymmetric case brought some improvement in terms of time correction, i.e., the phase difference between the curves decreased, but at expenses of an overestimated vertical CoM. For the asymmetric simulation led to a stable periodic solution, some of the initial conditions had to be altered. The initial velocity was increased in $15 \%$ from the original value, while the initial height had to be diminished in $2 \%$. These modifications are based on previous investigations of periodicity and stability for the asymmetric SLIP model (Merker et al., 2011).

Regarding the amputee group, the only stable and periodic solution based on the subjects characteristics was obtained for subject $\mathrm{B}$. The proper initial conditions for subjects $\mathrm{C}$ and $\mathrm{D}$ are not included in the return maps generated in the reference study (Merker et al., 2011), which made difficult the process of finding the initial condition that would lead to successful solutions, in terms of periodicity and stability. The solution for subject B is the result of including all the asymmetries of both legs on the model simulation. This is a positive result that demonstrated the capability of the SLIP model to deal with multiple variations of its parameters. The best agreement is obtained for the anterior-posterior component of the GRF. The vertical CoM from the SLIP solution exhibited the asymmetry in amplitude between the steps, like the real case, even though there is a phase different between the two waveforms. The initial velocity condition had also to be modified in order to obtain a successful SLIP solution, which might explain the time differences between the simulation and the real data.

Finally, a proposal of a different method to estimate the leg stiffness seems to have a good potential, based on the simulations results obtained here. Three situations of high, low and medium stiffness were simulated in the SLIP model to obtain the measurement information needed by the EKF. One would expect a convergence with very small errors given that the measurements were generated from the SLIP model itself. As the EKF needs an important number of SLIP measurements in order to converge to some value, it is possible that these particular solutions could not attain the stable state in only few steps and the differences in amplitude of the CoM oscillations might had influenced the performance of the filter.

\subsection{Conclusions}

In this chapter the spring-loaded inverted pendulum (SLIP) was investigated with the purpose of understanding the dynamics of human walking from a model point of view. The SLIP model is capable of reproducing the motion of the body center of mass using a simple mechanism. Additionally, the pattern of the GRF components are also well represented. Another attractive characteristic of the SLIP model is its self-stabilizing behavior, that is, the capacity of recovery from small perturbation without using external corrective strategies. 
The different patterns that can be obtained from proper combinations of initial conditions and parameter values justify its use as a model template to represent particular situations encountered in human walking. Nevertheless, a careful study of the space of the possible system parameter values and its correspondence initial conditions has to be made in order to achieved the desired walking patterns. In this work, the periodicity and stability was guaranteed by previous investigations from certain values of the leg length and the body mass (the independent SLIP parameters), which restricted our study for just two subjects. A periodicity and stability analysis will bring more insights about the dynamics of the SLIP model and a more objective evaluation of its capabilities and limitations can be carried out. Despite of this, the results obtained here can be used as a start point to adjust the SLIP model for the problem of representing special conditions of walking, like the asymmetries encountered in an amputee gait.

The estimation of the leg stiffness using the EKF formulation based on the SLIP model represents an alternative method to calculate this parameter, given that most of the current methods depend on force measurements and the accurate notion of the leg compression during the stride. The method proposed here only uses the information of the position and the velocity of the CoM, which not necessarily have to be extracted from kinetic information. Even though the results presented here are just simulations for three different stiffness scenarios, its potential use can be elucidated, not only for situations where leg symmetry is assumed, but also when the leg characteristics are apparently different. 


\section{CONCLUSIONS AND PERSPECTIVES}

\subsection{CONCLUDING REMARKS}

This thesis addressed the issue of the amputee gait as a particular case of the human gait, from the perspective of a gait analysis study in conjunction with an alternative approach using a dynamic walking model. The gait analysis gave us interesting insights about the effects of the compensatory mechanisms developed by the amputee subjects. The experimental results confirmed the existence of some of these compensations, reflected in the kinematic and kinetic variables that were measured. From this point, a set of measured variables were identified like the ones which reflected more differences among the subjects limbs. Specifically, the hip angle in the frontal plane (adduction/abduction), the ankle angle in the sagittal plane (dorsiflexion/plantarflexion) and the vertical CoM showed more differences between the subjects limbs; the latter also showed differences between each amputee pattern.

Furthermore, the calculation of the external mechanical power, which depends on the velocity of the CoM and the values of the GRF components, exhibited different patterns among subjects. This calculation pointed the discrepancies of the work contribution of each leg in the moment of the step-to-step transition, which coincides to the double support period. Even though the external mechanical work calculated on the CoM does not reflect the overall work done by the limbs (Neptune et al., 2004), it can give us an idea of the energetic implications of the amputee gait. The value of the COT is an attempt to represent in numbers these differences. The results of its calculation, based on the mechanical power, showed that the amputee gait was more costly in all the three cases, if compared to the COT extracted from the non-amputee subject.

The analysis of limb symmetry was completed by the use of two indices. The first one compared all the measured variables between the subjects limbs (intra-subject comparison), as well as each side of the amputee subject with one side of the reference subject (inter-subject comparison). From these results, the $S_{M}$ values confirmed what was found from the observations of the gait analysis experiments: high values of symmetry in all the variables from the reference subject, and a tendency of low values for all the amputee subjects. The use of the $S_{M}$ is then proposed as an index that can measure the similarities between gait variables waveforms obtained on each side during a gait cycle.

The spectral analysis of the CoM led us to the second index, which measured the symmetry between the oscillations of the vertical CoM in two subsequent steps. The different patterns of the CoM for the three amputee subjects are defined by means of their spectral components. The 
association of the odd components to asymmetric phenomenons that affect the vertical CoM is the basis for the $S_{C o M}$ index. From these values, it was confirmed the different levels of asymmetry in the CoM trajectory in all the amputee subjects. The use of the spectral analysis represents an interesting alternative to characterize the motion of the CoM. The reconstruction of the original signal from the selected components showed small distortion.

From the experimental results and the limb symmetry analysis, the CoM trajectory appeared to be an appropriate variable to represent, in a global manner, the interactions that take place in the limb segments as a person walks, in a normal or in a special condition like amputation. The use of dynamic walking models became the tool for representing walking by means of the CoM trajectory. The advantage of selecting a dynamic model for this representation lies on its simplicity and at the same time on its capability to represent basic aspects of walking. Specifically, the SLIP model uses a simple elastic system to reproduce the oscillatory motion of the CoM along the gait cycle. The results of its implementation showed the capacity of this model to obtain, from a single formulation, different walking solutions that resemble the human patterns in different conditions of gait. Even though our results depended on previous studies of periodicity and stability for this model, the simulations obtained here encouraged us to propose the SLIP as a model template for representing human walking in symmetric and asymmetric conditions.

\subsection{Perspectives}

The use of dynamic walking models in gait analysis is a promising field that combines the clinical knowledge of gait with mathematical models that represent human motion. The application of this approach are not limited to the case of amputee gait. Different kinds of mobility conditions can be represented using such models, if proper modifications for each condition are implemented. For our case, we believe that the SLIP model can be improved to represent aspects of amputee gait in a more accurate way that the results presented in chapter 6 . As stated before, the necessity of performing a complete study of the SLIP dynamics for a broader range of system parameters and initial condition would enlarge the possibilities of obtaining periodic and stable walking solutions. From this point, modifications of the original SLIP could be elucidated to improve the CoM patterns obtained from its original formulation. Related works have already proposed different modification on the SLIP model to improve its performance in terms of stability (Karssen \& Wisse, 2011; Ernst et al., 2012; Peuker et al., 2012); while other proposals are focused to better match its output with real data (Jung \& Park, 2014). These references, among many others not listed here, could be the starting point for this new investigation.

Regarding the leg stiffness estimation from the EKF-based approach, the implementation of the filter with real values is an issue that we consider should be explored in order to consolidate this proposal as an alternative method to estimate this parameter. As discussed in section 6.3, most of the methods use force measurements and leg compression information to calculate leg stiffness. However, both measurements are not easy to obtain without a proper equipment. The proposal presented here is based on the information of the CoM states during walking, which can be obtained from several ways (see section 3.1.5). One of this ways could be the CoM estimation from 
the spectral analysis explained in chapter 5 . From a single gait cycle obtained from experimental data, the CoM trajectory can be recreated once the spectral components (the DFS coefficients) are identified. The reconstruction in time domain will then represent the information needed by the EKF to converge to a stiffness value.

Finally, as discussed in chapter 4, it is still unclear how specific characteristics of the prosthesis used by the amputee subjects led to the compensatory mechanisms identified in each one of them. Furthermore, we did not find an exact explanation of how these mechanisms impact on each of the gait variables measured in our experiments. A more complete study concerning the characterization of the prosthetic leg could associate its operation to specific compensations. The obtained results would reveal the necessity of improvements on the prosthetic device or could identify problems related to misalignment or improper adjustment of the mechanism parameters. Additionally, a new study with modifications in the experimental conditions according to specific compensations could reveal which variables are more sensitive to such changes. 



\section{BIBLIOGRAPHY}

Adamczyk, P. G. \& Kuo, A. D. (2009). Redirection of center-of-mass velocity during the step-tostep transition of human walking. J. Exp. Biol., 212(Pt 16), 2668-78.

Adamczyk, P. G. \& Kuo, A. D. (2014). Mechanisms of Gait Asymmetry Due to Push-off Deficiency in Unilateral Amputees. IEEE Trans. Neural Syst. Rehabil. Eng., 4320(c).

Aldridge, J. M., Sturdy, J. T., \& Wilken, J. M. (2012). Stair ascent kinematics and kinetics with a powered lower leg system following transtibial amputation. Gait Posture, 36(2), 291-5.

Alexander, R. M. (1992). A model of bipedal locomotion on compliant legs. Philos. Trans. R. Soc. Lond. B. Biol. Sci., 338(1284), 189-98.

Alves, E. (2007). Proposta de um módulo sensorial para estimação de postura com relação ao solo de uma prótese robótica de perna. Technical report.

Au, S., Berniker, M., \& Herr, H. (2008). Powered ankle-foot prosthesis to assist level-ground and stair-descent gaits. Neural Netw., 21(4), 654-66.

Betker, A. L., Moussavi, Z. M. K., \& Szturm, T. (2006). Center of mass approximation and prediction as a function of body acceleration. IEEE Trans. Biomed. Eng., 53(4), 686-693.

Blickhan, R. (1989). The spring mass model for running and hopping. J. Biomech., 22(11), $1217-1227$.

Blum, Y., Lipfert, S. W., \& Seyfarth, A. (2009). Effective leg stiffness in running. J. Biomech., $42(14), 2400-5$.

Castro, M. P. D., Soares, D., \& Mendes, E. (2014). Plantar Pressures and Ground Reaction Forces During Walking of Individuals With Unilateral Transfemoral Amputation. J. Inj. Funct. Rehabil., (pp. 1-11).

Cavagna, G. a. (1975). Force platforms as ergometers. J. Appl. Physiol., 39(1), 174-179.

Cavagna, G. A., Heglund, N. C., \& Taylor, C. R. (1977). Mechanical work in terrestrial locomotion: two basic mechanisms for minimizing energy expenditure. Am. J. Physiol., 233(5), 243-61.

Cotton, S., Murray, A. P., \& Fraisse, P. (2009). Estimation of the Center of Mass : From Humanoid Robots to Human Beings. 14(6), 707-712. 
Crowe, A., Schiereck, P., De Boer, R. W., \& Keessen, W. (1995). Characterization of human gait by means of body center of mass oscillations derived from ground reaction forces. IEEE Trans. Biomed. Eng., 42(3), 293-303.

Delis-López, A. (2010). Metodologias de estimação do ângulo do joelho para detecção da intenção de movimento. $\mathrm{PhD}$ thesis.

Detrembleur, C., Vanmarsenille, J.-M., De Cuyper, F., \& Dierick, F. (2005). Relationship between energy cost, gait speed, vertical displacement of centre of body mass and efficiency of pendulumlike mechanism in unilateral amputee gait. Gait Posture, 21(3), 333-40.

Devan, H., Hendrick, P., Ribeiro, D. C., A Hale, L., \& Carman, A. (2014). Asymmetrical movements of the lumbopelvic region: is this a potential mechanism for low back pain in people with lower limb amputation? Med. Hypotheses, 82(1), 77-85.

Donelan, J., Kram, R., \& Kuo, A. D. (2002a). Simultaneous positive and negative external mechanical work in human walking. J. Biomech., 35, 117-124.

Donelan, J. M., Kram, R., \& Kuo, a. D. (2001). Mechanical and metabolic determinants of the preferred step width in human walking. Proc. Biol. Sci., 268(1480), 1985-1992.

Donelan, J. M., Kram, R., \& Kuo, A. D. (2002b). Mechanical work for step-to-step transitions is a major determinant of the metabolic cost of human walking. J. Exp. Biol., 205, 3717-3727.

Ellis, R. G., Howard, K. C., \& Kram, R. (2013). The metabolic and mechanical costs of step time asymmetry in walking. Proc. Biol. Sci., 280, 20122784.

Ephraim, P. L., Dillingham, T. R., Sector, M., Pezzin, L. E., \& MacKenzie, E. J. (2003). Epidemiology of limb loss and congenital limb deficiency: A review of the literature. Arch. Phys. Med. Rehabil., 84(5), 747-761.

Ernst, M., Geyer, H., \& Blickhan, R. (2012). Extension and customization of self-stability control in compliant legged systems. Bioinspir. Biomim., 7(4).

Farley, C. T. \& Gonzalez, O. (1996). Leg stiffness and stride frequency in human running. J. Biomech., 29(2), 181-186.

Fradet, L., Alimusaj, M., Braatz, F., \& Wolf, S. I. (2010). Biomechanical analysis of ramp ambulation of transtibial amputees with an adaptive ankle foot system. Gait Posture, 32(2), 191-8.

Gailey, R., Allen, K., Castles, J., Kucharik, J., \& Roeder, M. (2008). Review of secondary physical conditions associated with lower-limb amputation and long-term prosthesis use. J. Rehabil. Res. Dev., 45(1), 15-30.

Garcia, M., Chatterjee, a., Ruina, a., \& Coleman, M. (1998). The simplest walking model: stability, complexity, and scaling. J. Biomech. Eng., 120(2), 281-8. 
Gard, S. a., Miff, S. C., \& Kuo, A. D. (2004). Comparison of kinematic and kinetic methods for computing the vertical motion of the body center of mass during walking. Hum. Mov. Sci., $22(6), 597-610$.

Geyer, H. (2005). Simple Models of Legged Locomotion based on Compliant Limb Behavior. PhD thesis, Friedrich-Schiller University of Jena.

Geyer, H. \& Herr, H. (2010). A Muscle-Reflex Model That Encodes Principles of Legged Mechanics Produces Human Walking Dynamics and Muscle Activities. Neural Syst. Rehabil. Eng. IEEE Trans., 18(3), 263-273.

Geyer, H., Seyfarth, A., \& Blickhan, R. (2006). Compliant leg behaviour explains basic dynamics of walking and running. Proc. R. Soc. B, 273, 2861-2867.

Gitter, A., Paynter, K., Walden, G., \& Darm, T. (2002). Influence of rotators on the kinematic adaptations in stubby prosthetic gait. Am. J. Phys. Med. Rehabil., 81(4), 310-314.

Gordon, K. E., Ferris, D. P., \& Kuo, A. D. (2009). Metabolic and mechanical energy costs of reducing vertical center of mass movement during gait. Arch. Phys. Med. Rehabil., 90(1), 13644.

Gouwanda, D. \& Senanayake, A. S. M. N. (2011). Identifying gait asymmetry using gyroscopes A cross-correlation and Normalized Symmetry Index approach. J. Biomech., 44(5), 972-978.

Grabowski, A. M. \& Susan D'Andrea (2013). Effects of a powered ankle-foot prosthesis on kinetic loading of the unaffected leg during level-ground walking. J. Neuroeng. Rehabil., 10(49).

Highsmith, M. J., Kahle, J. T., Carey, S. L., Lura, D. J., Dubey, R. V., Csavina, K. R., \& Quillen, W. S. (2011). Kinetic asymmetry in transfemoral amputees while performing sit to stand and stand to sit movements. Gait Posture, 34(1), 86-91.

Holmes, P., Full, R. J., Koditschek, D., \& Guckenheimer, J. (2006). The Dynamics of Legged Locomotion: Models, Analyses, and Challenges. SIAM Rev., 48(2), 207-304.

Jaegers, S. M. H. J., Arendzen, J. H., \& De Jongh, H. J. (1995). Prosthetic gait of unilateral transfemoral amputees: A kinematic study. Arch. Phys. Med. Rehabil., 76(August), 736-743.

Johansson, J. L., Sherrill, D. M., Riley, P. O., Bonato, P., \& Herr, H. (2005). A Clinical Comparison of Variable-Damping and Mechanically Passive Prosthetic Knee Devices. Am. J. Phys. Med. Rehabil., 84(8), 563-575.

Jung, C. K. \& Park, S. (2014). Compliant bipedal model with the center of pressure excursion associated with oscillatory behavior of the center of mass reproduces the human gait dynamics. J. Biomech., 47(1), 223-9.

Júnior, C. (2005). Prótese Mecânica para Reabilitação Robótica. Technical report.

Kadaba, M., Ramakrishnan, H., \& Wootten, M. (1990). Measurement of lower extremity kinematics durig level walking. J. Orthop. Res., 8, 383-92. 
Kahle, J. T., Highsmith, M. J., \& Sandra L. Hubbard (2008). Comparison of nonmicroprocessor knee mechanism versus C-Leg on Prosthesis Evaluation Questionnaire, stumbles, falls, walking tests, stair descent, and knee preference. J. Rehabil. Res. Dev., 45(1), 1-14.

Kark, L., Vickers, D., McIntosh, A., \& Simmons, A. (2012). Use of gait summary measures with lower limb amputees. Gait Posture, 35(2), 238-243.

Karssen, J. D. \& Wisse, M. (2011). Running with improved disturbance rejection by using nonlinear leg springs. Int. J. Rob. Res., 30(13), 1585-1595.

Kuo, A. D. (2001). A simple model of bipedal walking predicts the preferred speed-step length relationship. J. Biomech. Eng., 123(3), 264-269.

Kuo, A. D. (2007). Choosing Your Steps Carefully. IEEE Robot. Autom. Mag., 1(June), 18-29.

Laferrier, J. Z. \& Gailey, R. (2010). Advances in lower-limb prosthetic technology. Phys. Med. Rehabil. Clin. N. Am., 21(1), 87-110.

Lee, C. R. \& Farley, C. T. (1998). Determinants of the center of mass trajectory in human walking and running. J. Exp. Biol., 201(Pt 21), 2935-2944.

Lipfert, S. W., Günther, M., Renjewski, D., Grimmer, S., \& Seyfarth, A. (2012). A modelexperiment comparison of system dynamics for human walking and running. J. Theor. Biol., $292,11-7$.

Martinez-Villalpando, E. C. \& Herr, H. (2009). Agonist-antagonist active knee prosthesis: A preliminary study in level-ground walking. J. Rehabil. Res. Dev., 46(3), 361-373.

Maus, H.-M., Seyfarth, A., \& Grimmer, S. (2011). Combining forces and kinematics for calculating consistent centre of mass trajectories. J. Exp. Biol., 214(Pt 21), 3511-7.

McGeer, T. (1990). Passive Dynamic Walking. Int. J. Rob. Res., (pp. 62-82).

Merker, A., Rummel, J., \& Seyfarth, A. (2011). Stable walking with asymmetric legs. Bioinspir. Biomim., 6(4).

Michaud, S. B., Gard, S. A., \& Childress, D. S. (2000). A preliminary investigation of pelvic obliquity patterns during gait in persons with transtibial and transfemoral amputation. $J$. Rehabil. Res. Dev., 37(1).

Miller, R. A., Thaut, M. H., McIntosh, G. C., \& Rice, R. R. (1996). Components of EMG symmetry and variability in parkinsonian and healthy elderly gait. Electroencephalogr. Clin. Neurophysiol., $4(1), 1-7$.

Minetti, A. E., Cisotti, C., \& Mian, O. S. (2011). The mathematical description of the body centre of mass 3D path in human and animal locomotion. J. Biomech., 44(8), 1471-1477.

Moe-Nilssen, R. \& Helbostad, J. L. (2004). Estimation of gait cycle characteristics by trunk accelerometry. J. Biomech., 37, 121-126. 
Morgenroth, D. C., Medverd, J. R., Seyedali, M., \& Czerniecki, J. M. (2014). The relationship between knee joint loading rate during walking and degenerative changes on magnetic resonance imaging. Clin. Biomech. (Bristol, Avon).

Morgenroth, D. C., Segal, A. D., Zelik, K. E., Czerniecki, J. M., Klute, G. K., Adamczyk, P. G., Orendurff, M. S., Hahn, M. E., Collins, S. H., \& Kuo, A. D. (2011). The effect of prosthetic foot push-off on mechanical loading associated with knee osteoarthritis in lower extremity amputees. Gait Posture, 34(4), 502-7.

Neptune, R. R., Zajac, F. E., \& Kautz, S. a. (2004). Muscle mechanical work requirements during normal walking: The energetic cost of raising the body's center-of-mass is significant. $J$. Biomech., 37(6), 817-825.

Neumann, D. A. (2002). Kinesiology of the Musculoskeletal System. Mosby.

Nolan, L. \& Lees, A. (2000). The functional demands on the intact limb during walking for active trans-femoral and trans-tibial amputees. Prosthet. Orthot. Int., 24(2), 117-125.

Nolan, L., Wit, A., Dudzin, K., Lees, A., Lake, M., \& Wychowan, M. (2003). Adjustments in gait symmetry with walking speed in trans-femoral and trans-tibial amputees. Gait Posture, 17(2), $142-51$.

Norvell, D. C., Czerniecki, J. M., Reiber, G. E., Maynard, C., Pecoraro, J. a., \& Weiss, N. S. (2005). The prevalence of knee pain and symptomatic knee osteoarthritis among veteran traumatic amputees and nonamputees. Arch. Phys. Med. Rehabil., 86(3), 487-93.

Ottobock (2015). 1c30 Trias - Product Information.

Perry, J. (1992). Gait Analysis: Normal and Pathological Function. SLACK Incorporated.

Peuker, F., Maufroy, C., \& Seyfarth, A. (2012). Leg-adjustment strategies for stable running in three dimensions. Bioinspir. Biomim., 7(3), 036002.

Rabuffetti, M., Recalcati, M., \& Ferrarin, M. (2005). Trans-femoral amputee gait: Socket-pelvis constraints and compensation strategies. Prosthet. Orthot. Int., 29(2), 183-192.

Remy, C. D. (2011). Optimal Exploitation of Natural Dynamics in Legged Locomotion. PhD thesis, ETH Zurich.

Robinson, R. O., Herzog, W., \& Nigg, B. M. (1987). Use of force platform variables to quantify the effects of chiropractic manipulation on gait symmetry. J. Manipulative Physiol. Ther., 10(4), $172-176$.

Rummel, J., Blum, Y., \& Seyfarth, A. (2010). Robust and efficient walking with spring-like legs. Bioinspir. Biomim., 5(4).

Sadeghi, H., Allard, P., Prince, F., \& Labelle, H. (2000a). Symmetry and limb dominance in able-bodied gait: a review. Gait Posture, 12(1), 34-45. 
Sadeghi, H., Prince, F., Sadeghi, S., \& Labelle, H. (2000b). Principal component analysis of the power developed in the flexion/extension muscles of the hip in able-bodied gait. Med. Eng. Phys., 22(2000), 703-710.

Sagawa, Y., Turcot, K., Armand, S., Thevenon, A., Vuillerme, N., \& Watelain, E. (2011). Biomechanics and physiological parameters during gait in lower-limb amputees: a systematic review. Gait Posture, 33(4), 511-26.

Sant'Anna, A., Salarian, A., \& Wickström, N. (2011). A new measure of movement symmetry in early Parkinson's disease patients using symbolic processing of inertial sensor data. IEEE Trans. Biomed. Eng., 58(7), 2127-2135.

Scandaroli, G. G. (2007). Controle adaptativo de juntas para uma prótese robótica de perna. Technical report.

Scandaroli, G. G. (2009). Estimação em sistemas com restrições de igualdade e aplicações em robótica móvel e de reabilitação. Technical report.

Scandaroli, G. G., Borges, G. A., Ishihara, J. Y., Terra, M. H., da Rocha, A. F., \& Nascimento, F. A. d. O. (2009). Estimation of foot orientation with respect to ground for an above knee robotic prosthesis. In 2009 IEEE/RSJ Int. Conf. Intell. Robot. Syst. (pp. 1112-1117).

Schaarschmidt, M., Lipfert, S. W., Meier-Gratz, C., Scholle, H.-C., \& Seyfarth, A. (2012). Functional gait asymmetry of unilateral transfemoral amputees. Hum. Mov. Sci., 31(4), 907-17.

Schmalz, T., Blumentritt, S., \& Jarasch, R. (2002). Energy expenditure and biomechanical characteristics of lower limb amputee gait: the influence of prosthetic alignment and different prosthetic components. Gait Posture, 16(3), 255-63.

Segal, A. D., Orendurff, M. S., Klute, G. K., McDowell, M. L., Pecoraro, J. a., Shofer, J., \& Czerniecki, J. M. (2006). Kinematic and kinetic comparisons of transfemoral amputee gait using C-Leg and Mauch SNS prosthetic knees. J. Rehabil. Res. Dev., 43(7), 857.

Seroussi, R. E., Gitter, A., Czerniecki, J. M., \& Weaver, K. (1996). Mechanical Work Adaptations of Above-Knee Amputee Ambulation. Prosthet. Orthot. Int., 77(November), 1209-1214.

Seyfarth, A., Geyer, H., Günther, M., \& Blickhan, R. (2002). A movement criterion for running. J. Biomech., 35(5), 649-55.

Simon, D. (2006). Optimal State Estimation: Kalman, H Infinity, and Nonlinear Approaches. Hoboken, New Jersey: Jhon Wiley \& Sons, Inc.

Smith, L., Weiss, E. L., \& Lehmkuhl, L. D. (1996). Brunnstrom's Clinical Kinesiology. F.A. Davis Company.

Spichler, D., Miranda, F. J., Spichler Stambovsky, E., \& Franco, L. J. (2004). Amputações maiores de membros inferiores por doença arterial periférica e diabetes melito no município do Rio de Janeiro. J. Vasc. Bras., 3(2), 111-122. 
Srinivasan, M. \& Ruina, A. (2006). Computer optimization of a minimal biped model discovers walking and running. Nature, 439(7072), 72-5.

Sup, F., Varol, H. A., Mitchell, J., Withrow, T. J., \& Goldfarb, M. (2009). Preliminary Evaluations of a Self-Contained Anthropomorphic Transfemoral Prosthesis. IEEE ASME Trans. Mechatron., 14(6), 667-676.

Tang, P. C. Y., Ravji, K., Key, J. J., Mahler, D. B., Blume, P. A., \& Sumpio, B. (2008). Let them walk! Current prosthesis options for leg and foot amputees. J. Am. Coll. Surg., 206(3), 548-60.

Tranberg, R., Zügner, R., \& Kärrholm, J. (2011). Improvements in hip- and pelvic motion for patients with osseointegrated trans-femoral prostheses. Gait Posture, 33(2), 165-168.

Vagenas, G. \& Hoshizaki, B. (1992). A multivariable analysis of lower-extremity kinematic asymmetry in running. Int. J. Sport Biomech., 8, 11-29.

Whittle, M. W. (2007). Gait Analysis: an introduction. Elservier.

Winter, D. A. (2009). Biomechanics and Motor Control of the Human Movement. Jhon Wiley \& Sons, Inc.

Wisse, M., Feliksadal, G., van Frankenhyyzen, J., \& Moyer, B. (2007). Passive-based walking robot. IEEE Robot. Autom. Mag., 14(2), 52-62.

Wisse, M., Schwab, a. L., \& van der Helm, F. C. T. (2004). Passive dynamic walking model with upper body. Robotica, 22(6), 681-688.

Yoneyama, M., Kurihara, Y., Watanabe, K., \& Mitoma, H. (2013). Accelerometry-Based Gait Analysis and its Applications to Parkinson's Disease Assessment-Part 1: Detection of Stride Event. IEEE Trans. neural Syst. Rehabil. Eng., 22(c), 3-7.

Zelik, K. E., Huang, T.-W. P., Adamczyk, P. G., \& Kuo, A. D. (2014). The role of series ankle elasticity in bipedal walking. J. Theor. Biol., 346, 75-85.

Ziegler-Graham, K., MacKenzie, E. J., Ephraim, P. L., Travison, T. G., \& Brookmeyer, R. (2008). Estimating the prevalence of limb loss in the United States: 2005 to 2050. Arch. Phys. Med. Rehabil., 89(3), 422-429. 



\section{APPENDICES}





\section{A. MARKER PROTOCOL FOR THE GAIT ANALYSIS EXPERIMENTS}

This appendix presents the marker protocol used for the gait analysis experiments. In order to measure the kinematics of the lower limb of the subjects, a total of 31 passive markers were placed on the lower limbs and the pelvis region (see Figure A.1). The marker labels and their corresponding anatomical locations are presented in Table A.1.

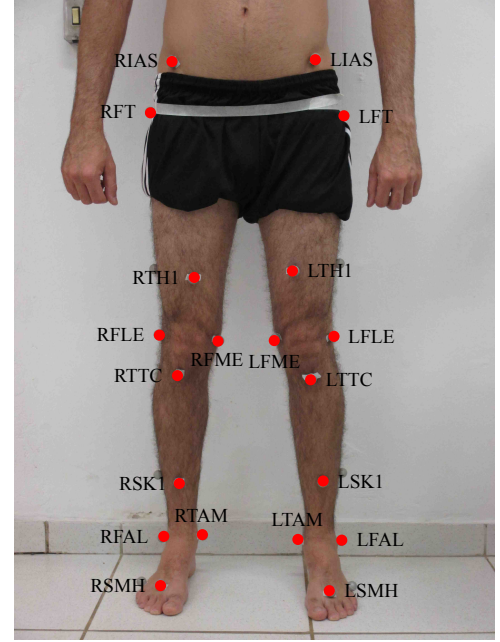

(a)

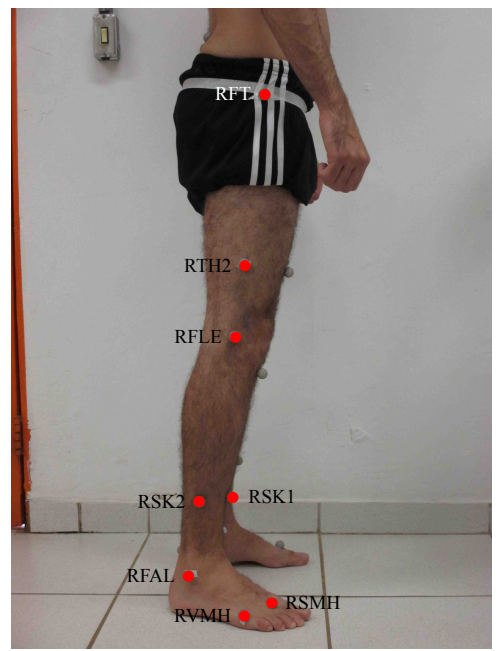

(c)

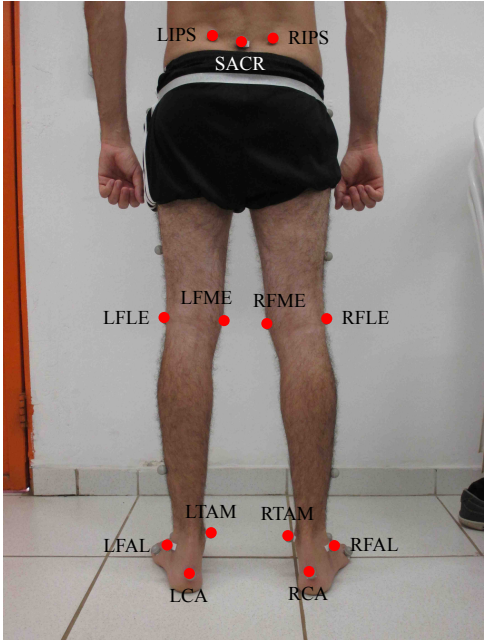

(b)

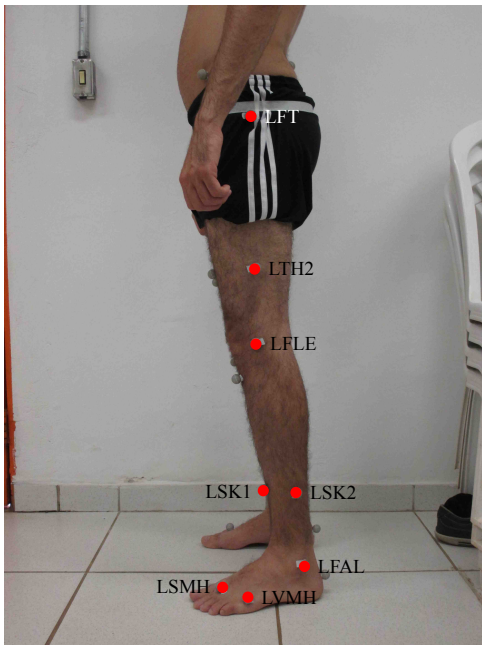

(d)

Figure A.1: The marker protocol for the kinematic capture : (a) frontal, (b) posterior and (c, d) lateral view. 
Table A.1: Marker labels and their corresponding anatomical locations.

\begin{tabular}{|c|c|c|}
\hline Segment & Marker Label & Description \\
\hline \multirow{5}{*}{ Pelvis } & SACR & Sacrum \\
\hline & RIPS & Right Ilium Posterior Superior \\
\hline & LIPS & Left Ilium Posterior Superior \\
\hline & RIAS & Right Ilium Anterior Superior \\
\hline & LIAS & Left Ilium Anterior Superior \\
\hline \multirow{10}{*}{ Thigh } & RFT & Right Femur great Trochanter \\
\hline & LFT & Left Femur great Trochanter \\
\hline & RTH1 & Right Mid-THigh 1 \\
\hline & RTH2 & Right Mid-THigh 2 \\
\hline & LTH1 & Left Mid-THigh 1 \\
\hline & LTH2 & Left Mid-THigh 2 \\
\hline & RFLE & Right Femur Lateral Epicondyle \\
\hline & LFLE & Left Femur Lateral Epicondyle \\
\hline & RFME & Right Femur Medial Epicondyle \\
\hline & LFME & Left Femur Medial Epicondyle \\
\hline \multirow{10}{*}{ Shank } & RTTC & Right Tibial Tuberosity \\
\hline & LTTC & Left Tibial Tuberosity \\
\hline & RSK1 & Right mid-ShanK 1 \\
\hline & RSK2 & Right mid-ShanK 2 \\
\hline & LSK1 & Left mid-ShanK 1 \\
\hline & LSK2 & Left mid-ShanK 2 \\
\hline & RFAL & Right Fibula Apex of Lateral malleolus \\
\hline & LFAL & Left Fibula Apex of Lateral malleolus \\
\hline & RTAM & Right Tibia Apex of Medial malleolus \\
\hline & LTAM & Left Tibia Apex of Medial malleolus \\
\hline \multirow{6}{*}{ Foot } & RCA & Right CAlcaneus \\
\hline & LCA & Left CAlcaneus \\
\hline & RSMH & Right Second Metatarsus \\
\hline & LSMH & Left Second Metatarsus \\
\hline & RVMH & Right Fifth Metatarsus \\
\hline & LVMH & Left Fifth Metatarsus \\
\hline
\end{tabular}




\section{B. APPROVED CONSENT BY THE ETHICS COMMITTEE}

\section{Universidade de Brasília \\ Faculdade de Ciências da Saúde \\ Comitê de Ética em Pesquisa - CEP/FS \\ PROCESSO DE ANÁLISE DE PROJETO DE PESOUISA}

Registro do Projeto no CEP: 119/11

Título do Projeto: "Tecnologias avançadas de próteses para amputados de membro inferior".

Pesquisadora Responsável: Geovany Araujo Borges

Data de Entrada: 31/08/11

Com base na Resolução 196/96, do CNS/MS, que regulamenta a ética em pesquisa com seres humanos, o Comitê de Ética em Pesquisa com Seres Humanos da Faculdade de Ciências da Saúde da Universidade de Brasília, após análise dos aspectos éticos e do contexto técnico-científico, resolveu APROVAR o projeto 119/11 com o título: "Tecnologias avançadas de próteses para amputados de membro inferior", Área Temática Especial - "Pesquisa Grupo I Novos Procedimentos, Novos Equipamentos" analisado na $3^{\mathrm{a}}$ reunião ordinária realizada no dia 12 de março de 2013.

O pesquisador responsável fica, desde já, notificado da obrigatoriedade da apresentação de um relatório semestral e relatório final sucinto e objetivo sobre o desenvolvimento do Projeto, no prazo de 1 (um) ano a contar da presente data (item VII.13 da Resolução 196/96).

Brasília, 14 de março de 2013.

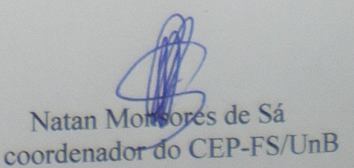

Comitê de Ética em Pesquisa com Seres Humanos - Faculdade de Ciências da Saúce

Universidade de Brasília - Campus Universitário Darcy Ribeiro - $C$

Telefone: (61)-3107-1947 Email: cepfs@unb.br 



\section{Publications}

Some ideas and figures have appeared previously in the following publications:

- Ochoa-Diaz. C.P., Menegaz H.M., Bo A.P.L., Borges G.A. (2013). An EKF-based approach for estimating leg stiffness during walking. In Proceedings of the IEEE Engineering in Medicine and Biology Conference (EMBC).

- Ochoa-Diaz. C.P., Rocha T.S., Oliveira L.L., Paredes M.E.G., Lima, R., Bo, A.P.L., Borges, G.A. (2014). An above-knee prosthesis with magnetorheological variable-damping. In Proceedings of the IEEE International Conference on Biomedical Robotics and Biomechatronics (BioRob).

Another publication during the $\mathrm{PhD}$ period was also developed:

- Ochoa-Diaz C.P., Gonçalves C. W., Alves, C. G., Coelho, Bo, A.P.L. (2012). Balance measurement system based on the center of mass computation using Kinect. In Proceedings of Congresso Brasileiro de Engenharia Biomédica (CBEB). 